\title{
Knowledge, adherence and outcome in glaucoma
}

Citation for published version (APA):

Hoevenaars, J. G. M. M. (2020). Knowledge, adherence and outcome in glaucoma. [Doctoral Thesis, Maastricht University]. Maastricht University. https://doi.org/10.26481/dis.20201120jh

Document status and date:

Published: 01/01/2020

DOI:

10.26481/dis.20201120jh

Document Version:

Publisher's PDF, also known as Version of record

\section{Please check the document version of this publication:}

- A submitted manuscript is the version of the article upon submission and before peer-review. There can be important differences between the submitted version and the official published version of record.

People interested in the research are advised to contact the author for the final version of the publication, or visit the DOI to the publisher's website.

- The final author version and the galley proof are versions of the publication after peer review.

- The final published version features the final layout of the paper including the volume, issue and page numbers.

Link to publication

\footnotetext{
General rights rights.

- You may freely distribute the URL identifying the publication in the public portal. please follow below link for the End User Agreement:

www.umlib.nl/taverne-license

Take down policy

If you believe that this document breaches copyright please contact us at:

repository@maastrichtuniversity.nl

providing details and we will investigate your claim.
}

Copyright and moral rights for the publications made accessible in the public portal are retained by the authors and/or other copyright owners and it is a condition of accessing publications that users recognise and abide by the legal requirements associated with these

- Users may download and print one copy of any publication from the public portal for the purpose of private study or research.

- You may not further distribute the material or use it for any profit-making activity or commercial gain

If the publication is distributed under the terms of Article $25 \mathrm{fa}$ of the Dutch Copyright Act, indicated by the "Taverne" license above, 


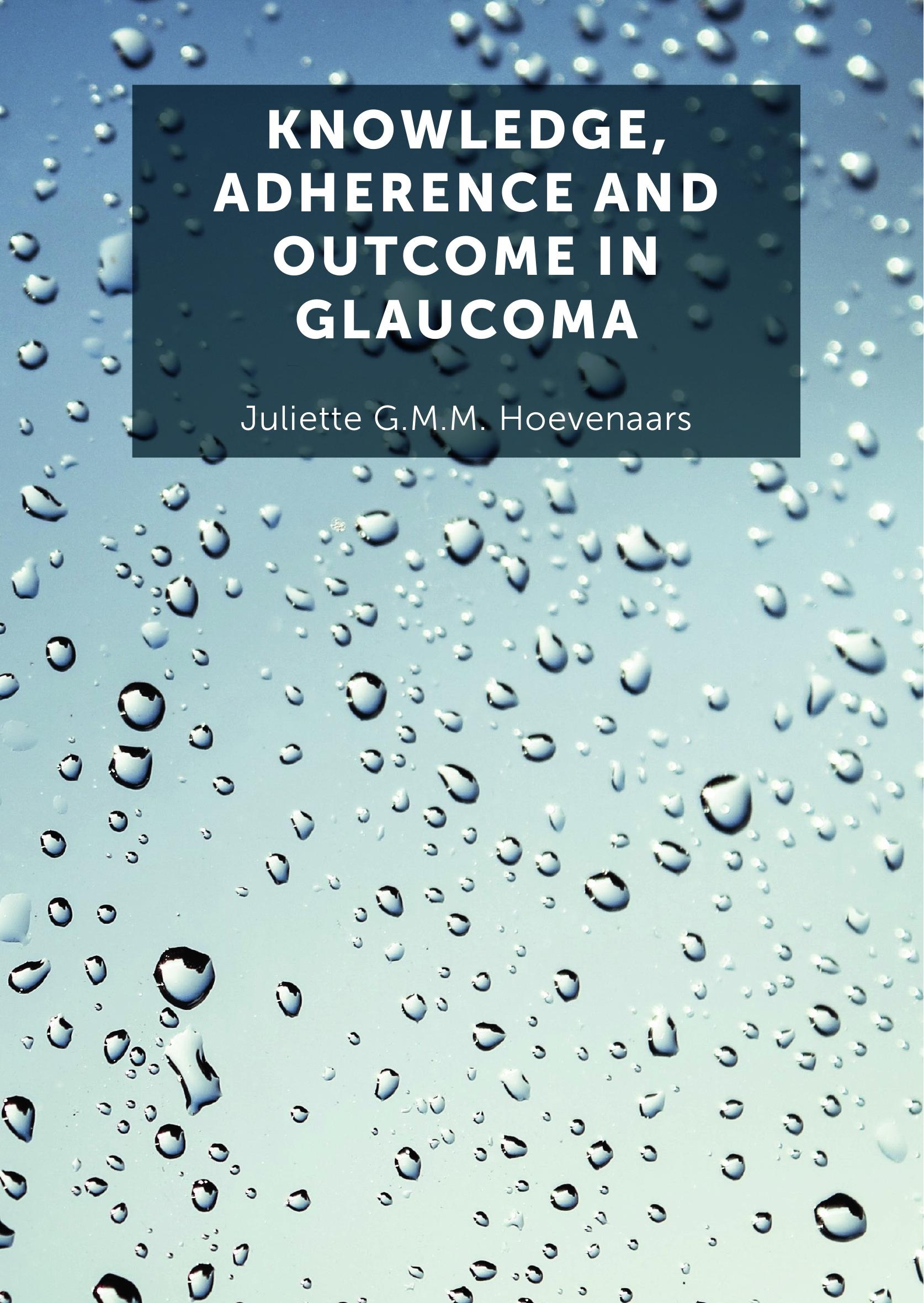


Knowledge, adherence and outcome in glaucoma 


\title{
Knowledge, adherence and outcome in glaucoma
}

\author{
Proefschrift
}

ter verkrijging van de graad van doctor aan de Universiteit Maastricht,

op gezag van de Rector Magnificus, prof. dr. Rianne M. Letschert

volgens het besluit van het College van Decanen,

in het openbaar te verdedigen

op vrijdag 20 november 2020 om 16.00 uur

door

Juliette Gertruda Maria Martine Hoevenaars

ISBN:

Cover:

Lay-out:

Printing:
978-94-6419-012-0

Ilse Modder | www.ilsemodder.nl

Ilse Modder | www.ilsemodder.nl

Gildeprint B.V. | www.gildeprint.nl

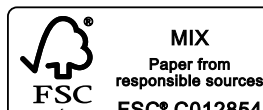

Copyright (C) J.G.M.M. Hoevenaars, 2020

All rights reserved. No parts of this publication may be reproduced or transmitted

in any form or by any means without permission of the author. The copyright of previously published chapters of this thesis also remains with the publisher or journal. 


\section{Promotor}

Prof. dr. C.A.B. Webers

\section{Copromotor}

Dr. J.S.A.G. Schouten (Canisius Wilhelmina Ziekenhuis, Nijmegen)

\section{Beoordelingscommissie}

Prof. dr. P.M. Steijlen (voorzitter)

Dr. med. F. Meier-Gibbons (Rapperswil, Switzerland)

Prof. dr. J.W.M. Muris

Dr. W.D. Ramdas (Erasmus Medisch Centrum, Rotterdam)

Prof. dr. G.D.E.M. van der Weijden

The studies in this thesis are partially supported by a grant from the National Health Care Institute, Diemen (College voor Zorgverzekeringen, currently Zorginstituut Nederland).

The research presented in this thesis was conducted at MHeNs School for Mental Health and Neuroscience and CAPHRI Care and Public Health Research Institute, Department Epidemiology, of Maastricht University. CAPHRI participates in the Netherlands School of Public Health and Care Research CaRe. 


\section{Table of contents}

Chapter 1

Chapter 2 Knowledge base and preferred methods of obtaining knowledge of glaucoma patients

Chapter 3 Socioeconomic differences in glaucoma patients'

knowledge, need for information and expectations of treatments

Chapter 4 Will improvement of knowledge lead to improvement of compliance with glaucoma medication?

Chapter 4.1 Letter to the editor from Mansouri \& Shaarawy

Chapter 4.2 Authors' reply

Prevalence and determinants of non-adherence to topical hypotensive treatment in Dutch glaucoma patients

Chapter 6

A practical tool to identify and improve non-adherence as a cause of unachieved target pressure in glaucoma patients

Chapter $7 \quad$ Non-adherence and glaucoma progression

Chapter 8 General discussion

Chapter 9 Samenvatting (Summary in Dutch)

Addendum

Valorisation

Dankwoord

Curriculum Vitae

List of publications 
$00^{\circ}: 0: \because 0 / 0^{0}: \varepsilon_{0}^{0}$

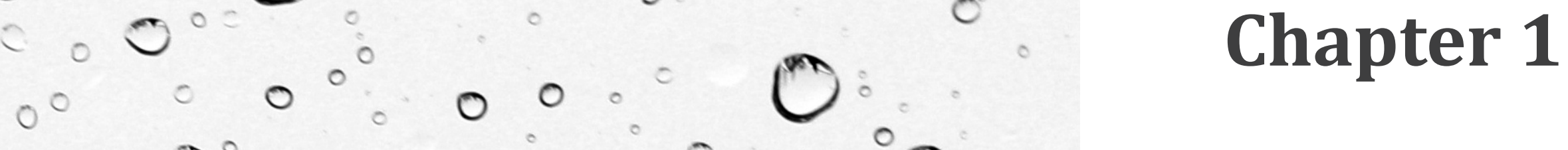

Introduction 


\section{Introduction}

\section{Definitions and classification of glaucoma}

Glaucoma consists of a group of eye conditions that are characterized by damage of the optic nerve and consequent, characteristic, visual field defects. In a glaucomatous eye, retinal ganglion cells are damaged and can no longer function adequately. As a result, the visual field deteriorates.

In glaucoma, the intraocular pressure (IOP) is an important risk factor. The IOP is determined by the rate of aqueous humor production by the ciliary body, the resistance to outflow of aqueous humor from the eye across the trabecular meshwork and Schlemm's canal in the anterior chamber angle, and the level of episcleral venous pressure. (figure 2$)^{1}$

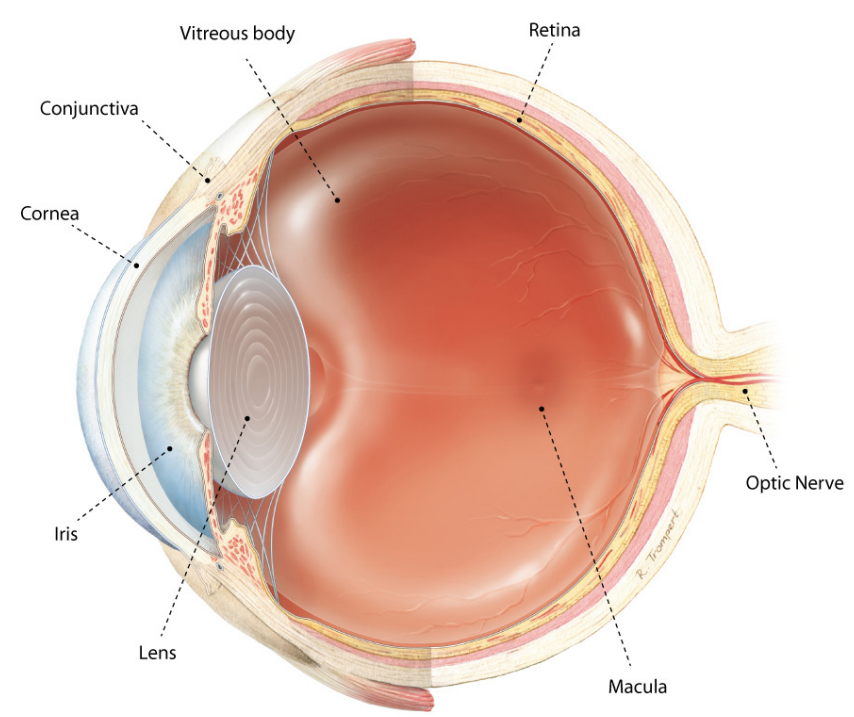

Figure 1. Anatomy of the eye.

Illustration from Rogier Trompert,Medical Art, with permission.

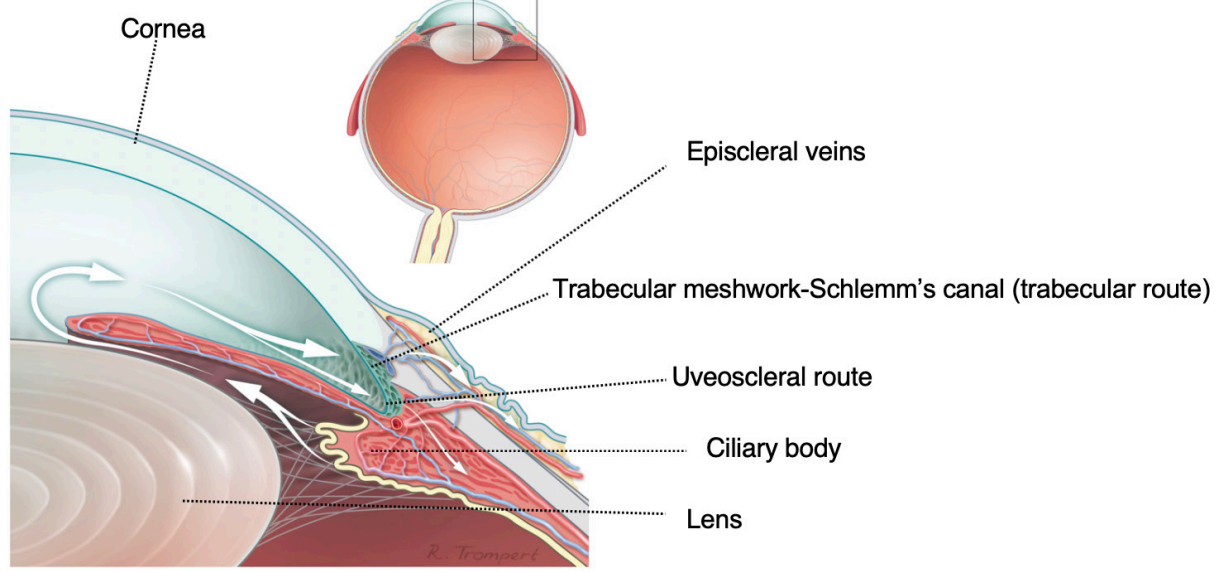

Figure 2. Cross section of the anterior segment of a normal eye. Illustration from Rogier Trompert,Medical Art, with permission.

Figure 3 and 4 show the optic nerve head changes in glaucoma.
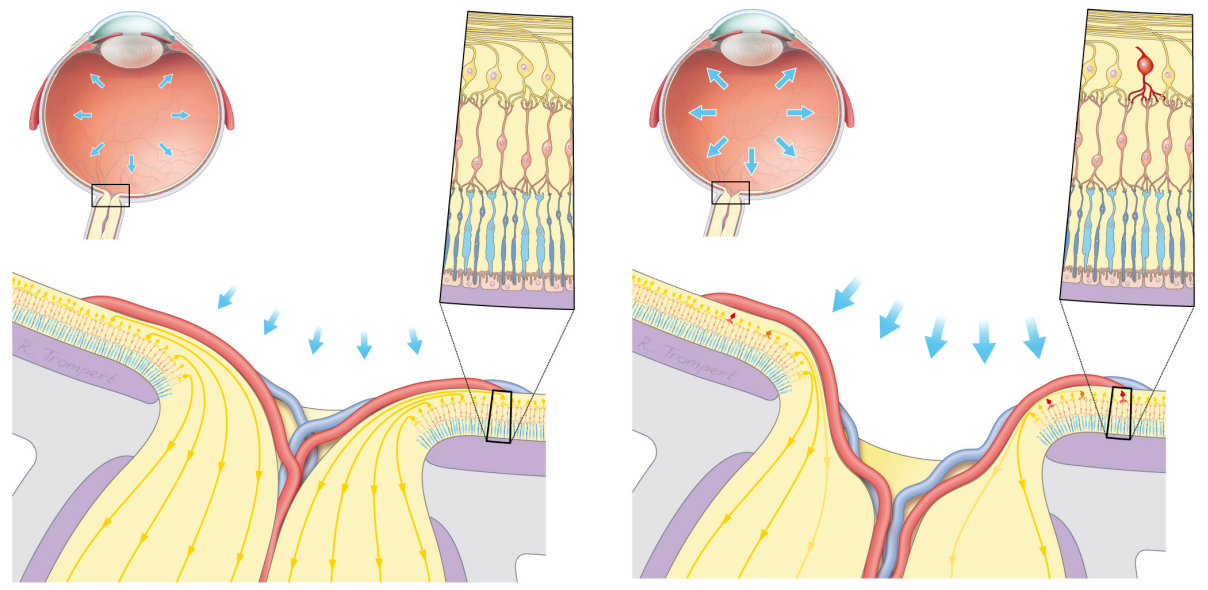

Figure 3. Normal optic nerve.

Figure 4. Glaucomatous optic nerve. 
Glaucoma is commonly classified as primary versus secondary and as openangle versus closed-angle glaucoma. Primary glaucomas are defined as being not associated with underlying ocular or systemic conditions whereas secondary glaucomas are the consequence of underlying ocular or systemic conditions. The difference in open-angle versus closed-angle glaucoma is based on the width of the anterior chamber angle.

According to the European Glaucoma Society (EGS) guidelines primary open-angle glaucoma (POAG) is defined as: "a chronic, progressive optic neuropathy with characteristic morphological changes at the optic nerve head and retinal nerve fibre layer in the absence of other ocular disease or congenital anomalies. Progressive retinal ganglion cell death and visual field loss are associated with these changes". 2 Primary angle-closure is defined as: "an occludable drainage angle and features indicating that trabecular obstruction by the peripheral iris has occurred. The term glaucoma is added if glaucomatous optic neuropathy is present: Primary angleclosure glaucoma (PACG)". ${ }^{2}$

\section{Epidemiology}

The prevalence of POAG is estimated to be $1.23 \%$ in individuals $40-89$ years of age. This figure is based on a meta-analysis that used relatively narrow definitions of POAG. This meta-analysis included all screening studies in the general population. ${ }^{3}$ In the Netherlands, in 2018, 314.900 individuals were estimated to be registered at their general practitioner with a type of glaucoma diagnosis. ${ }^{4}$ Based on a review of published prevalence data and modelling of the data, 79.6 million individuals with glaucoma will be counted worldwide in 2020 and about 11.1 million people will be bilaterally blind from glaucoma in 2020 . Open-angle glaucoma will account for $74 \%$ and angle-closure glaucoma for $26 \%$ of this number. ${ }^{5}$ A prevalence of $24.1 \%$ for unilateral glaucoma blindness and $10.6 \%$ for bilateral glaucoma blindness at the end of life has been reported for glaucoma patients. ${ }^{6}$

\section{Risk factors, predictive factors and prognostic factors}

Establishing risk factors, predictive factors and prognostic factors is important in order to identify patients in an early stage of glaucoma, to detect patients at risk of glaucoma progression and to adjust glaucoma therapy in these glaucoma patients.

Risk factors for open-angle glaucoma are determinants that are associated with the development of open-angle glaucoma in healthy eyes. ${ }^{7}$ Various risk factors for open-angle glaucoma have been identified ${ }^{2,7,8}$ such as older age, increased
IOP, ethnicity, i.e. African descent, family history of glaucoma, pseudoexfoliation, thin central corneal thickness and myopia. Studies on other (vascular) factors such as systemic blood pressure, vasospasm, atherosclerosis and acute systemic hypotension, diabetes, migraine headaches, Raynaud syndrome and obstructive sleep apnea do not show consistent results. ${ }^{2,8}$ And if related, vascular factors were found to be mainly associated with normal-tension glaucoma. ${ }^{8}$ Asian descent is a risk factor for narrow-angle glaucoma.

Predictive factors are determinants for the development of open-angle glaucoma in patients with ocular hypertension. ${ }^{7}$ Ocular hypertension means that the IOP is higher than normal with no optic nerve damage or visual field loss. Identified predictive factors are older age, higher IOP, larger cup-to-disc-ratio of the optic disc, higher pattern standard deviation value in the visual field analysis and thinner central corneal thickness. ${ }^{2,7,9}$

Prognostic factors are determinants for progression of open-angle glaucoma in patients with established glaucoma. ${ }^{7}$ Identified prognostic factors are older age, higher IOP at baseline, less IOP reduction on treatment, pseudoexfoliation, thinner central corneal thickness, optic disc haemorrhages, more baseline visual field loss and self-report of diabetes. ${ }^{2,7,9,10}$

The IOP is the only proven modifiable factor among these three sets of determinants. A raised IOP in primary open-angle glaucoma is caused by an impaired outflow of aqueous in the trabecular meshwork outflow pathways. ${ }^{1,2}$ The IOP in primary angle-closure glaucoma is raised because of impaired access of aqueous to the drainage system as a result of the apposition of the peripheral iris to the trabecular meshwork. $^{1}$

The IOP is measured by tonometry. The gold standard instrument is the Goldmann applanation tonometer, which measures the force required to flatten a fixed area of the cornea. ${ }^{1}$ The mean IOP is approximately $16 \mathrm{mmHg}$ with a standard deviation of nearly three mmHg in a general adult population. ${ }^{1,2}$ The IOP has a non-gaussian distribution with a right skew toward higher pressures. Normal IOP has been defined as two standard deviations above the mean. Therefore, an IOP above 21 mmHg is considered to be elevated. ${ }^{1,2}$ In general, an increased IOP causes optic nerve cupping and progressive visual field loss. However, in normal- or low-tension glaucoma, patients also have glaucomatous optic disc cupping and visual field loss despite a normal or low IOP. Thirty to fifty percent of the patients with glaucoma 
in the general population have normal- or low-tension glaucoma. ${ }^{1}$ Conversely, in ocular hypertension, patients have an isolated high IOP without glaucomatous damage.

\section{Treatment}

As there is no treatment to repair damaged retinal nerve fibres in glaucoma, therapy is directed at slowing down progression of retinal ganglion cell damage and associated visual field loss. The primary aim of glaucoma treatment is to preserve visual function and related quality of life by reducing the IOP to a level that is likely to prevent further damage to the retinal ganglion cells. Studies have shown the beneficial effect of IOP reduction on the risk of conversion of ocular hypertension to glaucoma or the risk of progression of glaucoma. ${ }^{11-13}$ The target IOP is the upper limit of the IOP that is expected to slow the rate of progression sufficiently to maintain the quality of life in the expected lifetime of the patient. The target IOP differs between patients and between eyes and thus needs to be estimated for each eye separately. Only in secondary glaucoma, treatment of the underlying condition can prevent the occurrence or progression of visual field loss. Three types of treatments can be distinguished: medical therapy, laser surgery or incisional surgery.

An ophthalmologist will follow general guidelines in recommending the most appropriate treatment, taking into account patient's characteristics. ${ }^{2}$ Ultimately, the ophthalmologist and the patient decide together, by means of shared decision making, which therapy is the first to start with. Eye drops are commonly used as the first-line therapy. In case of insufficient IOP lowering, side effects from eye drops or non-adherence with therapy, a laser- or surgical treatment can be performed. Laser- or surgical interventions can be considered as first-line treatment in certain types of glaucoma, expected non-adherence or present systemic illnesses or medications that seriously interfere with the use of eye drops. Currently this paradigm is changing based on the LiGHT trial that describes that selective laser trabeculoplasty should be offered as a first-line treatment for ocular hypertension and open-angle glaucoma. ${ }^{14}$ The LiGHT trial showed that initial treatment with selective laser trabeculoplasty provides better IOP stability and less need for glaucoma surgery compared to initial treatment with eye drops. ${ }^{14}$ A drop-free interval of at least three years was achieved for almost three quarters of patients that were treated initially with selective laser trabeculoplasty. ${ }^{14}$

Medical therapy implies the use of ocular hypotensive agents mostly as eye drops and to a much lesser extent oral medication, once or multiple times per day. These anti-glaucoma drugs lower IOP by reducing aqueous humor production, improving aqueous outflow or both. Several groups of ocular hypotensive agents that are widely used are: beta-receptor antagonists, parasympathomimetics, carbonic anhydrase inhibitors, alpha-2 adrenergic agonists, prostaglandin analogues, osmotics and combination therapies. ${ }^{2}$

Regularly used fixed combinations consist of a carbonic anhydrase inhibitor and an adrenergic agonist, or a beta-receptor antagonist and either a carbonic anhydrase inhibitor, a prostaglandin analogue, or an adrenergic agonist. ${ }^{2}$

Guidelines recommend to start treatment with medical monotherapy. ${ }^{2}$ If the initial anti-glaucoma drug is ineffective or is not tolerated, a switch to another monotherapy is recommended. The addition of a second anti-glaucoma drug is recommended if the chosen monotherapy is effective in lowering IOP and is well tolerated, but the target IOP is not reached. ${ }^{2}$ Ophthalmologists should individualize adjunctive therapy, taking into account additive efficacy, safety, dosing frequency and should also take into consideration the effects on adherence, wash-out effects of earlier medications and exposure to preservatives. When available, a fixed combination therapy is preferred to separate anti-glaucoma drugs. ${ }^{2}$

All these several types of drugs are effective in lowering IOP as is shown in a metaanalysis of randomized clinical trials for beta-adrenergic antagonists, carbonic anhydrase inhibitors, adrenergic agents and prostaglandin analogues. These drugs lowered IOP more effectively than placebo. ${ }^{15}$ Medical therapy to lower IOP in patients with glaucoma does not only saves sight, but it also saves money at the long term. ${ }^{16}$ Van Gestel et al. also showed that direct lowering IOP in ocular hypertension turned out to be a dominant cost-effective strategy over a watchful waiting strategy that started therapy after glaucoma had occurred..$^{17}$

In open-angle glaucoma a (selective) laser trabeculoplasty can be conducted to increase outflow facility by opening the drainage system of the trabecular meshwork. ${ }^{1}$ In angle-closure glaucoma based on a pupillary block, a laser iridotomy is necessary, while a peripheral laser iridoplasty should be performed in angleclosure resulting from a plateau iris configuration. ${ }^{1}$ Laser therapy of the ciliary body can be used to reduce the inflow of aqueous humor.

Incisional glaucoma surgery is the most invasive treatment for glaucoma. Commonly 
used techniques are filtration surgery, tube-shunt surgery and minimally invasive glaucoma surgery. The trabeculectomy is a commonly used filtration surgery in which a new pathway is created for the flow of aqueous humor from the posterior chamber via the anterior chamber through a surgical defect in the sclera into the subconjunctival space. ${ }^{1}$ In glaucoma tube-shunt surgery a tube is placed in the anterior chamber or in the posterior chamber through the pars plana. This tube shunts aqueous to an extraocular reservoir which is placed on the sclera. ${ }^{1}$ Minimally invasive glaucoma surgery is a term to cover some procedures aiming for safer and less invasive intraocular pressure reduction compared to the traditional incisional glaucoma surgery. ${ }^{18}$

\section{Glaucoma as a chronic disease}

Glaucoma is often discovered due to routine IOP measurements by the optician, examination by the ophthalmologist when presenting for other reasons than the presenting eye disease, or during screening because of a positive family history for glaucoma. Most patients do not have any subjective glaucoma-related complaints at the time of glaucoma diagnosis. They are told that glaucoma is a chronic, slowly progressive eye disease that can lead to severe visual impairment and blindness. Patients are told that they probably need a lifelong therapy with eye drops and follow-up visits. Eye drops need to be used regularly and patients can experience side effects of eye drops. These messages and actions influence patients' daily life and quality of life. Patients have to find new ways of coping with the altered circumstances.

Informing the patient and regularly discussing progress of the disease and treatment options are basic elements for the lifelong contact between the patient with glaucoma and the ophthalmologist. It is known that patients with a chronic disease lack knowledge about their disease and treatments. Current practice of shared decision making requires a well-informed patient. It is generally excepted that informed patients better understand their prognosis, are more adherent and cope more effectively with the required changes. ${ }^{19-23}$ It is the primary task of the physician to inform patients about their disease, the prognosis and treatment options.

The lifelong disease duration also necessitates lifelong adherence with follow-up visits and treatment. Clinicians are challenged to educate and motivate patients to use their glaucoma medication as prescribed. Given the asymptomatic nature of glaucoma and the potential side effects of treatment, patients are at risk for adherence problems with prescribed medication

These two basic elements, knowledge and adherence, important features of a chronic disease as glaucoma is, are the themes addressed in this thesis.

\section{Themes of this thesis}

In this PhD-thesis we sought to identify to what extent knowledge was lacking in patients with glaucoma. In addition, the items for which knowledge was lacking were identified as well as the sources that are preferable for patients with glaucoma to receive further information. (Chapter 2)

Patients from a lower social class more often lack knowledge. This difference could increase socioeconomic health differences. We therefore studied the relation between educational level and knowledge about glaucoma, its treatments and the patients' need for information. (Chapter 3)

Lack of knowledge could adversely affect the outcome of a disease. This could occur if the patient does not adhere to the treatment as prescribed by the ophthalmologist because the patient has not been informed about the need to regularly use eye drops or does not know the consequences of glaucoma. We therefore studied the relation between knowledge and the presence of non-adherence. (Chapter 4)

In addition, we studied determinants of non-adherence to identify groups at risk of being non-adherent or determinants that could be changed to influence nonadherence. (Chapter 5)

Non-adherence should affect the IOP or progression of glaucoma if treatments are prescribed that have been proven to be effective. However, there was scant empirical evidence of the relation between non-adherence and progression of glaucoma or between non-adherence and the IOP. Moreover, it is not known how much nonadherence is 'needed' to affect progression or IOP. We therefore quantified the contribution of non-adherence to the occurrence of an unachieved target IOP or progression. (Chapter 6 and 7 respectively) Moreover, we supplied questions that can be asked to discover relevant non-adherence in patients not achieving their target IOP in a clinical setting. (Chapter 6)

\section{Definition of adherence in this thesis}

Several terms describe whether medication is taken as prescribed. Compliance and adherence are synonymous terms to describe whether prescribed medication 
is taken according to a schedule in terms of timing, dosage and frequency. The terminology to describe compliance has evolved with time and has been overruled somewhat by the term adherence. The term compliance has been given a negative image as it implies the prescriber being the instructor and the patient being the follower of doctor's orders. Non-compliant patients could be judged as incompetent or unwilling in following orders. The term adherence is thought to have fewer negative connotations and to be less judgmental. ${ }^{24,25}$ In adherence, patient and physician have reached an alliance in which the patient has the freedom to decide whether or not to comply with a prescribed schedule..$^{24,26}$

Persistence or persistency describes the total duration of medication use from initiation to discontinuation. ${ }^{27}$ Therefore, a patient who is adherent with the treatment schedule in terms of dosing frequency and timing but who discontinues therapy earlier than prescribed, is adherent or compliant for the time using eye drops but not persistent. Persistence can be the result of the patient's satisfaction with treatment and the doctor's satisfaction with treatment outcome. ${ }^{28}$

Concordance is not synonymous to compliance or adherence but rather reflects the consultation process in a wider concept from prescribing medication to patient support in medicine taking. ${ }^{24}$ Concordance focuses on the shared decision making between physician and patients. It describes an agreement between a patient and his physician that respects the beliefs and wishes of the patient and the experience and expertise of the physician in determining the chosen therapy. ${ }^{24}$

In this thesis, we decided to use the term adherence to describe whether medication was taken as prescribed. However, in some chapters the synonymous term compliance is used to describe whether medication was taken as prescribed because of the evolution of the terminology in time or the preference of the journal in which the manuscript was published. Moreover, adherence was the focus of this thesis. Persistence was not studied.

\section{References}

1. American Academy of Ophthalmology. Basic and clinical science course 2006-2007 section 10: Glaucoma: American Academy of Ophthalmology, 2006.

2. European Glaucoma Society. Terminology and guidelines for glaucoma (4th ed.). Savona, Italy: PubliComm, 2014.

3. Tuck MW, Crick RP. The age distribution of primary open angle glaucoma. Ophthalmic Epidemiol 1998;5:173-83.

4. Rijksinstituut voor Volksgezondheid en Milieu. Gezichtsstoornissen. Prevalentie glaucoom in huisartsenpraktijk naar leeftijd en geslacht. Bilthoven: RIVM, http://www.volksgezondheidenzorg. info, 2019. Accessed: May 2020.

5. Quigley HA, Broman AT. The number of people with glaucoma worldwide in 2010 and 2020. Br J Ophthalmol 2006;90:262-7.

6. Mohkles P, Schouten J, Beckers H, et al. Glaucoma blindness at the end of life. Acta Ophthalmol 2017;95:10-1.

7. Coleman AL, Miglior S. Risk factors for glaucoma onset and progression. Surv Ophthalmol 2008;53 Suppl1:S3-10.

8. Omoti AE, Edema OT. A review of the risk factors in primary open angle glaucoma. Niger J Clin Pract 2007;10:79-82.

9. Peeters A, Webers CA, Prins MH, et al. Quantifying the effect of intraocular pressure reduction on the occurrence of glaucoma. Acta Ophthalmol 2010;88:5-11.

10. Ernest PJ, Schouten JS, Beckers HJ, et al. An evidence-based review of prognostic factors for glaucomatous visual field progression. Ophthalmology 2013;120:512-9.

11. Group CN-TGS. Comparison of glaucomatous progression between untreated patients with normal-tension glaucoma and patients with therapeutically reduced intra-ocular pressures. Am J Ophthalmol 1998;126:487-97.

12. Heijl A, Leske C, Bengtsson B, et al. Reduction of intraocular pressure and glaucoma progression. Results from the early manifest glaucoma trial. Arch Ophthalmol 2002;120:1268-79.

13. Kass MA, Heuer DK, Higginbotham EJ, et al. The Ocular Hypertension Treatment Study. A randomized trial determines that topical ocular hypotensive medication delays or prevents the onset of primary open-angle glaucoma. Arch Ophthalmol 2002;120:701-13.

14. Gazzard G, Konstantakopoulou E, Garway-Heath D, et al. Selective laser trabeculoplasty versus eye drops for first-line treatment of ocular hypertension and glaucoma (LiGHT): a multicentre randomised controlled trial. Lancet 2019;393:1505-16.

15. Van der Valk R, Schouten JS, Webers CA, et al. The impact of a nationwide introduction of new drugs and a treatment protocol for glaucoma on the number of glaucoma surgeries. J Glaucoma 2005;14:239-42.

16. van Gestel A, Webers CA, Severens JL, et al. The long-term outcomes of four alternative treatment 
strategies for primary open-angle glaucoma. Acta Ophthalmol 2012;90:20-31.

17. van Gestel A, Schouten JS, Beckers HJ, et al. The long term effectiveness and cost-effectiveness of initiating treatment for ocular hypertension. Acta Ophthalmol 2014;92:513-23.

18. Agrawal P, Bradshaw SE. Systematic Literature Review of Clinical and Economic Outcomes of Micro-Invasive Glaucoma Surgery (MIGS) in Primary Open-Angle Glaucoma. Ophthalmol Ther 2018;7:49-73.

19. Gonzalez S, Steinglass P, Reiss D. Putting the illness in its place: discussion groups for families with chronic medical illnesses. Fam Proc 1989;28:69-87.

20. Kim S, Stewart JFG, Emond MJ, et al. The effect of a brief education program on glaucoma patients. J Glaucoma 1997;6:146-51.

21. Spaeth GL. Visual loss in a glaucoma clinic. I. Sociological considerations. Invest Ophthalmol 1970;9:73-82.

22. Spaeth GL. Patient self-management skills influence the course of glaucoma. Ophthalmology 1997;104:1065-6.

23. Zimmerman TJ, Zalta AH. Facilitating patient compliance in glaucoma therapy. Surv Ophthalmol 1983;28:252-7.

24. Horne R. Compliance, adherence, and concordance: implications for asthma treatment. Chest 2006;130:65S-72S.

25. Broadway DC, Cate H. Pharmacotherapy and adherence issues in treating elderly patients with glaucoma. Drugs Aging 2015;32:569-81.

26. Haynes RB, Ackloo E, Sahota N, et al. Interventions for enhancing medication adherence. Cochrane Database Syst Rev 2008: Art.No.: CD000011. DOI:10.1002/14651858.CD000011.pub3.

27. Schwartz GF, Quigley HA. Adherence and persistence with glaucoma therapy. Surv Ophthalmol 2008;53:S57-68.

28. Deokule S, Sadiq S, Shah S. Chronic open angle glaucoma: patient awareness of the nature of the disease, topical medication, compliance and the prevalence of systemic symptoms. Ophthal Physiol Opt 2004;24:9-15. 


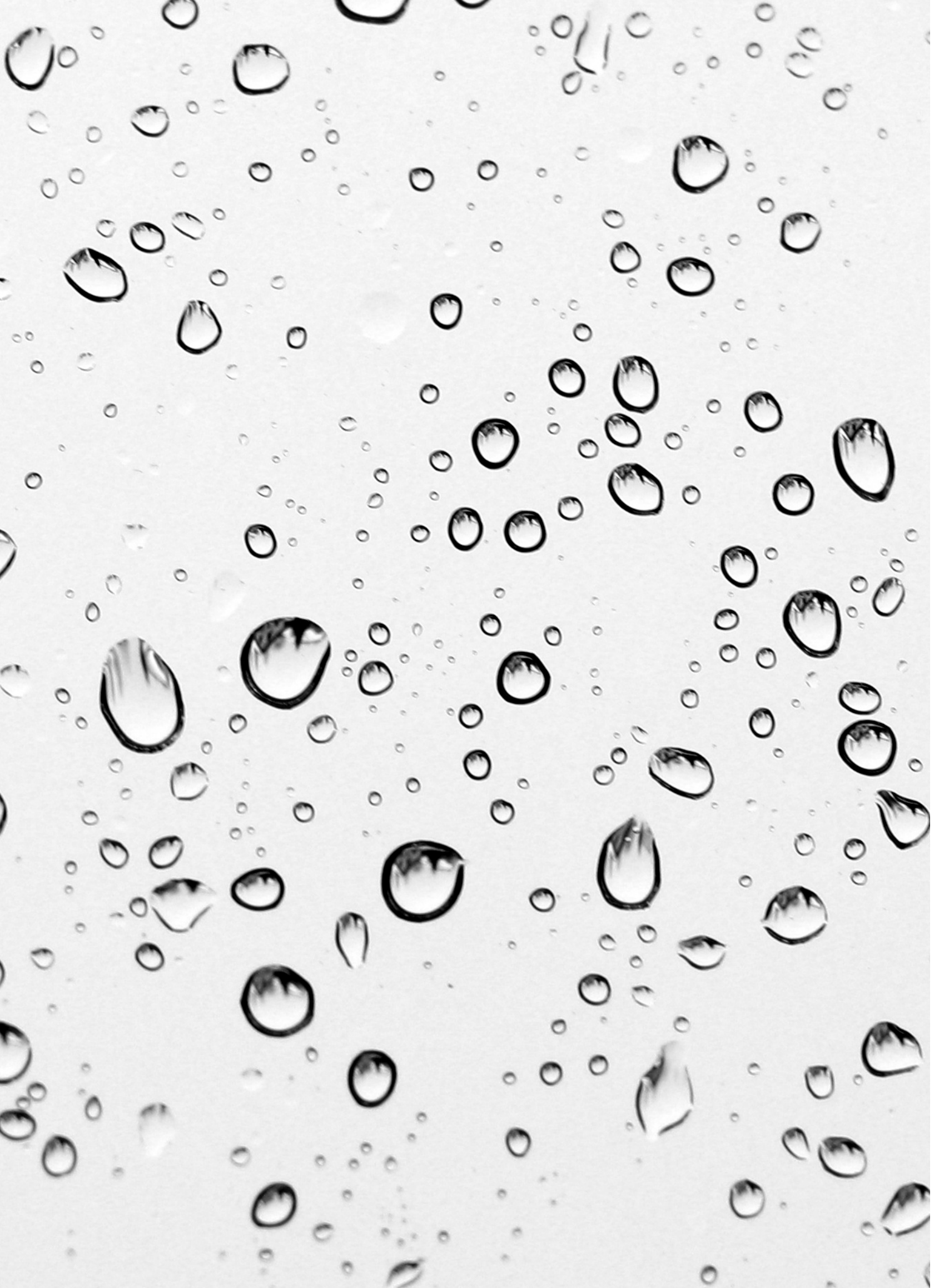




\section{Abstract}

\section{Purpose}

To gather information regarding patient's understanding of glaucoma and the manner in which patients wish to learn about the disease with the intent of improving patient education.

\section{Methods}

Forty-four of sixty randomly selected ophthalmologists (73\%) asked four of their patients consecutively to complete a questionnaire about glaucoma. The selection of questions was based on focus group interviews and suggestions from several experts. Topics included knowledge about glaucoma and its treatment, the need for information and preferred providers and methods of patient education.

\section{Results}

Fifty percent of the patients had $49 \%$ or less correct answers to questions about glaucoma or its treatment. Per item the correct answers ranged from 5\% to $90 \%$. Lack of knowledge was associated with low level of education, short duration of glaucoma, high age, and no preference for the Internet as method of supplying information. These variables, however, did not identify groups with a considerable lack of knowledge sufficiently accurately to target patient education. A high need for information was observed and included information about the patient's own glaucoma. Almost all patients preferred the ophthalmologist and many also a nurse or a representative of the Glaucoma Patient Society as providers of information. Written material was the preferred method.

\section{Conclusions}

Patient education should address all patients. A patient education program should cover a wide range of topics with a focus on general information through written material and information tailored to the individual glaucoma patient's needs. The ophthalmologist is a key-person, but others could play an important role in patient education.

\section{Introduction}

Patients with a chronic disease have a substantial need for information and frequently their knowledge about their disease is far from perfect, despite current opportunities to obtain information from their doctor and several other sources. ${ }^{1-13}$ Patients are often not satisfied with the content and amount of information they receive. ${ }^{9,11-13}$ Moreover, the meaning of medical information differs between patients and doctors. ${ }^{11}$ It is suggested that well-informed patients better understand their prognosis and manage their disease more adequately. ${ }^{14,15}$ They are also more compliant and more likely to cope effectively with the changes the illness requires. ${ }^{15-18}$ Providing accurate information may reduce emotional distress, psychological distress, anxiety, and pain that interfere with patients' adjustment to their disease. ${ }^{6,13}$

Studies from several countries report a lack of knowledge in glaucoma patients. ${ }^{1-5,7}$, ${ }^{14}$ For example, $45 \%$ of the glaucoma patients did not have any idea about the cause of glaucoma and $70 \%$ thought they would go blind if their glaucoma was not treated. ${ }^{1}$ Even though many patients fear blindness, they rarely ask their ophthalmologist if they will go blind from their glaucoma. ${ }^{19}$ It is assumed that, in glaucoma patients, improved knowledge and understanding could affect compliance with treatment and follow-up appointments and lead to better understanding of their prognosis. ${ }^{14}$, ${ }^{16,17}$ Well-informed patients are also more likely to encourage family members to check for glaucoma. ${ }^{14}$

Although these studies show the need for patient education, these studies do not provide sufficient knowledge to develop a patient education program. These articles do not show whether an educational program should be targeted to certain groups at risk of having a lack of knowledge, and do not provide an overview of the items that should be addressed or the providers and methods that should play a role in patient education. The studies also do not give insight in the subjective needs for information. Moreover, the studies were not based on a thorough and systematic process of item selection and the patients were often selected from one or only a few local settings, possibly leading to biased results.

We therefore undertook a study to assess the number of patients with a lack of knowledge, groups at risk of having less knowledge, items that need to be covered, the subjective needs for information, and the preferred providers and methods for patient education. 


\section{Methods}

A cross-sectional multicenter study with self-administered questionnaires was undertaken.

The selection of the items for the questionnaire was based on four focus group interviews with patients from three general hospitals and one university hospital. None of the hospitals were private hospitals since there are very few private hospitals for a very limited number of diseases and interventions in the Netherlands. One of the focus groups consisted of members of the Glaucoma Patient Society. Because there are fewer patients with a short duration of glaucoma, specials emphasis was given to the inclusion of these patients. Twentyone patients participated. The duration of the glaucoma was 1 year or less in eight patients. Nine were members of the Glaucoma Patient Society. The initial routing questions of the interview were developed by a health education specialist and were reviewed by two other health education specialists with experience in this field. The routing questions were adjusted after each focus group interview. The focus group interviews were recorded on tape and transcribed. This was used to select the items of the questionnaire. A concept of the questionnaire was submitted to a pharmacist with research experience in the use of glaucoma medication, an ophthalmologist specialized in glaucoma, two health education specialists with practical experience in patient education, a professor in patient education, and the chairman of the Glaucoma Patient Society. The questionnaire was pilot tested on 10 glaucoma patients.

The following topics were covered in the questionnaire: knowledge about glaucoma and its treatment, need for information, and the providers and methods patients prefer. Patients were given 19 and 18 statements about the knowledge of glaucoma and its treatment, respectively, which they could answer as yes, no, or don't know. Twenty-two topics concerning the need for information were listed. Patients could fill out whether they would like to receive a lot of, some, or no information about the stated topic. Various providers and methods were listed to investigate preferred providers and methods to supply information. Answers were 'yes', 'no' and 'don't know / no opinion'. Details about the specific items are shown in Tables 1-4.

Sixty ophthalmologists were randomly selected from the list of addresses of the Dutch Ophthalmological Society. To increase the response an incentive was included for both the ophthalmologist and the patients. All ophthalmologists were also contacted by telephone after 2 to 3 weeks and by mail after 6 to 8 weeks to improve participation.

Ophthalmologists asked four glaucoma patients consecutively to fill out the questionnaire during their stay at the outpatient department. No selection was made with regard to the duration of glaucoma or the type of glaucoma medication. If a patient refused to participate the ophthalmologists were asked to select the next consecutive patient and to number the patients according to the consecutive order.

Data were entered in a database by two typists independently of each other and were checked and corrected when needed. Missing answers for a question with "don't know/ no opinion" as an answer category were classified as "don't know/ no opinion". Statistical analyses were performed using SPSS software for Windows. Frequency distributions were calculated for each item of knowledge, need for information, and preference for providers and methods. The total number of correct answers was calculated for knowledge about glaucoma and its treatment. Mean value and $95 \%$ confidence intervals for this number were calculated for strata of sex, age, educational level, duration of glaucoma, and preference for Internet as method of supplying information. Multivariate linear regression was done with all these variables in the model to adjust for the other variables. In addition, an analysis of the relation of Internet preference with knowledge is presented per stratum of educational level. An analysis of variance was used to calculate the amount of explained variance for the multivariate model.

\section{Results}

Forty-four ophthalmologists (73\%) responded. Thirty-four ophthalmologists returned four questionnaires, two returned five, five returned three, two sent two and one returned one questionnaire. Therefore, 166 questionnaires were included in the study. Based on the information provided by the ophthalmologists it was calculated that $85 \%$ of the consecutive patients invited by the ophthalmologist to participate actually filled out the questionnaire. Reported reasons for not participating were cognitive dysfunction, language barriers and lack of time.

Some patient characteristics are presented in Table 5. Some had missing values for some variables. Mean age of the 166 participating patients was 65 years (standard deviation: 12, minimum: 26, maximum: 91 ). The patients in the study consisted 
of 86 men $(52,1 \%)$ and 79 women $(47,9 \%)$. In 39 patients $(23,5 \%)$ the glaucoma existed less than two years. Twenty-five $(15,3 \%)$ patients had undergone glaucoma surgery and $53(32,3 \%)$ patients had been treated with Argon laser trabeculoplasty (ALT).

Fifty percent had less than $49 \%$ correct answers. Twenty-five percent had a score of $38 \%$ or less and $75 \%$ had a score of $59 \%$ or less. Knowledge increased with higher levels of education, longer duration of glaucoma, preference for Internet as method of supplying information, and decreasing age (Tab. 5). There was no difference between sexes. The differences in knowledge remained after adjusting for the other variables. Although there were differences in the mean score for knowledge between levels of some risk factors, there is also considerable overlap in the distribution of the score for knowledge between levels of (Tab. 5). The difference between those who preferred Internet and those who did not was 10.3 (( $95 \%$ confidence interval (CI) 3.1-17.6)), 5.6 (95\% CI 1.4-9.7), and 3.6 (95\% CI 0.3-6.9) for low, medium, and high level of education, respectively. The total amount of explained variance of the multivariate model was $34 \%$.

Patients were given 19 statements about risk factors, pathophysiology, and consequences of glaucoma (Tab. 1). The percentage of patients that gave the correct answers ranged from $5 \%$ to $90 \%$ per item. The items with the highest score for the correct answer were "the chance of getting glaucoma is higher if the intraocular pressure is increased", "it is possible to have glaucoma without knowing", and "a patient always has to tell the ophthalmologist which other medicines (s)he is using". The ones with a low score concerned other risk factors and rate of progression without treatment.

Patients were given 18 statements about topics concerning treatment, including indications, effects, and adverse effects of treatments (Tab. 2). The percentage correct answers per item ranged from $5 \%$ to $88 \%$. The items with a high score for the correct answer were "even if the intraocular pressure is under control, the visual field has to be checked", "the course of the disease can be slowed down by eye drops", "stinging or burning of the eyes could be an adverse effect of eye drops", and "blurred vision after dropping could be an adverse effect of eye drops". Statements with a low score mainly addressed issues concerning some side effects of treatment.
Table 1. Number of glaucoma patients with correct answers about glaucoma.

\begin{tabular}{lc}
\hline Statement & No. (\%) \\
\hline The chance of getting glaucoma is higher if the intraocular pressure is increased & $149(90)$ \\
It is possible to have glaucoma without knowing it & $146(88)$ \\
A patient should always tell the ophthalmologist which other medicines (s)he is using & $132(80)$ \\
Glaucoma affects the visual field & $129(78)$ \\
The chance of getting glaucoma is higher if a family member has glaucoma & $119(72)$ \\
A patient should always tell the ophthalmologist which other diseases (s)he has & $116(70)$ \\
Young people more often have glaucoma than older people & $116(70)$ \\
Glaucoma causes reduction of visual acuity & $113(68)$ \\
The intraocular pressure is increased if it exceeds 25 mmHg & $101(61)$ \\
If the visual field is impaired, this can be repaired & $83(50)$ \\
Glaucoma often causes impaired reading & $76(46)$ \\
Nutrition influences glaucoma & $71(43)$ \\
There is only one type of glaucoma & $56(34)$ \\
The optic nerve is damaged in glaucoma & $54(33)$ \\
Medicines other than eye drops can influence the intraocular pressure & $54(33)$ \\
Without treatment, glaucoma is a fast progressing condition & $44(27)$ \\
The intraocular pressure is always increased in glaucoma & $29(18)$ \\
Strong myopia or hypermetropia gives a higher chance of getting glaucoma & $13(8)$ \\
African people have a higher chance of getting glaucoma & $9(5)$ \\
\hline
\end{tabular}

Table 2. Number of glaucoma patients with correct answers about the treatment of glaucoma.

\begin{tabular}{lc}
\hline Statement & No. (\%) \\
\hline Even if the intraocular pressure is under control, the visual field has to be checked & $146(88)$ \\
The course of the disease can be slowed down by eye drops & $145(87)$ \\
Stinging or burning of the eyes could be an adverse effect of eye drops & $131(79)$ \\
Blurred vision after dropping could be an adverse effect of eye drops & $126(76)$ \\
Eye drops can repair the damage caused by glaucoma & $112(68)$ \\
The pharmacy controls which medicines one is using & $106(64)$ \\
Glaucoma can only be treated by lowering the intraocular pressure & $105(63)$ \\
Each treatment is equally good for everyone & $90(54)$ \\
The use of eye drops will be redundant if one has had a laser treatment or surgery for & $74(45)$ \\
glaucoma & \\
Some eye drops should not be used by cardiac patients or asthma patients & $74(45)$ \\
Early detection and treatment will not slow the course of glaucoma & $72(43)$ \\
Eye drops can be replaced by tablets & $60(36)$ \\
Laser treatment or surgery for glaucoma can repair the damage caused by glaucoma & $59(36)$ \\
Discoloration of the iris may be an adverse effect of eye drops & $51(31)$ \\
Dyspnoea could be an adverse effect of eye drops & $29(18)$ \\
A slower heart rate could be an adverse effect of eye drops & $25(15)$ \\
It is possible to completely lose vision as a result of laser treatment or surgery for glaucoma & $12(7)$ \\
A high intraocular pressure must always be treated & $9(5)$ \\
\hline
\end{tabular}


The percentage of patients who needed information ranged from $16 \%$ to $79 \%$ per topic (Tab. 3). Many patients wanted information about glaucoma and its treatment and about the state and course of their own glaucoma. A need for information about the practical and social aspects of glaucoma was reported less frequently.

Table 3. Need for Information of glaucoma patients.

\begin{tabular}{lccc}
\hline How much information would you like to have about: & $\begin{array}{c}\text { Much, } \\
\text { No. (\%) }\end{array}$ & $\begin{array}{c}\text { Some, } \\
\text { No. (\%) }\end{array}$ & $\begin{array}{c}\text { Not at all, } \\
\text { No. (\%) }\end{array}$ \\
\hline New developments concerning glaucoma and its treatment & $123(79)$ & $22(14)$ & $11(7)$ \\
The possible course and consequences of your glaucoma & $118(77)$ & $21(14)$ & $14(9)$ \\
Possible results of treatments & $117(75)$ & $20(13)$ & $19(12)$ \\
The present condition of your glaucoma & $106(67)$ & $33(21)$ & $20(12)$ \\
Possible adverse effects of treatments & $99(63)$ & $36(23)$ & $22(14)$ \\
The cause of glaucoma & $95(62)$ & $38(25)$ & $21(13)$ \\
Heredity of glaucoma & $94(61)$ & $31(20)$ & $30(19)$ \\
Other diseases that influence glaucoma & $85(57)$ & $43(28)$ & $22(15)$ \\
Laser treatment and eye-surgery & $83(52)$ & $44(28)$ & $31(20)$ \\
Eye drops & $80(52)$ & $40(26)$ & $33(22)$ \\
Where to find good educational material about glaucoma & $77(50)$ & $48(31)$ & $30(19)$ \\
How to function better with glaucoma & $73(47)$ & $44(29)$ & $37(24)$ \\
How to learn to cope with glaucoma & $69(44)$ & $43(28)$ & $43(28)$ \\
Resources or rehabilitation for the visually impaired & $64(41)$ & $44(29)$ & $46(30)$ \\
Social aspects of glaucoma & $56(38)$ & $39(26)$ & $54(36)$ \\
Social securities for visually impaired people & $55(36)$ & $44(29)$ & $53(35)$ \\
Psychological aspects of glaucoma & $54(36)$ & $47(31)$ & $50(33)$ \\
How to use and apply eye drops & $41(27)$ & $36(24)$ & $74(49)$ \\
The Glaucoma Patient Society & $40(26)$ & $48(32)$ & $64(42)$ \\
Work and glaucoma & $29(20)$ & $45(31)$ & $72(49)$ \\
Experiences of other glaucoma patients & $25(17)$ & $65(43)$ & $61(40)$ \\
Social support or assistance at home & $25(16)$ & $59(38)$ & $70(46)$ \\
\hline
\end{tabular}

Ninety-four percent of the glaucoma patients preferred the ophthalmologist as provider (Tab. 4). Other preferred providers were "a representative of the Glaucoma Patient Society" (42\%), "a nurse of the ophthalmology outpatients' department" (39\%) and "the general practitioner" (32\%).

The most preferred methods of supplying the information were a brochure (72\%) and other written material. New media like e-mail (13\%) and Internet (16\%) were not mentioned often.
Table 4. Provider and method of information preferred by glaucoma patients

\begin{tabular}{|c|c|c|c|}
\hline Provider & $\begin{array}{c}\text { Yes } \\
\text { No. (\%) }\end{array}$ & $\begin{array}{c}\text { No } \\
\text { No. (\%) }\end{array}$ & $\begin{array}{c}\text { Don't know/ } \\
\text { no opinion, } \\
\text { No. }(\%)\end{array}$ \\
\hline Ophthalmologist & $156(94)$ & $3(2)$ & $7(4)$ \\
\hline Representative of the glaucoma patient society & $70(42)$ & $47(28)$ & $49(30)$ \\
\hline Nurse of the ophthalmology outpatients' department & $65(39)$ & $54(33)$ & $47(28)$ \\
\hline General practitioner & $53(32)$ & $70(42)$ & $43(26)$ \\
\hline Optician & $47(28)$ & $77(47)$ & $42(25)$ \\
\hline Pharmacist & $34(20)$ & $86(52)$ & $46(28)$ \\
\hline $\begin{array}{l}\text { Somebody of centeres for education and rehabilitation for } \\
\text { visually impaired patients }\end{array}$ & $32(19)$ & $70(42)$ & $64(39)$ \\
\hline Another glaucoma patient & $26(16)$ & $86(52)$ & $54(33)$ \\
\hline $\begin{array}{l}\text { Someone of the department for patient education from the } \\
\text { hospital }\end{array}$ & $24(14)$ & $78(47)$ & $64(39)$ \\
\hline Optometrist & $20(12)$ & $70(42)$ & $76(46)$ \\
\hline Doctor's assistant & $17(10)$ & $103(62)$ & $46(28)$ \\
\hline Pharmacist assistant & $16(9)$ & $104(63)$ & $46(28)$ \\
\hline A representative of the pharmaceutical industry & $8(5)$ & $104(63)$ & $54(32)$ \\
\hline \multicolumn{4}{|l|}{ Method } \\
\hline Leaflet or brochure & $119(72)$ & $23(14)$ & $24(14)$ \\
\hline A frequently sent information brochure about glaucoma & $90(54)$ & $41(25)$ & $35(21)$ \\
\hline Information brochure of one's health insurance company & $69(42)$ & $65(39)$ & $32(19)$ \\
\hline Health magazines & $49(29)$ & $76(46)$ & $41(25)$ \\
\hline Magazines for the elderly & $32(20)$ & $92(55)$ & $42(25)$ \\
\hline National newspapers or magazines & $29(18)$ & $95(57)$ & $42(25)$ \\
\hline Special telephone number & $29(17)$ & $91(55)$ & $46(28)$ \\
\hline Group meetings of glaucoma patients & $27(16)$ & $99(60)$ & $40(24)$ \\
\hline Internet & $26(16)$ & $97(58)$ & $43(26)$ \\
\hline e-mail & $21(13)$ & $102(61)$ & $43(26)$ \\
\hline Local or regional dailyy- or weekly magazines & $19(11)$ & $102(61)$ & $45(27)$ \\
\hline
\end{tabular}


Table 5. Mean number of correct answers about glaucoma and its treatment by sex, age, education, duration of glaucoma, and preference to internet as method of supplying information.

\begin{tabular}{|c|c|c|c|c|c|}
\hline & & \multicolumn{4}{|c|}{ Number of correct answers about glaucoma and its treatment } \\
\hline & & Range & $\begin{array}{l}\text { Mean values* } \\
(95 \% \mathrm{CI})\end{array}$ & $\begin{array}{c}\text { Unadjusted } \\
\text { difference }^{\dagger} \\
(95 \% \mathrm{CI})\end{array}$ & $\begin{array}{c}\text { Adjusted } \\
\text { difference }^{\dagger} \\
(95 \% \mathrm{CI})\end{array}$ \\
\hline \multirow[t]{2}{*}{ Sex } & Male $(\mathrm{n}=86)$ & $6-31$ & $18.2(17.0-19.5)$ & $0^{\ddagger}$ & $0^{\ddagger}$ \\
\hline & Female $(n=79)$ & $1-31$ & $18.4(17.1-19.7)$ & $0.2(-1.7-2.0)$ & $1.3(-0.4-2.9)$ \\
\hline \multirow[t]{4}{*}{ Age, yr } & $26-54(\mathrm{n}=40)$ & $9-31$ & $22.1(20.3-23.8)$ & $0^{\ddagger}$ & $0^{\ddagger}$ \\
\hline & $55-64(\mathrm{n}=31)$ & $9-30$ & $19.8(17.6-22.1)$ & $-2.2(-4.8-0.3)$ & $-1.7(-4.0-0.7)$ \\
\hline & $65-74(n=55)$ & $1-30$ & $16.4(15.0-17.8)$ & $-5.7(-7.9--3.4)$ & $-2.9(-5.2--0.7)$ \\
\hline & $\geq 75(\mathrm{n}=40)$ & $8-25$ & $16.0(14.6-17.3)$ & $-6.1(-8.5--3.7)$ & $-3.6(-6.0--1.2)$ \\
\hline \multirow[t]{3}{*}{ Education } & Low $(\mathrm{n}=69)$ & $1-29$ & $16.0(14.7-17.3)$ & $0^{\ddagger}$ & $0^{\ddagger}$ \\
\hline & Middle (n=53) & $9-31$ & $19.0(17.4-20.7)$ & $3.1(1.1-5.0)$ & $1.3(-0.6-3.1)$ \\
\hline & High $(n=43)$ & $9-31$ & $21.2(19.6-22.8)$ & $5.2(3.1-7.3)$ & $3.5(1.4-5.6)$ \\
\hline \multirow[t]{3}{*}{ Duration, yr } & $\leq 2(n=39)$ & $6-29$ & $16.3(14.7-18.0)$ & $0^{\ddagger}$ & $0^{\ddagger}$ \\
\hline & $2-5(n=44)$ & $9-31$ & $19.1(17.3-20.7)$ & $2.7(0.3-5.1)$ & $3.1(1.0-5.2)$ \\
\hline & $>5(\mathrm{n}=72)$ & $9-31$ & $19.4(18.0-20.7)$ & $3.0(0.9-5.2)$ & $3.4(1.5-5.4)$ \\
\hline \multirow[t]{2}{*}{ Internet } & No $(n=140)$ & $1-31$ & $17.3(16.3-18.2)$ & $0^{\ddagger}$ & $0^{\ddagger}$ \\
\hline & Yes $(n=26)$ & $13-31$ & $23.8(22.0-25.6)$ & $6.5(4.2-8.8)$ & $3.8(1.4-6.2)$ \\
\hline
\end{tabular}

* 95\% CI $=95 \%$ confidence interval

${ }^{+}$(Not) adjusted for the other variables, $\mathrm{n}=154$ adjusted mode

₹ Reference for linear regression

\section{Discussion}

The present study demonstrates a substantial lack of knowledge in patients and an urgent need for information on many different topics. This need concerns the state, course, and possible consequences of a patients' own glaucoma as well as items that may influence the quality of life. Lack of knowledge was associated with a low level of education, short duration of glaucoma, no preference for Internet as method of supplying information, and high age. The preferred providers were the ophthalmologist, a nurse from the ophthalmology outpatient department, a representative of the Glaucoma Patient Society, and the general practitioner. Written material was the preferred method.

The questionnaire was developed in a systemic way and was based on focus group interviews of patients from different hospitals and different relevant backgrounds of patients like duration of glaucoma and membership of the Glaucoma Patient Society. Moreover, consultation of several experts was involved in the development of focus group interviews and the questionnaire. As a result, an extensive questionnaire was formed with a complete list of relevant items for the development of a patient education program. The questionnaire had a good internal consistency, Cronbach's alpha was 0.83 , ranging from 0.81 to 0.83 after an item was deleted one at a time (data not shown).

The results were based on a nationwide random sample of patients. A high response rate among patients was achieved because patients were asked to fill out the questionnaire not at home but at the outpatient department. The response rate of the consecutive series of patients was $85 \%$. It cannot be excluded completely that a bias has occurred since we had no control over the distribution of the questionnaire in every hospital. It is, however, hardly imaginable that all ophthalmologist have made a selection in such a way that the observed relations occur. This would imply that patients with a long duration of glaucoma and high levels of knowledge would have been selected, as well as patients with a short duration if they had a low level of knowledge. Moreover, the observed relations of duration of glaucoma, educational level, age, and preference for Internet seem likely a priori. Alternatives to this strategy of selecting patients would almost certainly have induced a bias, for example if only a few hospitals participated, if an ophthalmologist was asked to select only one patient, or if members from the Glaucoma Patient Society were selected. The selection of several ophthalmologists also had the advantage that workload was reduced, thereby enhancing the response rate of ophthalmologists and preventing participation bias of ophthalmologists.

The preference for Internet does not seem to be a confounder for the relation between educational level and knowledge. It is more likely to be an intermediate variable between educational level and knowledge. In the multivariate model the relation between educational level and knowledge remained after adjusting for preference for Internet. Moreover, the relation between Internet preference and knowledge was present for every stratum of educational level. Although several risk factors are observed, they do not seem useful to select groups at risk for tailoring an educational program for patients. The overlap in level of knowledge is considerable and the amount of explained variance is $34 \%$. Much of the level of knowledge is therefore not explained by these variables. Since the level of knowledge is very low and no tailoring can take place, patient education should focus on every patient.

The present results do not seem to be relevant for Dutch patients only. Some results concerning lack of knowledge confirm earlier studies from other countries. ${ }^{1-5,7,14}$ In these earlier studies a lack of knowledge of causes and risk factors like intraocular 
pressure and heredity was also found, even among patients with a family history of glaucoma. ${ }^{1,3,7,20}$ Moreover, a need for information has been shown earlier, but details on subjects were lacking. ${ }^{1}$

Patient education may enhance self-management, coping, compliance, and understanding of the prognosis, and reduce emotional distress, psychological distress, and anxiety. ${ }^{6,13-18}$

Whether these effects can be achieved with a glaucoma patient education program has not been proven for every relevant outcome variable. However, the results of our study and others make it more likely that positive effects can be achieved if high needs for information and low levels of knowledge are addressed.

For example, patients often do not alert a relative to their higher chance of getting glaucoma while it is known that informed people and their relatives are more likely to visit an ophthalmologist before advanced visual field loss has occurred., ${ }^{21}$ It is also known that well-informed patients are more likely to encourage family members to check for glaucoma. ${ }^{14}$ It is therefore necessary for a patient education program to focus on issues relevant to early detection such as heredity as a cause, the importance of early detection, treatment, and the possibility of having glaucoma without knowing it.

Another advantage of patient education concerns the compliance with treatment recommendations. ${ }^{17,22}$ It is assumed that improved knowledge and understanding of the disease and treatment could affect compliance with treatment and followup appointments and could lead to better understanding of the prognosis. ${ }^{14,16,17}$ Several items from our study may be relevant in relation to compliance. These items concern intraocular pressure as a risk factor for glaucoma, reduction of intraocular pressure as the only treatment of glaucoma, the effect of treatment, adverse events, the impossibility to cure glaucoma, the relevance of regular checks of the visual field, the possible need to continue eyedrops after laser or surgery, and the practical use of eyedrops. Relevant items regarding prognosis like the rate of progression and glaucoma as a cause of reading impairment have also been identified.

Other issues to be addressed in a patient education program are the effect and occurrence of adverse events of treatment. Reduction of adverse events may be obtained when patients know and report relevant side effects and mention other drugs they use or other diseases they may have. ${ }^{17}$

The present study also supports the need to discuss the patients' present state, the course of the disease, and the possible consequences of having glaucoma to prevent unnecessary emotional distress. This need is supported by the fact that patients rarely ask their ophthalmologist if they will go blind from their glaucoma while many patients fear blindness and 70\% think they would go blind if their glaucoma is not treated. ${ }^{1,19}$

Glaucoma has an effect on the quality of life at several stages of visual field loss..$^{23-27}$ In the present study it was shown that a substantial number of glaucoma patients want information about "how to function better with glaucoma", "how to learn to cope with glaucoma", "resources or rehabilitation for the visually impaired", "social and psychological aspects of glaucoma", "social securities for visually impaired people" and work-related aspects. Therefore, patient education should also focus on these items to improve quality of life more directly.

The development of a patient education program does not only entail considerations of the content but also of providers and methods. In line with Odberg et al, nearly all patients perceive the ophthalmologist as most preferred provider of information. ${ }^{1}$ Ophthalmologists are closely involved in monitoring the patients' course of glaucoma and treatment. Since patients regularly visit their specialist, ophthalmologists ideally should undertake repeated patient education. ${ }^{9}$ The Glaucoma Patient Society and the nurse of the ophthalmology outpatient department may accomplish new roles, for the latter especially in providing the highly needed, individual information about a patient's own condition, disease course, and consequences of glaucoma.

Although only $16 \%$ of patients in the present study preferred peer group meetings of glaucoma patients as a source of information, this also deserves consideration. The participants of our focus groups thought it useful and pleasant to exchange knowledge and experiences. Petersson et al have also demonstrated this experience in cancer patients. ${ }^{28}$ Moreover, in meetings with peers patients could be taught to participate actively and to interact with their doctor, which would hopefully lead to better communication between patient and doctor and better ability to remember information. A consultation in which attention is paid to the patient's perceptions and needs has been shown to be more effective to achieve clinical outcome and satisfaction for both patients and doctors than a consultation in which only a 
standardized amount of information is given. ${ }^{29}$

Earlier studies have shown that an education program with a videotape, sometimes supplemented by brochures or interaction with a nurse, have a beneficial effect on knowledge about glaucoma. ${ }^{5,14,21}$ This information might well be given while patients wait for their appointment at the outpatient department. ${ }^{21}$ It has also been shown that patient education needs to be repeated at regular intervals to maintain its effectiveness and should involve relatives. ${ }^{7,14}$

\section{References}

1. Odberg T, Jakobsen JE, Hultgren SJ, Halseide R. The impact of glaucoma on the quality of life of patients in Norway. Acta Ophthalmol 2001;79:116-20.

2. Livingston PM, Lee SE, De Paola C, et al. Knowledge of glaucoma, and its relationship to self-care practices, in a population sample. Aust N Z J Ophthalmol 1995;23:37-41.

3. MacKean JM, Elkington AR. Alerting close relatives of patients with glaucoma. Br Med J 1984;289:800-1.

4. Attebo K, Mitchell P, Cumming R, Smith W. Knowledge and beliefs about common eye diseases. Aust N Z J Ophthalmol 1997;25:283-7.

5. Rosenthal AR, Zimmerman JF, Tanner J. Educating the glaucoma patient. Br J Ophthalmol 1983;67:814-7.

6. Rainey LC. Effects of preparatory patient education for radiation oncology patients. Cancer 1985;56:1056-61.

7. Huusko H, Viinamäki M, Krause K. Developing standards for instructions to patients with glaucoma. Nurs Pract 1990;3:23-6.

8. Orzeck SA, Staniloff HM. Comparison of patients' and spouses' needs during the posthospital convalescence phase of a myocardial infarction. J Cardiopulm Rehabil 1987;7:59-67.

9. Breemhaar B, van den Borne HW, Mullen PD. Inadequacies of surgical patient education. Patient Educ Couns 1996;28:31-44

10. Jaarsma T, Philipsen H, Kastermans MC, Dassen T. Informatiebehoefte en problemen van myocardinfarct- en coronaire-bypass-patiënten (Need for information and problems of patients with myocardial infarction or coronary artery bypass surgery). Verpleegkunde 1994;4:233-42.

11. Chaitchik S, Kreitler S, Shaked S, et al. Doctor-patient communication in a cancer ward. J Cancer Educ 1992;7:41-54.

12. Engström B. The patients' need for information during hospital stay. Int J Nurs Stud 1984;21:113-

13. Webber GC. Patient Education. a review of the issues. Med Care 1990;28:1089-103.

14. Kim S, Stewart JF, Emond MJ, et al. The effect of a brief education program on glaucoma patients. J Glaucoma 1997;6:146-51.

15. Spaeth GL. Patient self-management skills influence the course of glaucoma. Ophthalmology 1997;104:1065-6.

16. Spaeth GL. Visual loss in a glaucoma clinic. I. Sociological considerations. Invest Ophthalmol 1970;9:73-82.

17. Zimmerman TJ, Zalta AH. Facilitating patient compliance in glaucoma therapy. Surv Ophthalmol 1983;28:252-7.

18. Gonzalez S, Steinglass P, Reiss D. Putting the illness in its place: discussion groups for families with chronic medical illnesses. Fam Proc 1989;28:69-87. 
19. Samuelson TW, Spaeth GL. What is glaucoma? It depends on who you ask! Ophthalmic Surg Lasers 1997;28:711-2.

20. McNaught AI, Allen JG, Healey DL, et al. Accuracy and implications of a reported family history of glaucoma. Arch Ophthalmol 2000;118:900-4.

21. Oermann MH, Needham CA, Dobal MT, et al. Filling the waiting time in the clinic with education about glaucoma. Insight 2001;26:77-80.

22. Kosoko O, Quigley HA, Vitale S, et al. Risk factors for noncompliance with glaucoma follow-up visits in a residents's eye clinic. Ophthalmology 1998;105:2105-11.

23. Gutierrez P, Wilson R, Johnson C, et al. Influence of glaucomatous visual field loss on health-related quality of life. Arch Ophthalmol 1997;115:777-84.

24. Janz NK, Wren PA, Lichter PR, et al. Quality of life in newly diagnosed glaucoma patients. The collaborative initial glaucoma treatment study. Ophthalmology 2001;108:887-98.

25. Parrish II RK, Gedde SJ, Scott IU, et al. Visual function and qualtiy of life among patients with glaucoma. Arch Ophthalmol 1997;115:1447-55.

26. Sherwood MB, Garcia-Siekavizza A, Meltzer MI, et al. Glaucoma's impact on quality of life and its relation to clinical indicators. A pilot study. Ophthalmology 1998;105:561-6.

27. Wilson MR, Coleman AL, Yu F, et al. Functional status and well-being in patients with glaucoma as measured by the medical outcomes study short form-36 questionnaire. Ophthalmology 1998;105:2112-6.

28. Petersson LM, Berglund G, Brodin 0, et al. Group rehabilitation for cancer patients: satisfaction and perceived benefits. Patient Educ Couns 2000;40:219-29.

29. Frederikson LG. Exploring information-exchange in consultation: the patients' view of performance and outcomes. Patient Educ Couns 1995;25:237-46. 


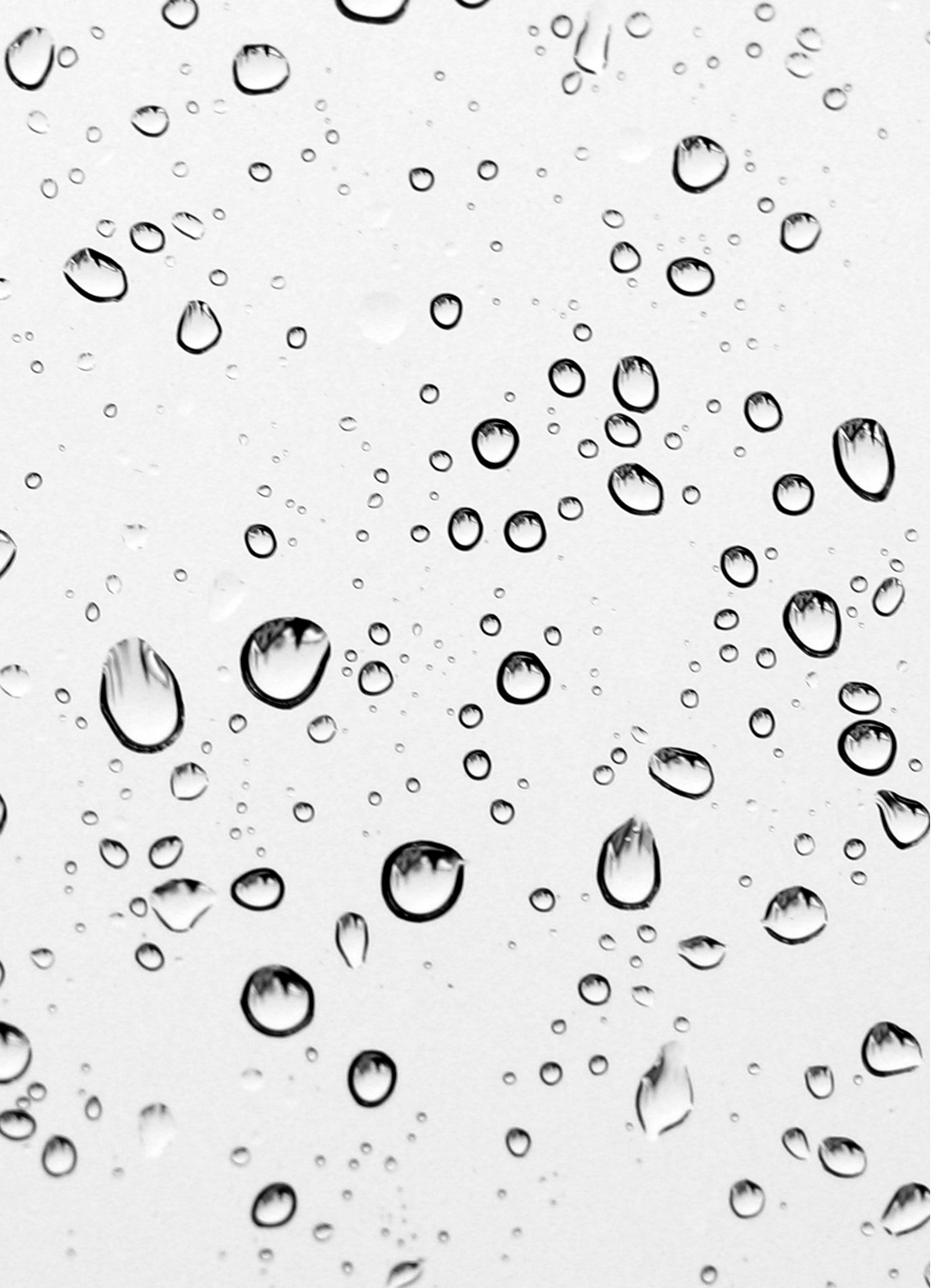




\section{Abstract}

\section{Purpose}

To study the specific items for which socioeconomic differences in glaucoma patients' knowledge, need for information and expectations of treatments exist, with the aim of developing a patient education programme.

\section{Methods}

A total of 44 randomly selected ophthalmologists assigned 166 consecutive outpatient glaucoma patients to complete a questionnaire that had been systematically developed based on focus group interviews, suggestions from several experts and a pilot test. Topics included knowledge about glaucoma and its treatment, need for information and expectations of treatment. Educational level was used as a measure for socioeconomic status. Logistic regression analysis was conducted to adjust for age, sex and duration of glaucoma.

\section{Results}

After adjusting for age, sex and duration of glaucoma, knowledge of glaucoma and its treatment was found to be positively correlated with socioeconomic status. Items on knowledge with socioeconomic differences concerned risk factors, pathophysiology and consequences of glaucoma, as well as effects and adverse effects of treatments. The lowest socioeconomic group demonstrated more need for information on public assistance and practical aspects of glaucoma and more often expected that glaucoma damage could be repaired.

\section{Conclusion}

Important socioeconomic differences in knowledge, need for information and expectations of treatment exist in glaucoma patients. Patient education should focus on every glaucoma patient, but better information for the lower socioeconomic groups about specific items mentioned in this study might reduce the negative effects of low socioeconomic status on visual impairment.

\section{Introduction}

Despite equal financial access to health care services and relatively small differences in health care utilization between socioeconomic groups, socioeconomic inequalities in health still exist in western Europe and in the Netherlands. ${ }^{1-4}$ In the Netherlands, men and women with low levels of education enjoy 15 years less of good health and live, respectively, 4.9 and 2.6 years less than more highly educated men and women. ${ }^{3}$ Compared with higher socioeconomic groups, people in lower socioeconomic groups report specific diseases and health complaints more often, have poorer general health and more often demonstrate unhealthy behaviour and unhealthy physical qualities. ${ }^{5-7}$ People in lower socioeconomic groups use health care services more often; they have contact with the general practitioner more often, although they use specialist care and preventive services less frequently., ${ }^{1,8}$

It has been shown that, in other countries, socioeconomic differences in health and health care use also exist in ophthalmology. People from lower socioeconomic groups use eye care services less frequently, although the prevalence of visual impairment and blindness is higher in these groups. ${ }^{9-22}$ Socioeconomic differences are also observed in glaucoma patients. Lower socioeconomic status is associated with a diminished quality of life, late presentation of glaucoma and more visual field loss at the time of diagnosis, possibly increasing the risk of becoming blind..$^{23-25}$ Other studies have pointed to a lack of knowledge concerning eye diseases and eye care in lower socioeconomic groups. In the general population, more years of formal education and higher socioeconomic status were positively correlated with knowledge and awareness of eye diseases, including glaucoma. ${ }^{26-29}$ In glaucoma patients, those with higher levels of education have more knowledge about glaucoma than patients with lower levels of education. ${ }^{30,31}$ Although studies show differences between socioeconomic groups in terms of knowledge of glaucoma, they do not describe the specific items for which such differences exist and the results do not give sufficient detailed information for the development of an educational programme to reduce the gap between high and low socioeconomic groups. We used an accurate and systematic process of item selection to identify in more detail the specific items for which a socioeconomic difference in knowledge exists. In addition, we investigated the socioeconomic differences in need for information and expectations of treatments. The present explorative study may therefore contribute to the development of a patient education programme. 


\section{Material and Methods}

\section{Design and participants}

A cross-sectional study with self-administered questionnaires was conducted. Sixty randomly selected ophthalmologists from the list of addresses of the Dutch Ophthalmological Society were asked to let four consecutive glaucoma patients fill in a questionnaire at the outpatient department. We aimed to achieve a maximum number of 240 patients. To increase the response rate, an incentive was included for both the ophthalmologists and patients. Moreover, all ophthalmologists were contacted by telephone after 2-3 weeks and by mail after 6-8 weeks to improve participation. No selection was made based on the duration of glaucoma or the type of glaucoma medication. If a patient refused or was unable to fill in the questionnaire, the ophthalmologists were asked to select the next consecutive patient and to number the patients according to the consecutive order.

\section{Measurements}

Focus group interviews were used to identify relevant items with respect to knowledge about glaucoma and its treatment, need for information and expectations with respect to treatment. Four focus group interviews with 22 patients from three general hospitals and one university hospital were carried out. None of the hospitals were private hospitals as there are only a few private hospitals for a limited number of diseases and interventions in the Netherlands. Nine of the patients were members of the Glaucoma Patient Society and were included in one focus group. Special emphasis was given to the inclusion of patients with a short duration of glaucoma as there are fewer of these patients. The duration of the glaucoma was 1 year or less in eight patients. The initial routing questions for the focus group interview were developed by a health education specialist and were reviewed by two other health education specialists with experience in this field. The routing questions were adjusted after each focus group interview. The focus group interviews were recorded on tape and transcribed. This was used to select the items for the questionnaire. A concept of the questionnaire was submitted to a pharmacist with research experience in the use of glaucoma medication, an ophthalmologist specialized in glaucoma, two health education specialists with practical experience in patient education, a professor in patient education and the chairman of the Glaucoma Patient Society. A pilot test on 10 glaucoma patients was undertaken. Topics covered in the questionnaire were knowledge about glaucoma and its treatment, need for information and expectations of treatment. Patients were asked to answer 19 statements concerning knowledge of glaucoma and 18 statements concerning its treatment. The possible answers to these statements were "yes", "no" or "don't know/ no opinion". Patients were asked to indicate whether they would like to receive much, some or no information on 22 topics concerning the need for information. Expectations started with the sentence "I expect that my treatment of glaucoma ..." and concerned 16 items which could be answered with "agree", "neither agree nor disagree", or "disagree". Socioeconomic status was based on the highest educational level of patients. Groups were defined as low (primary education, lower technical education), middle (secondary education), and high (bachelor's degree, master's degree, other tertiary education). Age and duration of glaucoma were categorised (Table 1).

\section{Statistical analysis}

Data were entered in a database by two typists independently of one another and were checked and corrected when needed. Missing answers for a question with "don't know/ no opinion" as an answer category were classified as "don't know/ no opinion". In the statistical analysis, the numbers of correct answers were separately calculated for knowledge about glaucoma and treatment of glaucoma. Mean values and $95 \%$ confidence intervals for the number of correct answers were calculated for every socioeconomic group. Linear regression analysis was conducted to adjust for age, sex and duration of glaucoma. As it was not known if there was a linear relation between the number of correct answers and socioeconomic status, age and duration of glaucoma, dummy variables were used. This made it possible to show any non-linear relation.

Percentages of correct answers were also calculated per statement for each socioeconomic group. Logistic regression analysis was conducted to adjust the proportion of correct answers on knowledge for age, sex and duration of glaucoma. The percentage of patients who stated a need for information was calculated per topic and per socioeconomic group. To adjust for age, sex and duration of glaucoma, logistic regression analysis was also conducted on the percentages of patients who indicated a need for information. Socioeconomic differences in knowledge and need for information are expressed as odds ratios (OR) with the corresponding 95\% confidence intervals for each of the statements and each of the socioeconomic groups, taking the high socioeconomic group as reference category $(\mathrm{OR}=1)$. The percentage answering each of three categories of expectations were calculated per socioeconomic group. A Chi-squared test was used to test for statistically significant differences. 


\section{Results}

In all, $73 \%$ of the ophthalmologists responded $(\mathrm{n}=44)$ and 166 patients participated. Thirty-four ophthalmologists returned four questionnaires, two returned five, five returned three, two sent two and one returned only one questionnaire. Based on reports from $30 \%$ of the participating ophthalmologists, it was calculated that $85 \%$ of the consecutive patients asked by the ophthalmologist participated. Reasons for not participating were cognitive dysfunction, language barriers and lack of time. The mean age of the patients was 65 (standard deviation 13 years). Eighty-six men (52\%) and 79 women (48\%) participated. The gender of one subject was unknown. In 40 patients (24\%) glaucoma had been diagnosed less than 2 years previously. Sixty-nine (42\%) patients belonged to the low socioeconomic group, 53 (32\%) to the middle socioeconomic group, and $43(26 \%)$ to the high socioeconomic group. The data for one patient were missing.

The association between the socioeconomic status of glaucoma patients and their knowledge of glaucoma and its treatment is given in tables 1, 2, and 3. Patients from the low socioeconomic group showed poorer results when compared with the middle and high socioeconomic groups (Table 1). Knowledge increased with longer duration of glaucoma and decreasing age. There was no difference between the sexes. The socioeconomic differences in knowledge remained present after adjusting for sex, age and duration of glaucoma.

The items in Tables 2 and 3 represent the sequence of the statements with the largest difference in correct answers between the high and low socioeconomic groups. More detailed analyses revealed socioeconomic differences in knowledge in 13 of 37 statements in the questionnaire (Tables 2 and 3). Ten of these statements showed differences between the low and high socioeconomic groups. Two statements showed socioeconomic differences for the low and middle socioeconomic groups, compared with the high socioeconomic group. One item showed a difference between the middle and high socioeconomic groups. Items showing a strong association between socioeconomic status and knowledge concerned risk factors, pathophysiology and consequences of glaucoma, as well as effects and adverse effects of the treatment of glaucoma.
Table 1. Mean values and differences to the lowest of the number of correct answers about glaucoma and its treatment related to socioeconomic status, gender, age and duration of glaucoma.

\begin{tabular}{|c|c|c|c|c|c|c|}
\hline & \multicolumn{3}{|c|}{$\begin{array}{l}\text { No. of correct answers on glaucoma } \\
\qquad(\mathrm{n}=19)\end{array}$} & \multicolumn{3}{|c|}{$\begin{array}{l}\text { No. of correct answers on treatment of glaucoma } \\
\qquad(\mathrm{n}=18)\end{array}$} \\
\hline & $\begin{array}{l}\text { Mean values } \\
(95 \% \mathrm{CI})\end{array}$ & $\begin{array}{c}\text { Unadjusted } \\
\text { difference* } \\
(95 \% \mathrm{CI})\end{array}$ & $\begin{array}{c}\text { Adjusted } \\
\text { difference* } \\
(95 \% \mathrm{CI})\end{array}$ & $\begin{array}{l}\text { Mean values } \\
(95 \% \mathrm{CI})\end{array}$ & $\begin{array}{l}\text { Unadjusted } \\
\text { difference* } \\
(95 \% \mathrm{CI})\end{array}$ & $\begin{array}{l}\text { Adjusted } \\
\text { difference* } \\
(95 \% \mathrm{CI})\end{array}$ \\
\hline \multicolumn{7}{|c|}{ Socioeconomic group } \\
\hline Low & $\begin{array}{c}8.4 \\
(7.6-9.1)\end{array}$ & $0^{+}$ & $0^{+}$ & $\begin{array}{c}7.6 \\
(6.9-8.2)\end{array}$ & $0^{+}$ & $0^{+}$ \\
\hline Middle & $\begin{array}{c}10.1 \\
(9.2-10.9)\end{array}$ & $\begin{array}{c}1.7 \\
(0.6-2.8)\end{array}$ & $\begin{array}{c}0.9 \\
(-0.1-2.0)\end{array}$ & $\begin{array}{c}9.0 \\
(8.1-9.8)\end{array}$ & $\begin{array}{c}1.4 \\
(0.3-2.4)\end{array}$ & $\begin{array}{c}0.6 \\
(-0.4-1.7)\end{array}$ \\
\hline High & $\begin{array}{c}11.4 \\
(10.6-12.2)\end{array}$ & $\begin{array}{c}3.0 \\
(1.8-4.2)\end{array}$ & $\begin{array}{c}2.5 \\
(1.3-3.7)\end{array}$ & $\begin{array}{c}9.8 \\
(8.9-10.7)\end{array}$ & $\begin{array}{c}2.2 \\
(1.1-3.3)\end{array}$ & $\begin{array}{c}1.8 \\
(0.7-2.9)\end{array}$ \\
\hline \multicolumn{7}{|l|}{ Gender } \\
\hline Male & $\begin{array}{c}9.7 \\
(8.9-10.6)\end{array}$ & $0^{+}$ & $0^{+}$ & $\begin{array}{c}8.5 \\
(7.8-9.2)\end{array}$ & $0^{+}$ & $0^{+}$ \\
\hline Female & $\begin{array}{c}9.7 \\
(9.0-10.5)\end{array}$ & $\begin{array}{c}0 \\
(-1.0-1.0)\end{array}$ & $\begin{array}{c}0.4 \\
(-0.5-1.4)\end{array}$ & $\begin{array}{c}8.7 \\
(8.0-9.3)\end{array}$ & $\begin{array}{c}0.2 \\
(-0.8-1.1)\end{array}$ & $\begin{array}{c}0.6 \\
(-0.3-1.5)\end{array}$ \\
\hline \multicolumn{7}{|c|}{ Age (years) } \\
\hline $26-54$ & $\begin{array}{c}11.6 \\
(10.7-12.5)\end{array}$ & $0^{+}$ & $0^{+}$ & $\begin{array}{c}10.4 \\
(9.5-11.4)\end{array}$ & $0^{+}$ & $0^{+}$ \\
\hline $55-64$ & $\begin{array}{c}10.5 \\
(9.3-11.8)\end{array}$ & $\begin{array}{c}-1.1 \\
(-2.5-0.3)\end{array}$ & $\begin{array}{c}-1.0 \\
(-2.4-0.3)\end{array}$ & $\begin{array}{c}9.3 \\
(8.2-10.4)\end{array}$ & $\begin{array}{c}-1.1 \\
(-2.4-0.2)\end{array}$ & $\begin{array}{c}-1.3 \\
(-2.6-0.03)\end{array}$ \\
\hline $65-74$ & $\begin{array}{c}8.8 \\
(8.0-9.7)\end{array}$ & $\begin{array}{c}-2.8 \\
(-4.0--1.5)\end{array}$ & $\begin{array}{c}-2.0 \\
(-3.2--0.7)\end{array}$ & $\begin{array}{c}7.6 \\
(6.9-8.3)\end{array}$ & $\begin{array}{c}-2.9 \\
(-4.0--1.7)\end{array}$ & $\begin{array}{c}-2.3 \\
(-3.5--1.1)\end{array}$ \\
\hline$\geq 75$ & $\begin{array}{c}8.3 \\
(7.6-9.0)\end{array}$ & $\begin{array}{c}-3.3 \\
(-4.6--2.0)\end{array}$ & $\begin{array}{c}-2.5 \\
(-3.9--1.2)\end{array}$ & $\begin{array}{c}7.6 \\
(6.8-8.5)\end{array}$ & $\begin{array}{c}-2.8 \\
(-4.0--1.5)\end{array}$ & $\begin{array}{c}-2.5 \\
(-3.7--1.2)\end{array}$ \\
\hline \multicolumn{7}{|c|}{ Duration (years) } \\
\hline$<2$ & $\begin{array}{c}8.9 \\
(7.9-9.9)\end{array}$ & $0^{+}$ & $0^{+}$ & $\begin{array}{c}7.5 \\
(6.6-8.3)\end{array}$ & $0^{+}$ & $0^{+}$ \\
\hline $2-5$ & $\begin{array}{c}10.0 \\
(9.1-10.9)\end{array}$ & $\begin{array}{c}1.2 \\
(-0.2-2.5)\end{array}$ & $\begin{array}{c}1.4 \\
(0.2-2.7)\end{array}$ & $\begin{array}{c}9.0 \\
(8.1-9.9)\end{array}$ & $\begin{array}{c}1.5 \\
(0.3-2.8)\end{array}$ & $\begin{array}{c}1.7 \\
(0.6-2.9)\end{array}$ \\
\hline$>5$ & $\begin{array}{c}10.2 \\
(9.4-10.9)\end{array}$ & $\begin{array}{c}1.3 \\
(0.1-2.6)\end{array}$ & $\begin{array}{c}1.5 \\
(0.4-2.6)\end{array}$ & $\begin{array}{c}9.2 \\
(8.5-9.9)\end{array}$ & $\begin{array}{c}1.7 \\
(0.6-2.9)\end{array}$ & $\begin{array}{c}1.8 \\
(0.8-2.9)\end{array}$ \\
\hline
\end{tabular}

Socioeconomic differences in terms of need for information were apparent in six of 22 topics (Table 4). Five of these topics showed differences for the low and middle socioeconomic groups compared with the high socioeconomic group. One topic showed a difference between the low and the high socioeconomic groups. The sequence of the topics in Table 4 is based on the highest difference in need for information between socioeconomic groups. Patients from the low socioeconomic 
group expressed more need for information, especially about the use of eyedrops, social support and assistance, social securities, resources and rehabilitation possibilities and how to learn to cope with glaucoma (Table 4).

Patients in the low socioeconomic group also differed from those in the other groups in their expectations of the treatment (results not shown). They more often expected that their glaucoma damage could be repaired. A total of $35 \%$ of those in the low socioeconomic group agreed with this statement, compared with $26 \%$ and $12 \%$ of the middle and high socioeconomic groups, respectively ( $\mathrm{p}=0.004)$. In terms of significant worsening of vision, $73 \%, 94 \%$ and $88 \%$ of patients in the low, middle and high socioeconomic groups, respectively, expected that their vision would not deteriorate substantially $(\mathrm{p}=0.012)$. The statement concerning the expectation that they could continue their activities of daily living easily was agreed with by $71 \%, 89 \%$ and $86 \%$ of the low, middle and high socioeconomic groups, respectively $(\mathrm{p}=0.09)$. The statement declaring that the respondent could expect to visit the ophthalmologist less often was agreed with by $36 \%, 19 \%$ and $19 \%$ of the low, middle and high socioeconomic groups, respectively $(\mathrm{p}=0.09)$.
Table 2. Number of correct answers about glaucoma stratified to each socioeconomic group and results of multiple logistic regression analysis.

\begin{tabular}{|c|c|c|c|}
\hline Statements about glaucoma & $\begin{array}{c}\text { Low SEC } \\
(\mathrm{n}=69) \\
\mathrm{n}(\%) \\
\text { OR }(95 \% \mathrm{CI})\end{array}$ & $\begin{array}{c}\text { Middle SEC } \\
(\mathrm{n}=53) \\
\mathrm{n}(\%) \\
\text { OR }(95 \% \mathrm{CI})\end{array}$ & $\begin{array}{c}\text { High SEC } \\
(\mathrm{n}=43) \\
\mathrm{n}(\%) \\
\text { OR }(95 \% \mathrm{CI}) \\
\end{array}$ \\
\hline $\begin{array}{l}\text { If the visual field is impaired, this can be } \\
\text { repaired }\end{array}$ & $\begin{array}{c}26(38) \\
0.3(0.1-0.8)\end{array}$ & $\begin{array}{c}29(55) \\
0.6(0.3-1.6)\end{array}$ & $\begin{array}{c}28(65) \\
1\end{array}$ \\
\hline $\begin{array}{l}\text { Young people more often have glaucoma } \\
\text { than older people }\end{array}$ & $\begin{array}{c}42(61) \\
0.2(0.1-0.72)\end{array}$ & $\begin{array}{c}36(68) \\
0.2(0.6-0.7)\end{array}$ & $\begin{array}{c}37(86) \\
1\end{array}$ \\
\hline Glaucoma often causes impaired reading & $\begin{array}{c}26(38) \\
0.6(0.2-1.7)\end{array}$ & $\begin{array}{c}23(43) \\
0.4(0.2-1.2)\end{array}$ & $\begin{array}{c}27(63) \\
1\end{array}$ \\
\hline There is only one type of glaucoma & $\begin{array}{c}18(26) \\
0.3(0.1-0.8)\end{array}$ & $\begin{array}{c}16(30) \\
0.3(0.1-0.8)\end{array}$ & $\begin{array}{l}22(51) \\
1\end{array}$ \\
\hline $\begin{array}{l}\text { Medicines other than eyedrops can influence } \\
\text { the intraocular pressure }\end{array}$ & $\begin{array}{c}20(29) \\
0.4(0.2-1.1)\end{array}$ & $\begin{array}{c}11(21) \\
0.2(0.1-0.5)\end{array}$ & $\begin{array}{l}22(51) \\
1\end{array}$ \\
\hline Glaucoma affects the visual field & $\begin{array}{c}46(67) \\
0.3(0.1-1.0)\end{array}$ & $\begin{array}{c}45(85) \\
0.7(0.2-2.3)\end{array}$ & $\begin{array}{c}38(88) \\
1\end{array}$ \\
\hline The optic nerve is damaged in glaucoma & $\begin{array}{c}16(23) \\
0.4(0.2-1.0)\end{array}$ & $\begin{array}{c}19(36) \\
0.6(0.3-1.5)\end{array}$ & $\begin{array}{l}19(44) \\
1\end{array}$ \\
\hline $\begin{array}{l}\text { It is possible to have glaucoma without } \\
\text { knowing it }\end{array}$ & $\begin{array}{c}53(77) \\
0.1(0.0-0.7)\end{array}$ & $\begin{array}{c}51(96) \\
0.5(0.0-5.6)\end{array}$ & $\begin{array}{l}42(98) \\
1\end{array}$ \\
\hline $\begin{array}{l}\text { Without treatment, glaucoma is a FAST } \\
\text { progressing condition }\end{array}$ & $\begin{array}{c}16(23) \\
0.7(0.3-2.0)\end{array}$ & $\begin{array}{c}10(19) \\
0.4(0.1-1.1)\end{array}$ & $\begin{array}{c}18(42) \\
1\end{array}$ \\
\hline Nutrition influences glaucoma & $\begin{array}{c}22(32) \\
0.5(0.2-1.3)\end{array}$ & $\begin{array}{c}27(51) \\
0.9(0.4-2.3)\end{array}$ & $\begin{array}{c}22(51) \\
1\end{array}$ \\
\hline $\begin{array}{l}\text { The chance of getting glaucoma is higher if a } \\
\text { family member has glaucoma }\end{array}$ & $\begin{array}{c}42(61) \\
0.5(0.2-1.4)\end{array}$ & $\begin{array}{c}42(79) \\
0.7(0.2-2.2)\end{array}$ & $\begin{array}{c}34(79) \\
1\end{array}$ \\
\hline $\begin{array}{l}\text { The intraocular pressure is increased if it } \\
\text { exceeds } 25\end{array}$ & $\begin{array}{c}33(48) \\
0.5(0.2-1.3)\end{array}$ & $\begin{array}{c}40(76) \\
1.8(0.7-4.5)\end{array}$ & $\begin{array}{c}28(65) \\
1\end{array}$ \\
\hline $\begin{array}{l}\text { The chance of getting glaucoma is higher if } \\
\text { the intraocular pressure is increased }\end{array}$ & $\begin{array}{c}57(83) \\
0.1(0.0-0.8)\end{array}$ & $\begin{array}{c}51(96) \\
0.8(0.1-6.5)\end{array}$ & $\begin{array}{l}41(95) \\
1\end{array}$ \\
\hline $\begin{array}{l}\text { A patient should always tell the } \\
\text { ophthalmologist which other diseases (s) } \\
\text { he has }\end{array}$ & $\begin{array}{c}45(65) \\
0.4(0.2-1.2)\end{array}$ & $\begin{array}{c}38(72) \\
0.8(0.3-2.2)\end{array}$ & $\begin{array}{c}32(74) \\
1\end{array}$ \\
\hline Glaucoma causes reduction of visual acuity & $\begin{array}{c}45(65) \\
0.7(0.3-1.8)\end{array}$ & $\begin{array}{c}37(70) \\
0.8(0.3-2.0)\end{array}$ & $\begin{array}{c}31(72) \\
1\end{array}$ \\
\hline $\begin{array}{l}\text { African people have a higher chance of } \\
\text { getting glaucoma }\end{array}$ & $\begin{array}{c}2(3) \\
0.6(0.1-4.4)\end{array}$ & $\begin{array}{c}4(8) \\
0.9(0.2-5.4)\end{array}$ & $\begin{array}{c}3(7) \\
1\end{array}$ \\
\hline $\begin{array}{l}\text { Strong myopia or hypermetropia gives a } \\
\text { higher chance of getting glaucoma }\end{array}$ & $\begin{array}{c}5(7) \\
0.6(0.1-3.3)\end{array}$ & $\begin{array}{c}4(8) \\
0.4(0.1-2.3)\end{array}$ & $\begin{array}{l}4(9) \\
1\end{array}$ \\
\hline $\begin{array}{l}\text { The intraocular pressure is always increased } \\
\text { in glaucoma }\end{array}$ & $\begin{array}{c}10(15) \\
1.0(0.3-3.2)\end{array}$ & $\begin{array}{c}11(21) \\
1.4(0.5-4.3)\end{array}$ & $\begin{array}{c}7(16) \\
1\end{array}$ \\
\hline $\begin{array}{l}\text { A patient should always tell the } \\
\text { ophthalmologist which other medicines } \\
\text { (s)he is using }\end{array}$ & $\begin{array}{c}55(80) \\
0.8(0.3-2.4)\end{array}$ & $\begin{array}{c}41(77) \\
0.8(0.3-2.2)\end{array}$ & $\begin{array}{c}35(81) \\
1\end{array}$ \\
\hline
\end{tabular}

$\mathrm{SEC}=$ socioeconomic group

OR $(95 \% \mathrm{CI})=$ odds ratio $(95 \%$ confidence interval) for knowledge about glaucoma adjusted for age, sex and duration of glaucoma. 
Table 3. Number of correct answers about the treatment of glaucoma stratified by socioeconomic group and results of multiple logistic regression analysis.

\begin{tabular}{|c|c|c|c|}
\hline $\begin{array}{l}\text { Statements about the treatment of } \\
\text { glaucoma }\end{array}$ & $\begin{array}{c}\text { Low SEC } \\
(\mathrm{n}=69) \\
\mathrm{n}(\%) \\
\text { OR }(95 \% \mathrm{CI}) \\
\end{array}$ & $\begin{array}{c}\text { Middle SEC } \\
(n=53) \\
n(\%) \\
\text { OR }(95 \% \mathrm{CI}) \\
\end{array}$ & $\begin{array}{c}\text { High SEC } \\
(\mathrm{n}=43) \\
\mathrm{n}(\%) \\
\text { OR }(95 \% \mathrm{CI})\end{array}$ \\
\hline $\begin{array}{l}\text { Early detection and treatment will NOT slow } \\
\text { down the course of glaucoma }\end{array}$ & $\begin{array}{c}19(28) \\
0.3(0.1-0.6)\end{array}$ & $\begin{array}{c}26(49) \\
0.6(0.2-1.4)\end{array}$ & $\begin{array}{c}27(63) \\
1\end{array}$ \\
\hline $\begin{array}{l}\text { Laser treatment or surgery for glaucoma can } \\
\text { repair the damage caused by glaucoma }\end{array}$ & $\begin{array}{c}15(22) \\
0.4(0.1-1.0)\end{array}$ & $\begin{array}{c}23(43) \\
0.8(0.3-2.1)\end{array}$ & $\begin{array}{c}21(49) \\
1\end{array}$ \\
\hline $\begin{array}{l}\text { Some eyedrops should not be used by } \\
\text { cardiac patients or asthma patients }\end{array}$ & $\begin{array}{c}23(33) \\
0.3(0.1-0.8)\end{array}$ & $\begin{array}{c}25(47) \\
0.5(0.2-1.3)\end{array}$ & $\begin{array}{l}25(58) \\
1\end{array}$ \\
\hline $\begin{array}{l}\text { Eyedrops can repair the damage caused by } \\
\text { glaucoma }\end{array}$ & $\begin{array}{c}39(57) \\
0.4(0.1-1.2)\end{array}$ & $\begin{array}{c}38(72) \\
0.5(0.2-1.4)\end{array}$ & $\begin{array}{c}35(81) \\
1\end{array}$ \\
\hline $\begin{array}{l}\text { A slower heart rate could be an adverse } \\
\text { effect of eyedrops }\end{array}$ & $\begin{array}{c}3(4) \\
0.1(0.0-0.6)\end{array}$ & $\begin{array}{c}10(19) \\
0.6(0.2-1.9)\end{array}$ & $\begin{array}{l}12(28) \\
1\end{array}$ \\
\hline $\begin{array}{l}\text { Dyspnoea could be an adverse effect of } \\
\text { eyedrops }\end{array}$ & $\begin{array}{c}5(7) \\
0.2(0.1-0.8)\end{array}$ & $\begin{array}{c}12(23) \\
0.6(0.2-1.8)\end{array}$ & $12(28)$ \\
\hline Each treatment is equally good for everyone & $\begin{array}{c}33(48) \\
0.6(0.3-1.5)\end{array}$ & $\begin{array}{c}29(55) \\
0.6(0.2-1.4)\end{array}$ & $\begin{array}{c}28(65) \\
1\end{array}$ \\
\hline $\begin{array}{l}\text { Stinging or burning of the eyes could be an } \\
\text { adverse effect of eyedrops }\end{array}$ & $\begin{array}{c}49(71) \\
0.7(0.2-2.0)\end{array}$ & $\begin{array}{c}45(85) \\
1.0(0.3-3.3)\end{array}$ & $\begin{array}{c}36(84) \\
1\end{array}$ \\
\hline Eyedrops can be replaced by tablets & $\begin{array}{c}22(32) \\
0.7(0.3-1.8)\end{array}$ & $\begin{array}{c}19(36) \\
0.6(0.2-1.4)\end{array}$ & $\begin{array}{l}19(44) \\
1\end{array}$ \\
\hline $\begin{array}{l}\text { The course of the disease can be slowed } \\
\text { down by eyedrops }\end{array}$ & $\begin{array}{c}58(84) \\
0.4(0.1-1.8)\end{array}$ & $\begin{array}{c}46(87) \\
0.4(0.1-1.5)\end{array}$ & $\begin{array}{c}40(93) \\
1\end{array}$ \\
\hline $\begin{array}{l}\text { The use of eyedrops is redundant after laser } \\
\text { treatment or surgery for glaucoma }\end{array}$ & $\begin{array}{c}24(35) \\
0.7(0.3-1.7)\end{array}$ & $\begin{array}{c}31(59) \\
1.6(0.7-3.7)\end{array}$ & $\begin{array}{c}19(44) \\
1\end{array}$ \\
\hline $\begin{array}{l}\text { A high intraocular pressure must always be } \\
\text { treated }\end{array}$ & $\begin{array}{c}1(1) \\
0.5(0.0-7.2)\end{array}$ & $\begin{array}{c}4(8) \\
0.6(0.1-3.9)\end{array}$ & $\begin{array}{l}4(9) \\
1\end{array}$ \\
\hline $\begin{array}{l}\text { Discoloration of the iris may be an adverse } \\
\text { effect of eyedrops }\end{array}$ & $\begin{array}{c}18(26) \\
0.7(0.3-1.9)\end{array}$ & $\begin{array}{c}19(36) \\
1.1(0.5-2.7)\end{array}$ & $\begin{array}{c}14(33) \\
1\end{array}$ \\
\hline $\begin{array}{l}\text { Blurred vision after dropping could be an } \\
\text { adverse effect of eyedrops }\end{array}$ & $\begin{array}{c}51(74) \\
0.7(0.3-2.0)\end{array}$ & $\begin{array}{c}40(76) \\
0.7(0.3-2.1)\end{array}$ & $34(79)$ \\
\hline $\begin{array}{l}\text { Even if the intraocular pressure is under } \\
\text { control, the visual field has to be checked }\end{array}$ & $\begin{array}{c}61(88) \\
0.6(0.1-2.9)\end{array}$ & $\begin{array}{c}45(85) \\
0.4(0.1-1.8)\end{array}$ & $\begin{array}{l}39(91) \\
1\end{array}$ \\
\hline $\begin{array}{l}\text { It is possible to lose vision completely as } \\
\text { a result of laser treatment or surgery for } \\
\text { glaucoma }\end{array}$ & $\begin{array}{c}7(10) \\
0.8(0.2-4.5)\end{array}$ & $\begin{array}{c}2(4) \\
0.5(0.1-3.3)\end{array}$ & $\begin{array}{c}3(7) \\
1\end{array}$ \\
\hline $\begin{array}{l}\text { The pharmacy checks which medicines one } \\
\text { is using }\end{array}$ & $\begin{array}{c}47(68) \\
1.2(0.5-3.0)\end{array}$ & $\begin{array}{c}31(59) \\
0.7(0.3-1.7)\end{array}$ & $\begin{array}{c}27(63) \\
1\end{array}$ \\
\hline $\begin{array}{l}\text { Glaucoma can only be treated by lowering } \\
\text { the intraocular pressure }\end{array}$ & $\begin{array}{c}49(71) \\
1.5(0.6-3.8)\end{array}$ & $\begin{array}{c}30(57) \\
0.8(0.3-1.8)\end{array}$ & $\begin{array}{c}26(61) \\
1\end{array}$ \\
\hline
\end{tabular}

OR $(95 \% \mathrm{CI})=$ odds ratio $(95 \%$ confidence interval) for knowledge about the treatment of glaucoma adjusted for age, sex and duration of glaucoma.
Table 4. Number of patients demonstrating a need for information, stratified to socioeconomic group and results of multiple logistic regression analysis.

\begin{tabular}{|c|c|c|c|}
\hline Topic & $\begin{array}{c}\text { Low SEC } \\
n=69 \\
n(\%) \\
\text { OR }(95 \% \mathrm{CI}) \\
\end{array}$ & $\begin{array}{c}\text { Middle SEC } \\
\text { n=53 } \\
\mathrm{n}(\%) \\
\text { OR }(95 \% \mathrm{CI}) \\
\end{array}$ & $\begin{array}{c}\text { High SEC } \\
\mathrm{n}=43 \\
\mathrm{n}(\%) \\
\text { OR }(95 \% \mathrm{CI})\end{array}$ \\
\hline How to use and apply eyedrops & $\begin{array}{c}38(64) \\
6.0(2.2-16.3)\end{array}$ & $\begin{array}{c}25(49) \\
2.9(1.1-7.3)\end{array}$ & $\begin{array}{c}14(34) \\
1\end{array}$ \\
\hline Social support or assistance at home & $\begin{array}{c}38(61) \\
3.0(1.2-7.7)\end{array}$ & $\begin{array}{c}31(62) \\
2.9(1.2-7.3)\end{array}$ & $\begin{array}{c}14(34) \\
1\end{array}$ \\
\hline $\begin{array}{l}\text { Resources or rehabilitation for the visually } \\
\text { impaired }\end{array}$ & $\begin{array}{c}45(73) \\
3.2(1.2-8.7)\end{array}$ & $\begin{array}{c}40(80) \\
3.8(0.4-10.7)\end{array}$ & $\begin{array}{l}22(54) \\
\quad 1\end{array}$ \\
\hline Experiences of other glaucoma patients & $\begin{array}{c}35(58) \\
2.7(1.0-7.3)\end{array}$ & $\begin{array}{c}36(72) \\
3.5(1.3-9.2)\end{array}$ & $\begin{array}{c}19(46) \\
1\end{array}$ \\
\hline Social securities for visually impaired people & $\begin{array}{c}42(70) \\
2.8(1.1-7.1)\end{array}$ & $\begin{array}{c}37(73) \\
2.6(1.0-6.6)\end{array}$ & $\begin{array}{l}20(49) \\
\quad 1\end{array}$ \\
\hline Other diseases that influence glaucoma & $\begin{array}{c}43(73) \\
0.2(0.0-1.2)\end{array}$ & $\begin{array}{c}47(92) \\
0.7(0.1-4.4)\end{array}$ & $\begin{array}{l}38(95) \\
\quad 1\end{array}$ \\
\hline How to learn to cope with glaucoma & $\begin{array}{c}49(78) \\
3.4(1.3-9.2)\end{array}$ & $\begin{array}{c}38(78) \\
3.1(1.1-8.3)\end{array}$ & $\begin{array}{c}24(57) \\
1\end{array}$ \\
\hline Laser treatment and eye-surgery & $\begin{array}{c}46(73) \\
0.9(0.3-2.8)\end{array}$ & $\begin{array}{c}46(89) \\
2.1(0.6-7.3)\end{array}$ & $\begin{array}{c}34(81) \\
1\end{array}$ \\
\hline Possible results of treatments & $\begin{array}{c}52(83) \\
1.2(0.3-5.0)\end{array}$ & $\begin{array}{c}50(96) \\
3.8(0.6-22.5)\end{array}$ & $\begin{array}{l}35(85) \\
1\end{array}$ \\
\hline The present condition of your glaucoma & $\begin{array}{c}53(82) \\
0.7(0.2-2.8)\end{array}$ & $\begin{array}{c}48(94) \\
1.7(0.4-8.4)\end{array}$ & $\begin{array}{l}37(88) \\
\quad 1\end{array}$ \\
\hline $\begin{array}{l}\text { The possible course and consequences of your } \\
\text { glaucoma }\end{array}$ & $\begin{array}{c}52(85) \\
0.6(0.1-3.2)\end{array}$ & $\begin{array}{c}48(96) \\
1.5(0.2-10.6)\end{array}$ & $\begin{array}{c}39(93) \\
1\end{array}$ \\
\hline $\begin{array}{l}\text { New developments concerning glaucoma and } \\
\text { its treatment }\end{array}$ & $\begin{array}{c}54(87) \\
0.2(0.0-2.0)\end{array}$ & $\begin{array}{c}50(96) \\
0.5(0.0-6.2)\end{array}$ & $\begin{array}{l}41(98) \\
\quad 1\end{array}$ \\
\hline The cause of glaucoma & $\begin{array}{c}51(82) \\
0.6(0.1-2.8)\end{array}$ & $\begin{array}{c}45(87) \\
0.7(0.2-3.4)\end{array}$ & $\begin{array}{l}37(93) \\
1\end{array}$ \\
\hline Eyedrops & $\begin{array}{c}50(81) \\
2.7(0.9-8.2)\end{array}$ & $\begin{array}{c}41(80) \\
2.2(0.7-6.6)\end{array}$ & $\begin{array}{l}29(73) \\
1\end{array}$ \\
\hline Possible adverse effects of treatments & $\begin{array}{c}53(83) \\
1.1(0.3-4.1)\end{array}$ & $\begin{array}{c}47(90) \\
1.6(0.4-6.9)\end{array}$ & $\begin{array}{c}35(85) \\
1\end{array}$ \\
\hline The Glaucoma Patient Society & $\begin{array}{c}35(58) \\
1.3(0.5-3.2)\end{array}$ & $\begin{array}{c}28(55) \\
0.9(0.4-2.3)\end{array}$ & $\begin{array}{c}25(61) \\
1\end{array}$ \\
\hline Heredity of glaucoma & $\begin{array}{c}48(77) \\
1.1(0.3-3.8)\end{array}$ & $\begin{array}{c}42(82) \\
0.9(0.3-3.1)\end{array}$ & $\begin{array}{l}35(83) \\
1\end{array}$ \\
\hline $\begin{array}{l}\text { Where to find good education material about } \\
\text { glaucoma }\end{array}$ & $\begin{array}{c}48(77) \\
1.1(0.4-3.5)\end{array}$ & $\begin{array}{c}42(82) \\
1.1(0.3-3.4)\end{array}$ & $\begin{array}{c}35(83) \\
1\end{array}$ \\
\hline How to function better with glaucoma & $\begin{array}{c}49(79) \\
1.6(0.6-4.4)\end{array}$ & $\begin{array}{c}38(75) \\
1.1(0.4-3.0)\end{array}$ & $\begin{array}{l}30(73) \\
1\end{array}$ \\
\hline Work and glaucoma & $\begin{array}{c}27(48) \\
2.3(0.8-6.3)\end{array}$ & $\begin{array}{c}27(54) \\
1.9(0.7-5.0)\end{array}$ & $\begin{array}{l}20(50) \\
\quad 1\end{array}$ \\
\hline Social aspects of glaucoma & $\begin{array}{c}37(63) \\
0.8(0.3-2.2)\end{array}$ & $\begin{array}{c}31(62) \\
0.8(0.3-2.2)\end{array}$ & $\begin{array}{l}27(68) \\
1\end{array}$ \\
\hline Psychological aspects of glaucoma & $\begin{array}{c}42(69) \\
1.2(0.5-3.1)\end{array}$ & $\begin{array}{c}33(66) \\
1.0(0.4-2.6) \\
\end{array}$ & $\begin{array}{c}26(65) \\
1 \\
\end{array}$ \\
\hline
\end{tabular}

$\mathrm{SEC}=$ socioeconomic group.

OR $(95 \% \mathrm{CI})=$ odds ratio ( $95 \%$ confidence interval) for need for information adjusted for age, sex and duration of glaucoma. 


\section{Discussion}

The present study shows socioeconomic differences in glaucoma patients' knowledge about glaucoma and its treatment, even when differences in age, gender and duration of glaucoma are taken into account. The most and largest differences exist between the low and high socioeconomic groups, while the middle and high socioeconomic groups show rather small differences. Patients in the low socioeconomic group also have a need for information about other items, compared with those in the other groups, and have other expectations of their treatment. Concerning the need for information, great differences exist between the low and high socioeconomic groups, as well as between the middle and high socioeconomic groups.

An important advantage of this study is the development of the questionnaire, which was based on a systematic item selection through focus group interviews and consultation with several experts. The questionnaire was very extensive and contained important items with which to develop a new patient education programme. The questionnaire had good internal consistency; Cronbach's alpha was 0.83 , ranging from 0.81 to 0.83 when items were deleted one at a time (data not shown).

The results were based on a nationwide sample of patients. The selection of patients might be a shortcoming of the study. It is difficult to assess case order. The high response rate of $85 \%$ was achieved because patients were asked to fill in the questionnaire at the outpatient department. It was impossible to control whether ophthalmologists asked four consecutive patients to fill in the questionnaire or whether they selected the patients. It is, however, hardly imaginable that all ophthalmologists selected patients in a consistent manner, thus biasing the reported results. It is unknown whether patients who refused or were unable to fill in the questionnaire had a specific lower or higher level of knowledge. However, it is difficult to select patients otherwise. If patients were selected from one hospital or from the national Glaucoma Patient Society, bias would certainly have been introduced. In conclusion, although not perfect, the selection method was the best we could achieve to reduce selection bias.

This study confirms the results of other studies in which differences between socioeconomic groups in terms of knowledge were also observed..$^{30,31}$
It has been reported that glaucoma patients from lower socioeconomic groups have more severe visual field loss at the time of diagnosis, which might increase the risk of becoming blind. ${ }^{23,24}$ The results of the present study suggest that there might be a relation between differences in knowledge, need for information and expectations, and this late presentation with glaucoma. For example, in our study, patients from the low socioeconomic group less often knew that the likelihood of getting glaucoma is higher if the intraocular pressure is increased, that it is possible to have glaucoma without knowing it and that early detection and treatment will slow down the course of glaucoma. Because they are also less aware of the fact that a family predisposition is a risk factor for glaucoma, they do not encourage their family members to check for glaucoma, leading to more avoidable visual impairment in the lower socioeconomic group. This could also be one of the explanations for the fact that patients from lower socioeconomic groups use eye care services less often than patients from higher socioeconomic groups.

The quality of life for glaucoma patients is also worse in patients from low socioeconomic groups. ${ }^{25}$ This might be a result of more severe glaucoma at presentation, but may also be due to less effective treatment or more adverse effects of treatment. For example, patients in the low socioeconomic group less often knew that some eyedrops should not be used in patients with cardiac disease or asthma. They were also less aware of the symptoms that may indicate an adverse effect of the glaucoma medication. This might result in more unnecessary adverse effects in these groups and lower rates of compliance. ${ }^{32}$ Moreover, patients in the low socioeconomic group more often expected that their treatment could repair their glaucoma damage. This unrealistic expectation may lead to more dissatisfaction when patients from low socioeconomic groups receive treatment.

The socioeconomic groups did not differ much on items like "Strong myopia or hypermetropia gives a higher chance of getting glaucoma" and "It is possible to lose vision completely as a result of laser treatment or surgery for glaucoma". Only a few patients in each group knew the correct answers to these statements.

In general, the low socioeconomic group demonstrated greater need for information. Odberg et al. reported that patients aged less than 60 years missed twice as much information about their disease as older patients did. Younger patients especially wanted to know more about the causes of glaucoma and the risk of going blind. ${ }^{33} \mathrm{In}$ the current study, patients in the low socioeconomic group more often expressed the need for information on the use and application of eyedrops, implying that their 
current use may possibly be less effective. The quality of life of low socioeconomic group patients with glaucoma may also be influenced by the lack of support to compensate the consequences of having glaucoma. When compared to the other socioeconomic groups, more of these patients expressed a need for information on social support or assistance at home, aids or rehabilitation facilities for the visually impaired, information on how to learn to cope with glaucoma and information on available social security benefits. If this information need is fulfilled, patients in lower socioeconomic groups might be able to deal with the consequences of their glaucoma better, thereby improving their quality of life. Patients in all socioeconomic groups expressed a roughly equivalent, but high, need for information on items such as "The Glaucoma Patient Society", "Heredity of glaucoma", "How to function better with glaucoma" and "Psychological aspects of glaucoma”.

In conclusion, the current study shows important socioeconomic differences in knowledge, need for information and expectations of glaucoma patients. As the overlap in level of knowledge between socioeconomic groups is considerable, and the level of knowledge is low in every socioeconomic group, patient education should focus on every glaucoma patient. We suggest that better provision of information to patients in lower socioeconomic groups about the specific items mentioned above could reduce their higher risk of becoming blind, contribute to an earlier presentation of glaucoma, improve their quality of life, adjust their expectations, reduce the incidence of adverse effects and improve compliance. In this way, the socioeconomic differences in eye care utilization and prevalence of visual impairment in glaucoma patients might be reduced.

\section{References}

1. Jansen J, ten Dam JJ. Verklarende factoren van gezondheidsverschillen. In: Volksgezondheid Toekomst Verkenning, Nationaal Kompas Volksgezondheid. Bilthoven: RIVM. http://www. nationaalkompas.nl, 2002. Accessed: 22 February 2005.

2. Mackenbach JP, Kunst AE, Cavelaars AE, et al. Socioeconomic inequalities in morbidity and mortality in western Europe. Lancet 1997;349:1655-9.

3. van der Lucht F. Sociaal-economische verschillen samengevat. In: Volksgezondheid Toekomst Verkenning, Nationaal Kompas Volksgezondheid. Bilthoven: RIVM, http://www.nationaalkompas. nl, 2002. Accessed 22 February 2005.

4. Verkleij H, Mackenbach JP. Volksgezondheid toekomst verkenning 1997. III. Gezondheidsverschillen in Nederland. Ned Tijdschr Geneeskd 1998;142:1219-23.

5. van Lenthe FJ, Schrijvers CT, Droomers M, et al. Investigating explanations of socio-economic inequalities in health. The Dutch GLOBE study. Eur J Public Health 2004;14:63-70.

6. Stronks K, Van de Mheen HD, Mackenbach JP. A higher prevalence of health problems in low income groups: does it reflect relative deprivation? J Epidemiol Community Health 1998;52:548-57.

7. van der Lucht F, Picavet HS. Sociaal-economische verschillen in persoonskenmerken. In: Volksgezondheid Toekomst Verkenning, Nationaal Kompas Volksgezondheid. Bilthoven: RIVM. http://www.nationaalkompas.nl, 2003. Accessed: 22 February 2005.

8. van der Meer JB, van den Bos J, Mackenbach JP. Socioeconomic differences in the utilization of health services in a Dutch population: the contribution of health status. Health Policy 1996;37:1-

9. Dana MR, Tielsch JM, Enger C, et al. Visual impairment in a rural Appalachian community. Prevalence and causes. JAMA 1990;264:2400-5.

10. Dandona L, Dandona R, Naduvilath TJ, et al. Burden of moderate visual impairment in an urban population in southern India. Ophthalmology 1999;106:497-504

11. Dandona L, Dandona R, Srinivas M, et al. Blindness in the Indian State of Andhra Pradesh. Invest Ophthalmol Vis Sci 2001;42:908-16.

12. Dandona R, Dandona L. Socioeconomic status and blindness. Br J Ophthalmol 2001;85:1484-8.

13. Dandona R, Dandona L, Srinivas M, et al. Planning low vision services in India. A population-based perspective. Ophthalmology 2002;109:1871-8.

14. Dandona R, Dandona L, Srinivas M, et al. Moderate visual impairment in India: the Andhra Pradesh Eye Disease Study. Br J Ophthalmol 2002;86:373-377.

15. Ho VH, Schwab IR. Social economic development in the prevention of global blindness. Br J Ophthalmol 2001;85:653-7.

16. Klein $\mathrm{R}$, Klein $\mathrm{BE}$, Jensen $\mathrm{SC}$, et al. The relation of socioeconomic factors to age-related cataract, maculopathy, and impaired vision. The Beaver Dam Eye Study. Ophthalmology 1994;101:1969-79.

17. Michon JJ, Lau J, Chan WS, Ellwein LB. Prevalence of visual impairment, blindness, and cataract 
surgery in the Hong Kong elderly. Br J Ophthalmol 2002;86:133-9.

18. Munoz B, West SK, Rodriguez J, et al. Blindness, visual impairment and the problem of uncorrected refractive error in a Mexican-American population: Proyecto VER. Invest Ophthalmol Vis Sci 2002;43:608-14

19. Salive ME, Guralnik J, Christen W, et al. Functional blindness and visual impairment in older adults from three communities. Ophthalmology 1992;99:1840-7.

20. Schaumberg DA, Christen WG, Glynn RJ, Burning JE. Demographic predictors of eye care utilization among women. Med Care 2000;38:638-46.

21. Srivastava RN, Verma BL. An epidemiological study of blindness in an Indian rural community. J Epidemiol Community Health 1978;32:131-5.

22. Tielsch JM, Sommer A, Katz J, et al. Socioeconomic status and visual impairment among urban Americans. Arch Ophthalmol 1991;109:637-41.

23. Fraser S, Bunce C, Wormald R, Brunner E. Deprivation and late presentation of glaucoma: casecontrol study. BMJ 2001;322:639-43.

24. Oliver JE, Hattenhauer MG, Herman D, et al. Blindness and glaucoma: a comparison of patients progressing to blindness from glaucoma with patients maintaining vision. Am J Ophthalmol 2002;133:764-72.

25. Sherwood MB, Garcia-Siekavizza A, Meltzer MI, et al. Glaucoma's impact on quality of life and its relation to clinical indicators. A pilot study. Ophthalmology 1998;105:561-6.

26. Attebo K, Mitchell P, Cumming R, Smith W. Knowledge and beliefs about common eye diseases. Aust N Z J Ophthalmol 1997;25:283-7.

27. Dandona R, Dandona L, John RK, et al. Awareness of eye diseases in an urban population in southern India. Bull World Health Organ 2001;79:96-102.

28. Lau JT, Lee V, Fan D, et al. Knowledge about cataract, glaucoma, and age related macular degeneration in the Hong Kong Chinese population. Br J Ophthalmol 2002;86:1080-4.

29. Livingston PM, Lee SE, De Paola C, et al. Knowledge of glaucoma, and its relationship to self-care practices, in a population sample. Aust N Z J Ophthalmol 1995;23:37-41.

30. Hoevenaars JG, Schouten JS, van den Borne B, et al. Knowledge base and preferred methods of obtaining knowledge of glaucoma patients. Eur J Ophthalmol 2005;15:32-40.

31. Kim S, Stewart JF, Emond MJ, et al. The effect of a brief education program on glaucoma patients. J Glaucoma 1997;6:146-51.

32. Zimmerman TJ, Zalta AH. Facilitating patient compliance in glaucoma therapy. Surv Ophthalmol 1983;28:252-7.

33. Odberg T, Jakobsen JE, Hultgren SJ, Halseide R. The impact of glaucoma on the quality of life of patients in Norway. Acta Ophthalmol Scand 2001;79:116-20. 


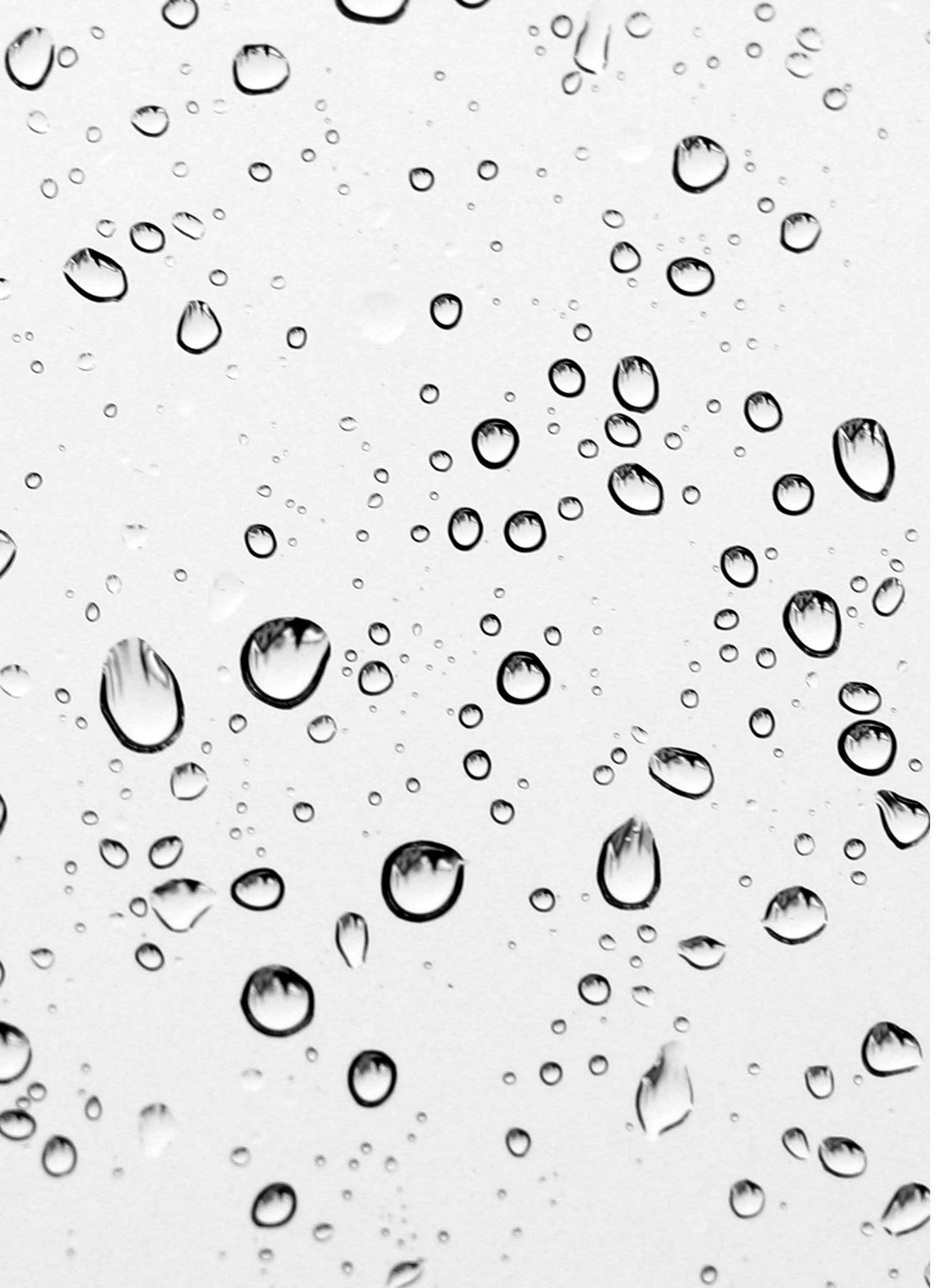




\section{Abstract}

\section{Purpose}

To identify specific items on knowledge and need for information that could be used to improve compliance with glaucoma medication.

\section{Methods}

Forty-four randomly selected ophthalmologists assigned 166 consecutive glaucoma patients to complete a questionnaire. The questionnaire was developed systematically based on focus group interviews, consultation of experts and a pilot test. Items included knowledge about glaucoma and its treatment, need for information and compliance with therapy.

\section{Results}

No statistically significant correlation was found between the total level of knowledge and compliance. Concerning knowledge of glaucoma, one out of 19 items had a statistically significant negative correlation with compliance. Concerning knowledge of glaucoma treatment, one out of 18 items had a statistically significant positive correlation with compliance. Regarding total need for information, no statistically significant correlation with compliance was found. Three out of 22 items had a statistically significant positive correlation with compliance.

\section{Conclusion}

Given the number of related items, their direction and limited strength of correlation and the difficulty of hypothesizing a causal relation for some items, it is unlikely that further improving knowledge will greatly improve compliance with glaucoma medication. Interventions focused on attitude and discipline may be of more benefit in improving compliance with therapy.

\section{Introduction}

Presently, there is an increased interest in compliance with glaucoma medication. Although there is no consistent evidence of the impact of non-compliance on the outcome of glaucoma ${ }^{1}$, compliance is assumed to be an important issue in the prevention of visual impairment caused by glaucoma. ${ }^{2-6}$ Because medical therapy is becoming more important in the treatment of glaucoma - from both clinical and economical perspectives - compliance will remain an important issue. ${ }^{7}$ The possibility of mistaking non-compliance for lack of effectiveness might result in additional risks and costs because of switching to other medications or advancing to surgery.

Given the asymptomatic nature of glaucoma and the lifelong therapeutic regimen without apparent subjective improvement, glaucoma patients are at risk of noncompliance with their treatment. The growing attention on organized screening programmes and their expected cost-effectiveness, especially in older patients, will lead to the identification of more asymptomatic patients. ${ }^{8}$ This could lead to a greater need for attention on compliance. Clinicians should play an active role in improving compliance, with the aim of preventing advanced stages of glaucoma; patients with severe glaucomatous damage seem to have lower utility and quality of life. ${ }^{9}$

The reported rate of non-compliance varies between $4.6 \%$ and $80 \%{ }^{1}$ Fifty per cent of articles reported a rate of non-compliance above $29 \%{ }^{2,5,6,10-27}$

Several studies have reported that knowledge of some glaucoma-related items is correlated with better compliance. ${ }^{1,12,13,16,17,19,28}$ Compliant and non-compliant patients seem to differ with regard to their knowledge of specific items rather than their overall level of knowledge., 13,16 A patient education programme has been mentioned as one of the available interventions to enhance compliance. ${ }^{1,3,4,29} \mathrm{An}$ education and tailoring programme on compliance with glaucoma medication has been shown to have a positive effect in a short-term trial. ${ }^{30,31}$

Previous studies describing the correlation between knowledge and compliance did not systematically select the items to investigate knowledge. ${ }^{12,13,16,17,19}$ In some studies, only a few items were used to investigate knowledge and an adjustment for other variables in the analysis was not always made. ${ }^{12,16,19}$ While a need to identify specific items has been mentioned ${ }^{11}{ }^{19}$, these studies do not provide the exact 
items that should be addressed in order to improve compliance with glaucoma medication. In the present study, all relevant items concerning knowledge and need for information were collected systematically. Addressing identified items might lead to better compliance with medication. Confounding variables were taken into account.

\section{Materials and Methods}

Between January and March 2002 a cross-sectional multi-centre study was conducted in which 60 ophthalmologists were asked to select four consecutive glaucoma patients to complete a questionnaire at the outpatient department. Ethics Committee approval was obtained.

The ophthalmologists were selected randomly from a list of addresses of the Dutch Ophthalmological Society. All participating ophthalmologists practised ophthalmology in the Netherlands. Because of the random selection, a variation in level of experience is to be expected. Whenever two ophthalmologists from the same hospital were selected, the one specialized in glaucoma was asked to participate while the other one was excluded from participation. For this reason, nine ophthalmologists from six hospitals were not selected. To increase the response rate, an incentive was included for both the ophthalmologists and the patients. To further improve participation, all ophthalmologists were contacted by telephone after 2-3 weeks and by mail after 6-8 weeks.

The questionnaire was developed in a systematic way and was based on focus group interviews, expert opinions and a pilot test. For a complete and detailed description of the development of the questionnaire and the selection of patients, we refer to a previous article ${ }^{32}$. The questionnaire included 19 items about glaucoma and 18 items about glaucoma treatment. Patients could answer with "yes", "no" or "don't know/no opinion". In addition, 22 items concerning patients' subjective need for information were listed. Patients were asked to fill in whether they would like to receive much, some or no information about the stated item.

To obtain the rate of compliance, patients were asked how many times they had not used their glaucoma medication in the past 4 weeks. They could fill in whether they missed their dose never, once, twice, three, four, five, six or seven or more times in the past 4 weeks. A strict definition of compliance was used, in which patients were regarded as non-compliant if they admitted to have missed one dose or more. Furthermore, questions were asked concerning causes of non-compliance (Olthoff et al. submitted).

Two typists entered data in a database independently of each other and checked for discrepancies. Missing answers concerning knowledge were classified as "don't know/no opinion". Eleven patients did not fill in how often they had missed an eyedrop in the past 4 weeks. According to their answers on the questions concerning causes of non-compliance, these patients were classified as compliant or non-compliant. Four patients who could not be determined as compliant or noncompliant and eight patients who did not use eyedrops for glaucoma treatment were excluded from further analysis.

The percentage of compliant patients was calculated per quartile of total knowledge of glaucoma and total knowledge of glaucoma treatment and per quartile of need for information. A Pearson chi-squared test was used to examine statistically significant differences. Unadjusted odds ratios (ORs) were calculated with the first quartile of total knowledge or need for information as a reference category. ORs were adjusted for age, gender, length of time since diagnosis of glaucoma, educational level, prescribed medication and history of laser therapy or surgery. The percentage of compliant patients out of patients with an incorrect and correct answer was calculated for each item concerning knowledge of glaucoma and its treatment. The percentage of compliant patients out of patients with some/much and no need for information was calculated for each individual item. Logistic regression analysis was conducted per item to calculate ORs for being compliant. ORs were adjusted for the variables mentioned above. ORs and $95 \%$ confidence intervals were presented to describe the correlation between improved knowledge and compliance on the one hand, and between fulfilled need for information and compliance on the other hand.

\section{Results}

Seventy-three per cent of the ophthalmologists responded $(n=44)$ and 166 patients participated. Demographic variables have been described in detail elsewhere. ${ }^{33}$ The response rate of patients was counted to be $85 \%$. Forty-two (27.3\%) of 154 included patients were classified as non-compliant. Of the non-compliant patients, 40 (95\%) reported one or more reasons for being non-compliant. 
Table 1 shows the percentage of compliant patients per quartile of total level of knowledge and need for information. No statistically significant correlation was found between total level of knowledge of glaucoma and compliance $(P=0.12$, pearson chi-squared test) or between total level of knowledge of glaucoma treatment and compliance $(P=0.46)$, nor was a statistically significant correlation found regarding total level of need for information $(P=0.19)$.

Tables 2-4 are designed so that they show the influence on compliance of an improvement of knowledge or a fulfilled need for information on a specific item. Table 2 represents 19 items about glaucoma. The item "a patient should always tell the ophthalmologist which other medicines (s)he is using" had a statistically significant negative correlation with compliance, meaning that patients who know the correct answer are less compliant. Table 3 shows 18 items about glaucoma treatment. The item "eyedrops can repair the damage caused by glaucoma" had a statistically significant positive correlation with compliance, meaning that patients who know the correct answer are more compliant. Although most items about knowledge of glaucoma and its treatment did not reach significance, 18 items showed a negative relation with compliance; 19 items showed a positive relation with compliance. Table 4 shows 22 items concerning need for information. Three items had a statistically significant positive correlation with compliance: "how to function better with glaucoma", "experiences of other glaucoma patients" and "heredity of glaucoma". This means that patients are more compliant when they have no need or a fulfilled need for information on these items. Although only three items reached statistical significance, 19 out of 22 items showed a positive relation with compliance.

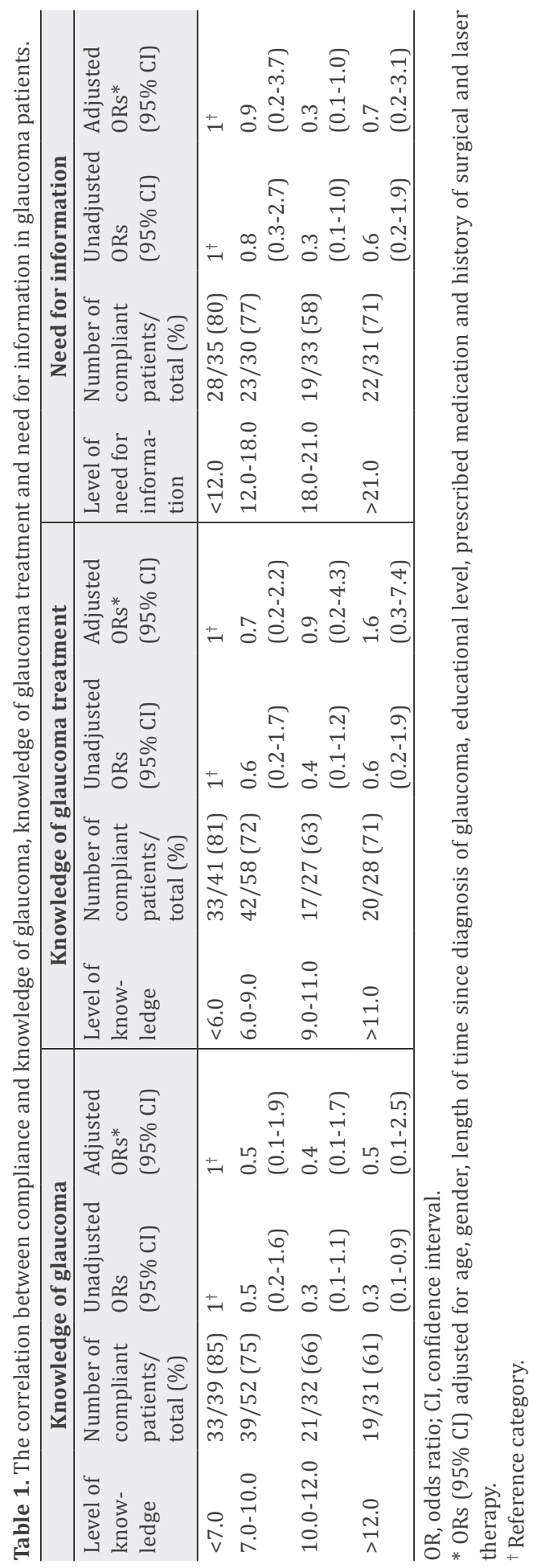


Table 2. The correlation between knowledge of glaucoma and compliance in glaucoma patients.

\begin{tabular}{|c|c|c|c|c|}
\hline \multirow[t]{2}{*}{$\begin{array}{l}\text { Items about glaucoma (correct } \\
\text { answer) }\end{array}$} & \multirow{2}{*}{$\begin{array}{c}\begin{array}{c}\text { Incorrect } \\
\text { answer }\end{array} \\
\text { Number of } \\
\text { compliant } \\
\text { patients/total } \\
(\%) \\
\end{array}$} & \multirow{2}{*}{$\begin{array}{c}\text { Correct } \\
\text { answer } \\
\text { Number of } \\
\text { compliant } \\
\text { patients/total } \\
(\%) \\
\end{array}$} & \multirow[t]{2}{*}{$\begin{array}{l}\text { Unadjusted } \\
\text { OR ( } 95 \% \mathrm{CI})\end{array}$} & \multirow[t]{2}{*}{$\begin{array}{c}\text { Adjusted } \\
\text { OR }(95 \% \mathrm{CI})\end{array}$} \\
\hline & & & & \\
\hline $\begin{array}{l}\text { A patient should always tell the } \\
\text { ophthalmologist which other } \\
\text { medicines (s)he is using (Yes) }\end{array}$ & $27 / 31(87)$ & $85 / 123(69)$ & $0.3(0.1-1.0)^{\dagger}$ & $0.1(0.0-0.6)^{\dagger}$ \\
\hline $\begin{array}{l}\text { African people have a higher chance of } \\
\text { getting glaucoma (Yes) }\end{array}$ & $109 / 146(75)$ & $3 / 8$ (38) & $0.2(0.0-0.9)^{+}$ & $0.2(0.0-1.4)$ \\
\hline $\begin{array}{l}\text { The chance of getting glaucoma is } \\
\text { higher if intraocular pressure is } \\
\text { increased (Yes) }\end{array}$ & $12 / 13(92)$ & $100 / 141(71)$ & $0.2(0.0-1.6)$ & $0.3(0.0-2.7)$ \\
\hline $\begin{array}{l}\text { Strong myopia or hypermetropia gives } \\
\text { a higher chance of getting glaucoma } \\
\text { (Yes) }\end{array}$ & $105 / 141(75)$ & $7 / 13(54)$ & $0.4(0.1-1.3)$ & $0.4(0.1-1.7)$ \\
\hline $\begin{array}{l}\text { A patient should always tell the } \\
\text { ophthalmologist which other diseases } \\
\text { (s)he has (Yes) }\end{array}$ & $35 / 44(80)$ & $77 / 110(70)$ & $0.6(0.3-1.4)$ & $0.4(0.2-1.3)$ \\
\hline $\begin{array}{l}\text { Intraocular pressure is always } \\
\text { increased in glaucoma (No) }\end{array}$ & $96 / 129$ (74) & $16 / 25(64)$ & $0.6(0.2-1.5)$ & $0.4(0.1-1.4)$ \\
\hline $\begin{array}{l}\text { Without treatment, glaucoma is a fast- } \\
\text { progressing condition (No) }\end{array}$ & 89/115 (77) & $23 / 39$ (59) & $0.4(0.2-0.9)^{\dagger}$ & $0.6(0.2-1.8)$ \\
\hline $\begin{array}{l}\text { It is possible to have glaucoma without } \\
\text { knowing it (Yes) }\end{array}$ & $14 / 17(82)$ & 98 /137 (72) & $0.5(0.1-2.0)$ & $0.6(0.1-3.3)$ \\
\hline $\begin{array}{l}\text { Medicines other than eyedrops can } \\
\text { influence intraocular pressure (Yes) }\end{array}$ & 78/103 (76) & $34 / 51$ (67) & $0.6(0.3-1.3)$ & $0.6(0.2-1.5)$ \\
\hline $\begin{array}{l}\text { Young people more often have } \\
\text { glaucoma than older people (No) }\end{array}$ & $38 / 48$ (79) & 74 /106 (70) & $0.6(0.3-1.4)$ & $0.6(0.2-1.8)$ \\
\hline $\begin{array}{l}\text { The chance of getting glaucoma } \\
\text { is higher if a family member has } \\
\text { glaucoma (Yes) }\end{array}$ & $34 / 42(81)$ & 78/112 (70) & $0.5(0.2-1.3)$ & $0.8(0.3-2.5)$ \\
\hline $\begin{array}{l}\text { There is only one type of glaucoma } \\
\text { (No) }\end{array}$ & $80 / 105(76)$ & $32 / 49(65)$ & $0.6(0.3-1.2)$ & $0.8(0.3-2.0)$ \\
\hline $\begin{array}{l}\text { Glaucoma often causes impaired } \\
\text { reading (No) }\end{array}$ & $68 / 86$ (79) & $44 / 68$ (65) & $0.5(0.2-1.0)^{\dagger}$ & $0.9(0.3-2.4)$ \\
\hline $\begin{array}{l}\text { Glaucoma causes reduction of vision } \\
\text { (Yes) }\end{array}$ & $36 / 49$ (74) & $76 / 105(72)$ & $0.9(0.4-2.0)$ & $1.1(0.4-2.7)$ \\
\hline $\begin{array}{l}\text { If the visual field is impaired, this can } \\
\text { be repaired (No) }\end{array}$ & $59 / 77(77)$ & $53 / 77$ (69) & $0.7(0.3-1.4)$ & $1.3(0.5-3.5)$ \\
\hline Glaucoma affects the visual field (Yes) & 23/31 (74) & 89/123 (72) & $0.9(0.4-2.2)$ & $1.6(0.5-4.7)$ \\
\hline $\begin{array}{l}\text { The optic nerve is damaged in } \\
\text { glaucoma (Yes) }\end{array}$ & 73/102 (72) & $39 / 52(75)$ & $1.2(0.6-2.6)$ & $1.6(0.6-4.1)$ \\
\hline $\begin{array}{l}\text { Intraocular pressure is increased if it } \\
\text { exceeds } 25 \text { (Yes) }\end{array}$ & $41 / 59(70)$ & $71 / 95(75)$ & $1.3(0.6-2.7)$ & $2.0(0.8-4.7)$ \\
\hline Nutrition influences glaucoma (No) & $65 / 89(73)$ & $47 / 65(72)$ & $1.0(0.5-2.0)$ & $2.0(0.8-5.4)$ \\
\hline
\end{tabular}

Table 3. The correlation between knowledge of glaucoma treatment and compliance.

\begin{tabular}{lllll}
\hline Items about glaucoma treatment & Incorrect & Correct & Unadjusted & Adjusted
\end{tabular}

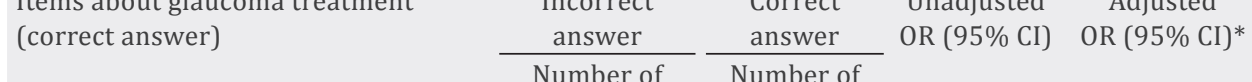

\begin{tabular}{|c|c|c|}
\hline answer & answer & \multirow[t]{2}{*}{ OR $(95 \% \mathrm{CI})$} \\
\hline $\begin{array}{c}\text { Number of } \\
\text { compliant } \\
\text { patients/total } \\
(\%)\end{array}$ & $\begin{array}{l}\text { Number of } \\
\text { compliant } \\
\text { patients/ } \\
\text { total (\%) }\end{array}$ & \\
\hline
\end{tabular}

The use of eyedrops will be redundant $\quad 68 / 85(80)$

if one has had laser treatment or

surgery for glaucoma (No)

Blurred vision after dropping could be $\quad 29 / 36(81) \quad 83 / 118(70) \quad 0.6(0.2-1.4) \quad 0.5(0.2-1.5)$

an adverse effect of eyedrops (Yes)

Even if intraocular pressure is und

control, the visual field has to be

checked (Yes)

Dyspnoea could be an adverse effect of $\quad 97 / 128$ (76) $\quad 15 / 26(58) \quad 0.4(0.2-1.0) \quad 0.7(0.2-2.3)$ eyedrops (Yes)

$\begin{array}{lllll}\text { The pharmacy checks which medicines } & 40 / 53(76) & 72 / 101(71) & 0.8(0.4-1.7) & 0.7(0.3-1.7)\end{array}$

one is using (Yes)

Early detection and treatment will not $\quad 66 / 87(78) \quad 44 / 67(66) \quad 0.5(0.3-1.1) \quad 0.9(0.4-2.2)$ slow down the course of glaucoma

(No)

The course of the disease can be $\quad 13 / 17(77) \quad 99 / 137(72) \quad 0.8(0.2-2.6) \quad 1.2(0.3-4.5)$ slowed down by eyedrops (Yes)

Some eyedrops should not be used by $\quad 61 / 83(74) \quad 51 / 71(72) \quad 0.9(0.5-1.9) \quad 1.2(0.5-2.8)$ cardiac patients or asthma patients

(Yes)

Laser treatment or surgery for glaucoma can repair the damage caused by glaucoma (No)

A slower heart rate could be an

adverse effect of eyedrops (Yes)

Each treatment is equally good for

everyone (No)

It is possible to lose vision completely $\quad 104 / 143(73) \quad 8 / 11(73) \quad 1.0(0.3-4.0) \quad 1.4(0.2-8.1)$ as a result of laser treatment or

surgery for glaucoma (Yes)

Stinging or burning of the eyes could $\quad 22 / 31(71) \quad 90 / 123(73) \quad 1.1(0.5-2.7) \quad 1.6(0.5-4.6)$

be an adverse effect of eyedrops (Yes)

Glaucoma can only be treated by

lowering intraocular pressure (Yes)

Discoloration of the iris may be an adverse effect of eyedrops (Yes)

Eyedrops can be replaced by tablets

( $\mathrm{No}$

Eyedrops can repair the damage

caused by glaucoma (No)

High intraocular pressure must always $\quad 105 / 146(72) \quad 7 / 8(88) \quad 2.7(0.3-22.9) \quad 5.8$ (0.5-66.3) be treated (No)

${ }^{*} \mathrm{OR}(95 \% \mathrm{CI})$ adjusted for age, gender, length of time since diagnosis of glaucoma, educational level, prescribed medication and history of surgical and laser therapy.

${ }^{+} P$-value $<0.05$. 
Table 4. The correlation between need for information and compliance.

\begin{tabular}{|c|c|c|c|c|}
\hline \multirow[t]{2}{*}{ Items } & $\begin{array}{l}\text { Some/much } \\
\text { need for } \\
\text { information }\end{array}$ & $\begin{array}{l}\text { No need for } \\
\text { information }\end{array}$ & \multirow[t]{2}{*}{$\begin{array}{l}\text { Unadjusted } \\
\text { OR }(95 \% \mathrm{CI})\end{array}$} & \multirow[t]{2}{*}{$\begin{array}{c}\text { Adjusted OR } \\
(95 \% \mathrm{CI})^{*}\end{array}$} \\
\hline & $\begin{array}{l}\text { Number of } \\
\text { compliant } \\
\text { patients / } \\
\text { total (\%) }\end{array}$ & $\begin{array}{l}\text { Number of } \\
\text { compliant } \\
\text { patients / } \\
\text { total (\%) }\end{array}$ & & \\
\hline $\begin{array}{l}\text { Other diseases that influence } \\
\text { glaucoma }\end{array}$ & $88 / 121(73)$ & $16 / 22(73)$ & $1.0(0.4-2.8)$ & $0.5(0.1-2.2)$ \\
\hline $\begin{array}{l}\text { New developments concerning } \\
\text { glaucoma and its treatment }\end{array}$ & 100/137 (73) & $8 / 11(73)$ & $1.0(0.2-3.9)$ & $0.5(0.1-2.7)$ \\
\hline How to use and apply eyedrops & $51 / 72(71)$ & $53 / 72(74)$ & $1.1(0.6-2.4)$ & $0.9(0.4-2.4)$ \\
\hline The Glaucoma Patient Society & $58 / 80(73)$ & $46 / 63(73)$ & $1.0(0.5-2.2)$ & $1.0(0.4-2.6)$ \\
\hline Social aspects of glaucoma & 66/91 (73) & $37 / 52(71)$ & $0.9(0.4-2.0)$ & $1.1(0.4-2.8)$ \\
\hline The nature of glaucoma & $90 / 126(71)$ & $17 / 21(81)$ & $1.7(0.5-5.4)$ & $1.1(0.3-4.1)$ \\
\hline $\begin{array}{l}\text { Where to find good educational } \\
\text { material about glaucoma }\end{array}$ & $83 / 116(72)$ & $24 / 30$ (80) & $1.6(0.6-4.2)$ & $1.2(0.4-3.5)$ \\
\hline Psychological aspects of glaucoma & 69/97 (71) & $35 / 47$ (75) & $1.2(0.5-2.6)$ & $1.4(0.6-3.7)$ \\
\hline $\begin{array}{l}\text { The possible course and consequences } \\
\text { of your glaucoma }\end{array}$ & 94/132 (71) & $12 / 14(86)$ & $2.4(0.5-11.4)$ & $1.4(0.3-8.2)$ \\
\hline Eyedrops & 77/111 (69) & 27/33 (82) & $2.0(0.8-5.3)$ & $1.6(0.5-5.0)$ \\
\hline $\begin{array}{l}\text { Resources or rehabilitation for the } \\
\text { visually impaired }\end{array}$ & $72 / 100(72)$ & $36 / 46$ (78) & $1.4(0.6-3.2)$ & $1.9(0.7-5.2)$ \\
\hline $\begin{array}{l}\text { Social securities for visually impaired } \\
\text { people }\end{array}$ & $64 / 92(70)$ & $41 / 52$ (79) & $1.6(0.7-3.6)$ & $2.0(0.8-5.4)$ \\
\hline Work and glaucoma & $43 / 67(64)$ & $58 / 72(81)$ & $2.3(1.1-5.0)^{\dagger}$ & $2.0(0.7-5.5)$ \\
\hline Laser treatment and eye surgery & $84 / 120(70)$ & 25/30 (83) & $2.1(0.8-6.0)$ & $2.2(0.7-7.2)$ \\
\hline Social support or assistance at home & $53 / 77$ (69) & $54 / 69(78)$ & $1.6(0.8-3.4)$ & $2.4(0.9-6.2)$ \\
\hline How to learn to cope with glaucoma & $74 / 106(70)$ & $33 / 41$ (81) & $1.8(0.7-4.3)$ & $2.4(0.8-6.8)$ \\
\hline Possible adverse effects of treatments & $89 / 127(70)$ & 19/22 (86) & $2.7(0.8-9.7)$ & $2.9(0.7-12.3)$ \\
\hline $\begin{array}{l}\text { The present condition of your } \\
\text { glaucoma }\end{array}$ & $93 / 130(72)$ & $17 / 19(90)$ & $3.4(0.7-15.4)$ & $2.9(0.5-15.4)$ \\
\hline How to function better with glaucoma & $75 / 109(69)$ & $31 / 37(84)$ & $2.3(0.9-6.1)$ & $3.1(1.0-9.8)^{\dagger}$ \\
\hline $\begin{array}{l}\text { Experiences of other glaucoma } \\
\text { patients }\end{array}$ & $56 / 85(66)$ & $48 / 59(81)$ & $2.3(1.0-5.0)^{\dagger}$ & $3.3(1.1-9.3)^{\dagger}$ \\
\hline Possible results of treatments & $91 / 129(71)$ & $17 / 19(90)$ & $3.5(0.8-16.1)$ & $3.5(0.6-19.1)$ \\
\hline Heredity of glaucoma & $79 / 116(68)$ & $27 / 30(90)$ & $4.2(1.2-14.8)^{\dagger}$ & $4.1(1.0-17.0)^{\dagger}$ \\
\hline
\end{tabular}
OR, odds ratio; $\mathrm{CI}$, confidence interval.

${ }^{*} \mathrm{OR}(95 \% \mathrm{CI})$ adjusted for age, gender, length of time since diagnosis of glaucoma, educational level, prescribed medication and history of surgical and laser therapy.

${ }^{+} P$-value $\leq 0.055$.

\section{Discussion}

The present study did not find any statistically significant correlation between the total level of knowledge about glaucoma and its treatment and compliance with glaucoma medication. Only two out of 37 items showed a statistically significant correlation between knowledge and compliance. No correlation with compliance could be demonstrated for the issue of total need for information. Three out of 22 items showed a statistically significant positive correlation with compliance.

An advantage of the present study was the systematic development of an extensive questionnaire based on items derived from focus group interviews, consultation of several experts and a pilot test. The questionnaire had a good internal consistency; Cronbach's alpha was 0.83 .

A self-administered questionnaire was used to measure the rate of non-compliance. The advantage of this method is that it is relatively simple and inexpensive. The risk of recall bias is minimized in this study by asking for non-compliance only in the past 4 weeks. The risk of overestimation of compliance is dealt with by the strict definition and low cut-off level of non-compliance (i.e. omitting eye medication on one or more occasions). Socially acceptable behaviour is not expected in this study; $95 \%$ of non-compliant patients gave one or more reasons for being non-compliant. It is not expected that the use of questionnaires caused any bias in this study; our result of $27.3 \%$ non-compliant patients corresponds with those of other reports that used questionnaires ${ }^{13,34}$, pharmacy refill records $\mathrm{s}^{22,23}$ or electronic medication monitors ${ }^{25}$ to assess compliance. Moreover, half of studies reported non-compliance below $29 \%, 25 \%$ of studies found less than $23 \%$ non-compliant patients and $75 \%$ of studies reported non-compliance below $42 \%$. $^{2,5,6,10-27}$

We tried to explore the relation between patients who were very non-compliant and their knowledge about glaucoma and their treatment. However, because only seven patients did not use their medication more than six times in the past 4 weeks, an analysis on this subject would not be reliable.

The results from the present study are somewhat unexpected and it is sometimes difficult to give a causal interpretation. We realize that it is possible that some of our statistically significant results are caused by chance because of the many variables that we have explored. Knowing that one should always tell the ophthalmologist which other medicines one is using was statistically significantly 
correlated with worse compliance, while knowing that eyedrops cannot repair the damage caused by glaucoma was statistically significantly correlated with better compliance. Unknown variables, for example the severity of glaucoma, might play a role. Fulfilling the patients' need for information on how to function better with glaucoma may lead to improved compliance. Patients with prior experience from other glaucoma patients or patients with a history of hereditary glaucoma may also be more compliant with medication. An explanation for the positive correlation concerning heredity of glaucoma may be that patients take an example from their relatives or that patients experience more social control on compliance with therapy. However, a highly motivated or anxious patient might not be equal to a well-informed patient. Although not statistically significant, there was a strong positive relation for the topic "possible results of their own treatments", which can be explained by the fact that patients who know the results of treatments have more confidence in their treatment and are therefore more compliant. The results that providing information on the experiences of other glaucoma patients and about how functioning better with glaucoma is correlated with better compliance may indicate that non-compliant patients do not believe that medical therapy is effective any more or that they suffer from end-stage glaucoma.

The finding that only two items concerning knowledge and three items concerning need for information reached statistical significance does not mean that other items with a non-significant, but strong, positive or negative relation can be ignored. For example, the result that providing information about social support and assistance at home was correlated with better compliance may indicate that non-compliant patients are more in need of support. Moreover, it is relevant to realize that knowing that glaucoma is a slow-progressing condition without treatment was correlated with worse compliance.

The finding that some specific items, rather than an overall level of knowledge, were correlated with compliance is in agreement with previous studies. ${ }^{1,13,16,19}$

Of course, we would prefer to have shown that improvement of knowledge would lead to a great improvement of compliance with glaucoma medication. Based on these results, we do not expect an improvement of compliance when the current level of knowledge is improved. Moreover, alertness on the items that will be discussed is necessary because knowledge on some items was shown to be correlated negatively with compliance. Patient education on a population level remains important, but strategies on enhancing compliance should not focus on further improving knowledge above the current level or addressing the need for information on an individual level. Especially in the context of growing consciousness of the importance of cost-effective allocation of resources in glaucoma management ${ }^{7}$, we think that a patient education programme will not be of added value in improving compliance. We realize that the results of the present study are sometimes difficult to interpret and that long-term clinical trials are necessary to study the influence of a patient education programme on compliance with glaucoma therapy in practice. However, compliance with medication is based not only on knowledge but also on behavioural aspects. Although knowledge about the disease and its treatment was increased, no effect upon compliance with therapy was found from a health education programme for hypertension. ${ }^{35}$ A pharmacy care programme led to improved compliance with antihypertensive and cholesterol-lowering agents, but continued intervention was required ${ }^{36}$ In general, most successful compliance interventions are complex and include combinations of educational, behavioural and affective components. ${ }^{37,38}$ Other possible interventions include reducing forgetfulness, integration of the treatment regimen into one's daily life, usage of a medication schedule, improving communication, asking patients at what time they prefer to use their eyedrops, limiting side-effects and minimizing dose frequency. ${ }^{1}$ $3,4,6,12,16,28,39-43$ Because forgetfulness is mentioned as one of the main reasons for non-compliance, we expect that an intervention that is focused on patients' attitude and discipline may be of more benefit in improving compliance with therapy than

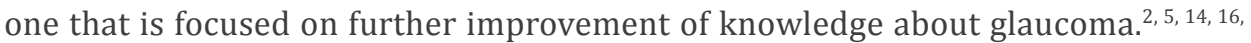
44-46 


\section{References}

1. Olthoff CM, Schouten JS, Van de Borne BW, Webers CA. Noncompliance with ocular hypotensive treatment in patients with glaucoma or ocular hypertension. Ophthalmology 2005;112:953-61.

2. Konstas AG, Maskaleris G, Gratsonidis S, Sardelli C. Compliance and viewpoint of glaucoma patients in Greece. Eye 2000;14:752-6.

3. Lee DA, Fechtner RD, Fiscella RG, et al. Emerging perspectives on glaucoma: highlights of a roundtable discussion. Am J Ophthalmol 2000;130:S1-S11.

4. Zimmerman TJ, Zalta AH. Facilitating patient compliance in glaucoma therapy. Surv Ophthalmol 1983;28:252-7.

5. Patel SC, Spaeth GL. Compliance in patients prescribed eyedrops for glaucoma. Ophthalmic Surg 1995;26:233-6.

6. Deokule S, Sadiq S, Shah S. Chronic open angle glaucoma: patient awareness of the nature of the disease, topical medication, compliance and the prevalence of systemic symptoms. Ophthalmic Physiol Opt 2004;24:9-15.

7. Lindblom B, Nordmann J-P, Sellem E, et al. A multicentre, retrospective study of resource utilization and costs associated with glaucoma management in France and Sweden. Acta Ophthalmol Scand 2006;84:74-83.

8. Vaahtoranta-Lehtonen H, Tuulonen A, Aronen P, et al. Cost effectiveness and cost utility of an organized screening programma for glaucoma. Acta Ophthalmol Scand 2007;85:508-18

9. Kobelt G, Jonsson B, Bergstrom A, et al. Cost-effectiveness analysis in glaucoma: what drives utility? Results from a pilot study in Sweden. Acta Ophthalmol Scand 2006;84:363-71.

10. Pecori Giraldi J, Liguori A, Mollicone A, Paone E. Compliance and psychological conditions: A longterm investigation in 245 glaucomatous patients. Acta Ophthalmol Scand Suppl 1999;229:66-7.

11. Rocheblave A. La coopération des malades porteurs d'un glaucome chronique primitif à angle ouvert. [Cooperation of patient with open-angle glaucoma]. J Fr Ophtalmol 1983;6:837-41.

12. Amon M, Menapace R, Wedrich A, Radax U. Aspekte der Betreuung von Glaukompatienten und deren Auswirkung auf die Compliance. [Aspects of glaucoma patient care and its impact on compliance]. Spektrum Augenheilkd 1990;4:5-8.

13. Bloch S, Rosenthal AR, Friedman DS, Caldarolla P. Patient compliance in glaucoma. Br J Ophthalmol 1977;61:531-4.

14. Bour T, Blanchard F, Segal A. Observance therapeutique et vecu du glaucome primitif a angle ouvert. A propos de 341 cas dans la Marne [Therapeutic observance and life of patients with primary open-angle glaucoma. Apropos of 341 cases in the department of Marne]. J Fr Ophtalmol 1993;16:380-91.

15. Konstas AG, Tsatsos I, Kardasopoulos A, et al. Preoperative features of patients with exfoliation glaucoma and primary open-angle glaucoma. The AHEPA study. Acta Ophthalmol Scand 1998;76:208-12.
16. MacKean JM, Elkington AR. Compliance with treatment of patients with chronic open-angle glaucoma. Br J Ophthalmol 1983;67:46-9.

17. Spaeth GL. Visual loss in a glaucoma clinic. I. Sociological considerations. Invest Ophthalmol 1970;9:73-82.

18. Tsai JC, McClure CA, Ramos SE, et al. Compliance barriers in glaucoma: a systematic classification. J Glaucoma 2003;12:393-8.

19. Vincent PA. Patients' viewpoint of glaucoma therapy. Sight Sav Rev 1972;42:213-21.

20. Lehto I. Side effects of topical treatment in pigmentary glaucoma. Acta Ophthalmol 1992;70:225-7.

21. Alward PD, Wilensky JT. Determination of acetazolamide compliance in patients with glaucoma. Arch Ophthalmol 1981;99:1973-6.

22. Gurwitz JH, Glynn RJ, Monane M, et al. Treatment for glaucoma: adherence by the elderly. Am J Public Health 1993;83:711-6.

23. Gurwitz JH, Yeomans SM, Glynn RJ, et al. Patient noncompliance in the managed care setting; the case of medical therapy for glaucoma. Med Care 1998;36:357-69.

24. Kass MA, Gordon M, Morley RE, et al. Compliance with topical timolol treatment. Am J Ophthalmol 1987;103:188-93.

25. Kass MA, Meltzer DW, Gordon M, et al. Compliance with topical pilocarpine treatment. Am J Ophthalmol 1986;101:515-23.

26. Norell SE, Granström PA. Self-medication with pilocarpine among outpatients in a glaucoma clinic. Br J Ophthalmol 1980;64:137-41.

27. Rotchford AP, Murphy KM. Compliance with timolol treatment in glaucoma. Eye 1998;12:234-6.

28. Chawla A, McGalliard J, Batterbury M. Use of eyedrops in glaucoma: how can we help to reduce non-compliance? Acta Ophthalmol Scand 2007;85:464.

29. Tsai JC. Medication adherence in glaucoma: approaches in optimizing patient compliance. Curr Opin Ophthalmol 2006;17:190-5.

30. Norell SE. Improving medication compliance: a randomised clinical trial. Br Med J 1979;2:1031-3.

31. Granström PA. Glaucoma patients not compliant with their drug therapy: clinical and behavioural aspects. Br J Ophthalmol 1982;66:464-70.

32. Hoevenaars JG, Schouten JS, Van den Borne B, et al. Socioeconomic differences in glaucoma patients' knowledge, need for information and expectations of treatments. Acta Ophthalmol Scand 2006;84:84-91.

33. Hoevenaars JGMM, Schouten JSAG, Van den Borne B, et al. Knowledge base and preferred methods of obtaining knowledge of glaucoma patients. Eur J Ophthalmol 2005;15:32-40.

34. Winfield AJ, Jessiman D, Esakowitz L. A study of the causes of non-compliance by patients prescribed eyedrops. Br J Ophthalmol 1990;74:477-80.

35. Sackett DL, Haynes RB, Gibson ES, et al. Randomised clinical trial of strategies for improving medication compliance in primary hypertension. Lancet 1975;1:1205-7.

36. Lee JK, Grace KA, Taylor AJ. Effect of a pharmacy care program on medication adherence and 
persistence, blood pressure, and low-density lipoprotein cholesterol; a randomized controlled trial. JAMA 2006;296:2563-71.

37. Roter DL, Hall JA, Merisca R, et al. Effectiveness of interventions to improve patient compliance; a meta-analysis. Med Care 1998;36:1138-61.

38. McDonald HP, Garg AX, Haynes RB. Interventions to enhance patient adherence to medication prescriptions; scientific review. JAMA 2002;288:2868-79.

39. Vogel A, Pfeiffer N, Schwenn O. Patientencompliance in der Glaukomtherapie. [Patient compliance in glaucoma therapy]. Ophthalmologe 2002;99:964-72.

40. Mansukani SS. Improving adherence to drug-treatment regimens for glaucoma. Manag Care 2002;11:49-53.

41. Schwartz GF. Compliance and persistency in glaucoma follow-up treatment. Curr Opin Ophthalmol 2005;16:114-21.

42. Stewart WC, Konstas AG, Pfeiffer N. Patient and ophthalmologist attitudes concerning compliance and dosing in glaucoma treatment. J Ocul Pharmacol Ther 2004;20:461-9.

43. Buller A, Hercules BL. Should patients choose their own eyedrops? Acta Ophthalmol Scand 2006;84:150-1.

44. Kosoko O, Quigley HA, Vitale S, et al. Risk factors for noncompliance with glaucoma follow-up visits in a residents's eye clinic. Ophthalmology 1998;105:2105-11.

45. Sleath B, Robin AL, Covert D, et al. Patient-reported behavior and problems in using glaucoma medications. Ophthalmology 2006;113:431-6.

46. Taylor S, Galbraith S, Mills R. Causes of non-compliance with drug regimens in glaucoma patients: a qualitative study. J Ocul Pharmacol Ther 2002;18:401-9. 
Editor,

We read with interest the paper by Hoevenaars et al. ${ }^{1}$ The authors are to be complimented for designing an extensive study attempting to find out whether addressing specific items of improved knowledge of glaucoma leads to better compliance. In their study, 44 randomly selected ophthalmologists each selected four consecutive patients $(n=166)$ to complete a structured questionnaire. The results could not show a statistically significant correlation between the total level of knowledge and compliance. The authors conclude that it would be 'unlikely that further improving knowledge will greatly improve compliance with glaucoma medication'. They recommend that strategies on enhancing compliance should not focus on further improving knowledge and that a patient education programme will not be of added value in improving compliance.

We beg to differ with their conclusions. Firstly, their counterintuitive findings are in contradiction to most of the published literature, which shows a positive correlation between better understanding of glaucoma and compliance. ${ }^{2-4}$ Recently, this relationship was shown to have a risk ratio (RR) of 2.05 [95\% confidence interval (CI) 1.07-3.93] in a study of 105 Omani and a RR of 4.54 (95\% CI 1.4514.16) in 200 Swiss glaucoma patients (K. Mansouri et al., unpublished).

However, because most studies on compliance lacked sufficient power to assess the effect of patient knowledge and compliance, a significant majority of participants did not have an accurate viewpoint of glaucoma, thus reducing the numbers available for analysis. ${ }^{5}$ The educational level of patients is also positively correlated with better compliance ${ }^{6}$ : several studies have demonstrated that less formally educated individuals, particularly those with less than secondary education, were more unlikely to be familiar with glaucoma. ${ }^{7-10}$ Also, patients with chronic disease (including glaucoma) frequently complain of a lack of information ${ }^{11,12}$, making this a major barrier to improving compliance. Interestingly enough, Hoevenaars et al.'s recent recommendation is also in contradiction of an earlier report by the same group that analysed the same cohort for socioeconomic determinants, which suggested that 'better provision of information to patients ... could reduce their risk of becoming blind ... and improve compliance. 8

Their study suffers from a number of limitations that might have contributed to the surprising findings:

(1) The definition of non-compliance (one missed dose in the past 4 weeks) is unusual. Most reports use a less strict criterion of one or more doses in the past week.

(2) The definition of 'total level of knowledge' (some questions were too complex for an average patient) does not necessarily reflect useful knowledge of glaucoma.

(3) The response rate was relatively low, with only 166 out of 240 targeted patients $(69.1 \%)$ and $73 \%$ of ophthalmologists participating compared to the reported $85 \%$ of patients. Eleven patients did not fill in the number of doses missed and a further 12 were excluded for various reasons, reducing the effective reponse rate to $59.5 \%$.

(4) It could further be argued that selecting only four patients per practice could lead to potential selection bias and chance.

(5) Furthermore, the issue of dyscompliance (how to correctly instill drops), an important part of achieving a treatment response, was not addressed in this study. It can be reasonably argued that dyscompliance could be reduced by adequate education and the provision of instillation aids through the healthcare provider.

(6) We believe that the study design does not allow the authors to arrive at the above-mentioned conclusions. The authors should have conducted an interventional trial with a study group receiving education on glaucoma and a control group not receiving any additional education.

Even in the absence of these short-comings, the conclusion drawn would still not be justified: the authors themselves demonstrate that three out of 22 items showed a significant positive correlation with compliance (such as patients knowing that eyedrops cannot repair glaucoma damage), and a further 19 items showed a positive relation with compliance while not being significant. Therefore, we would like to caution practitioners and policy-makers to interpret these conclusions carefully and in the context of the other published literature. Nevertheless, we appreciate the effort invested by the authors to address an often neglected field of glaucoma research. 


\section{References}

1. Hoevenaars JG, Schouten JS, van den Borne B, et al. Will improvement of knowledge lead to improvement of compliance with glaucoma medication? Acta Ophthalmol 2008;86:849-55.

2. Khandekar R, Shama ME-S, Mohammed AJ. Noncompliance with medical treatment among glaucoma patients in Oman-a cross-sectional descriptive study. Ophthalmic Epidemiol 2005;12:303-9.

3. MacKean JM, Elkington AR. Compliance with treatment of patients with chronic open-angle glaucoma. Br J Ophthalmol 1983;67:46-9.

4. Zimmerman TJ, Zalta AH. Facilitating patient compliance in glaucoma therapy. Surv Ophthalmol 1983;28:252-7.

5. Konstas AG, Maskaleris G, Gratsonidis S, Sardelli C. Compliance and viewpoint of glaucoma patients in Greece. Eye 2000;14:752-6.

6. Sleath B, Robin AL, Covert D, et al. Patient-reported behavior and problems in using glaucoma medications. Ophthalmology 2006;113:431-6.

7. Gasch AT, Wang P, Pasquale LR. Determinants of glaucoma awareness in a general eye clinic. Ophthalmology 2000;107:303-8.

8. Hoevenaars JG, Schouten JS, van den Borne B, et al. Socioeconomic differences in glaucoma patients' knowledge, need for information and expectations of treatments. Acta Ophthalmol Scand 2006;84:84-91.

9. Lau JT, Lee V, Fan D, et al. Knowledge about cataract, glaucoma, and age related macular degeneration in the Hong Kong Chinese population. Br J Ophthalmol 2002;86:1080-4.

10. Olthoff CM, Schouten JS, van de Borne BW, Webers CA. Noncompliance with ocular hypotensive treatment in patients with glaucoma or ocular hypertension an evidence-based review. Ophthalmology 2005;112:953-61.

11. Mansouri K, Orgul S, Meier-Gibbons F, Mermoud A. Awareness about glaucoma and related eye health attitudes in Switzerland: a survey of the general public. Ophthalmologica 2006;220:101-8.

12. Osterberg L, Blaschke T. Adherence to medication. N Engl J Med 2005;353:487-97. 


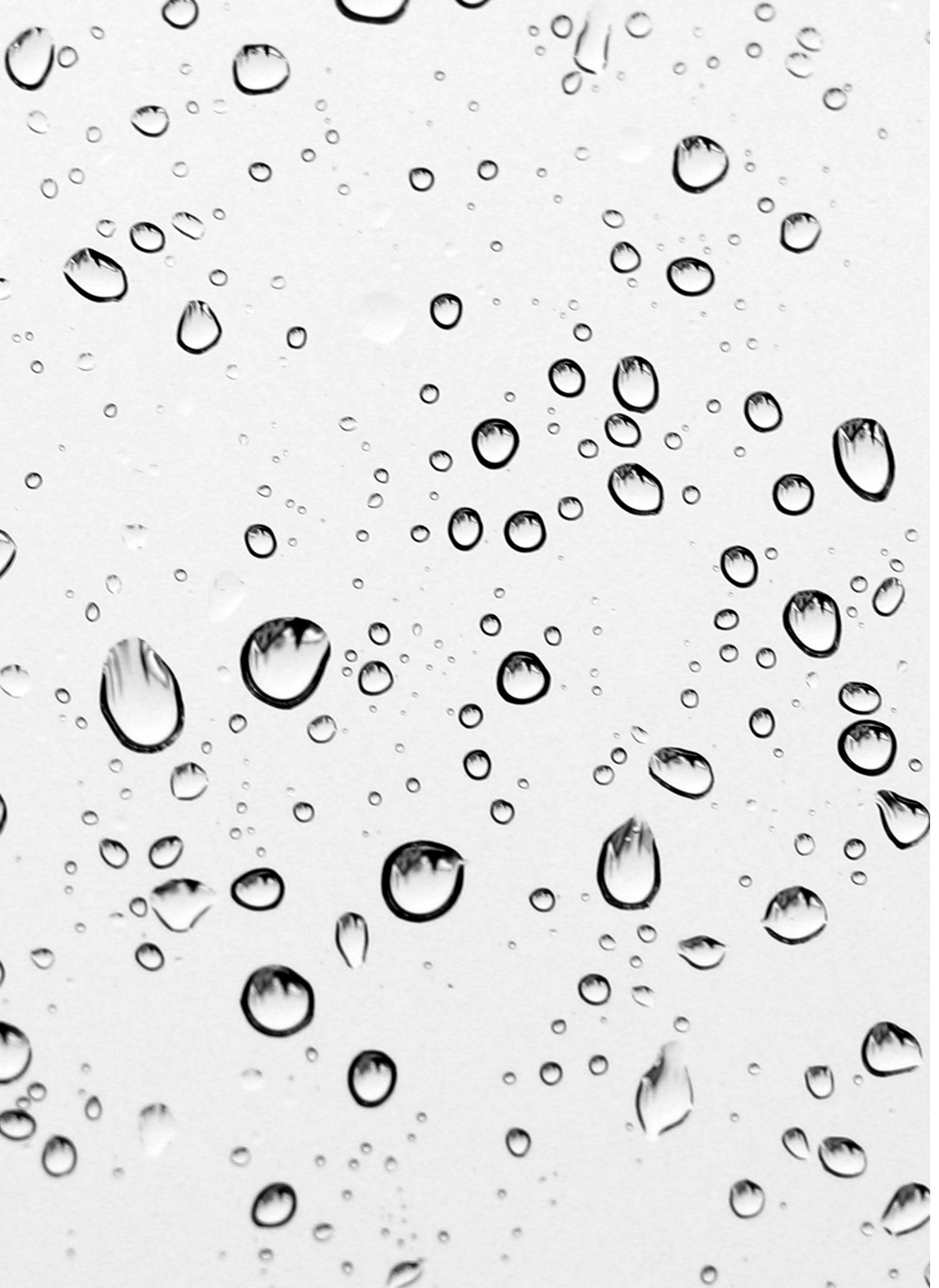


Editor,

We would like to thank Mansouri \& Shaarawy ${ }^{1}$ for their comments on our paper 'Will improvement of knowledge lead to improvement of compliance with glaucoma medication??.' In our article we suggest that patient education on a population level remains important, but that it is unlikely that improving knowledge beyond the current level will greatly improve compliance with glaucoma medication in Dutch patients.

Mansouri \& Shaarawy ${ }^{1}$ write that our findings are in contradiction to the positive correlation between better understanding of glaucoma and compliance described in three other articles.-5 However, the study of Khandekar et al., investigating non-compliance with medical treatment among glaucoma patients in Oman, is not comparable to our study. Firstly, $67.6 \%$ of Khandekar et al.'s study population was illiterate. Only a small minority of the Dutch population is illiterate and no patient in our study population was illiterate. Moreover, Khandekar et al. did not explain the development of the questionnaire and used only five questions to investigate knowledge, compared to the 37 items that we used. They stated that adequate knowledge was negatively associated with non-compliance and showed a risk ratio of 2.05. ${ }^{3}$ However, they did not apply any correction for confounding. In our study, we presented unadjusted odds ratios as well as adjusted odds ratios for each item. Odds ratios were adjusted for age, gender, length of time since diagnosis of glaucoma, educational level, prescribed medication and history of laser therapy and surgery. Zimmerman \& Zalta described showing patients a 10-min video presenting basic information about glaucoma and its treatment. The film was reinforced with a booklet in which patients outlined their daily schedules, recorded medications, dosages and instillation times, and documented any problems that they encountered. Patients also noted any other physicians and medications in this booklet. Their office personnel were trained to question, instruct, review and reinforce patients. They also reviewed the booklets, praised compliance, identified reasons for non-compliance and solved problems. Zimmerman \& Zalta mentioned that this reinforcement programme of patient education and tailoring may be the most efficient way to help patient compliance and provide safety from sideeffects. However, they did not investigate this programme. They did not report the results of this intervention in their article. ${ }^{5}$ MacKean \& Elkington have investigated knowledge of glaucoma patients by asking patients if they knew the name of their eye condition. If patients knew they had glaucoma, they were asked whether they had heard of it before being diagnosed and how much they knew about it now. The interviewers asked all patients if they knew what would happen if they had no treatment. Their results showed that patients who knew the name of their disease or who knew the possible effect of no treatment were more compliant. Knowledge of the disease mechanism and prediagnostic knowledge of glaucoma was not found to affect compliance. However, this method of measuring for knowledge is not comparable to our method, in which we used a systematically developed questionnaire based on focus-group interviews, expert opinions and a pilot test. We used 37 items to investigate knowledge of glaucoma and its treatment. ${ }^{4}$ Mansouri \& Shaarawy also refer to unpublished data of their own. Of course, we can not judge any unpublished data.

Mansouri \& Shaarawy ${ }^{1}$ state that our definition of non-compliance is unusual. We defined non-compliance as missing one or more eyedrops in the last 4 weeks. This is not an unusual definition. Different studies used varying definitions of compliance and different assessment methods. Several studies used as strict a definition as our own. ${ }^{6-11}$ Our result of $27.3 \%$ non-compliant patients corresponds with the findings of other reports that used questionnaires ${ }^{12,13}$, pharmacy refill records ${ }^{14,15}$ or electronic medication monitors ${ }^{16}$ to assess compliance. By using our definition of non-compliance the risk of socially acceptable behaviour and overestimation of compliance was diminished. Some reports used a less strict definition of noncompliance, but these definitions are also arbitrary because nobody can tell the correct cut-off value of relevant non-compliance. It is probably a continuum in relation to outcome of treatments.

We agree with Mansouri \& Shaarawy ${ }^{1}$ that the total level of knowledge does not necessarily reflect the useful knowledge of patients. However, it is a useful definition to assess the relation between overall level of knowledge and compliance. Moreover, we did not limit ourselves to this definition and also described the correlation between improved knowledge and compliance per individual item of the questionnaire. Only two out of 37 items showed a statistically significant correlation between knowledge and compliance, of which one item showed a positive statistically significant correlation.

In their third comment Mansouri \& Shaarawy ${ }^{1}$ have miscalculated. Their statement that the effective response rate was $59.5 \%$ is incorrect. In the study, 60 ophthalmologists were asked to select four consecutive glaucoma patients. Fortyfour ophthalmologists participated. Thirty-four ophthalmologists returned four questionnaires, two returned five, five returned three, two returned two and one 
returned one. Therefore, 166 questionnaires were included in the study. If all 44 ophthalmologists had returned four questionnaires, 176 questionnaires would have been included in the study. We have performed preliminary statistical sample size calculations. Based on a response rate of $50 \%$ and a target number of 100 patients, we planned to ask 200 patients to participate in the study. The $95 \%$ confidence interval of a frequency of one certain item would be: freq $\pm 1.96 \mathrm{x}$ [freq $\mathrm{x}$ (1-freq) $/ n]^{1 / 2}$. In the event of 100 responding patients and a frequency of $10 \%$, the $95 \%$ confidence interval would have been $4 \%-16 \%$. In the event of 100 responding patients and a frequency of $50 \%$, the $95 \%$ confidence interval would have been 40\%-60\%. However, 166 patients participated in this study. The $95 \%$ confidence interval is $5.4 \%-14.6 \%$ in the event of a frequency of $10 \%$, and $42.4 \%-57.6 \%$ in the event of a frequency of $50 \%$.

Moreover, the statement that 12 patients were excluded for various reasons alongside the 11 patients who did not provide compliance information is not correct. Indeed, 11 patients did not fill in how often they had missed an eyedrop, but according to their answers, seven of these patients could be classified as compliant or non-compliant. The four patients who could not be determined as compliant or non-compliant and the eight patients who did not use eyedrops for glaucoma treatment were excluded from analysis. In total, 12 patients were excluded, contrary to the 23 patients stated by Mansouri \& Shaarawy. ${ }^{1}$

We cannot exclude the possibility of selection bias and chance in the selection of patients because we were not present at the time of selection. It is difficult to assess case order. However, selection bias was minimized by asking ophthalmologists to invite four consecutive patients to participate. Selecting one patient from each ophthalmologist, selecting patients from only one hospital, from non-randomly selected hospitals, during pharmacy visits or from members of the Glaucoma Patient Society, would certainly have led to selection bias. Moreover, by asking ophthalmologists to invite four consecutive patients, workload was minimized. Therefore, it was the best method for reducing selection bias compared to alternative methods.

We have not addressed the issue of dyscompliance in this paper. We have addressed this important point in another article. ${ }^{17}$ However, it was not the scope of this paper to investigate this issue.

Mansouri \& Shaarawy ${ }^{1}$ state that our recommendation is in contradiction to an earlier report about socioeconomic determinants. In this previous article we defined socioeconomic classes based on educational level. We found that patients from lower socioeconomic classes had a lower level of knowledge about glaucoma and its treatment. We did not investigate the relationship between lower socioeconomic class and compliance. Therefore, we made a suggestion and no more than a suggestion - that better provision of information about the specific items mentioned in that article to patients in lower socioeconomic groups could reduce their risk of becoming blind, contribute to an earlier presentation of glaucoma, improve their quality of life, adjust their expectations, reduce the incidence of adverse effect and improve compliance. ${ }^{18}$ This is not in contradiction to the study being discussed here.

Mansouri \& Shaarawy ${ }^{1}$ do not fully appreciate the design of our study. The development of the questionnaire was based on systematic item selection through focus-group interviews and consultation with several experts. The questionnaire was very extensive and contained 37 items on knowledge about glaucoma and its treatment. Interestingly enough, Mansouri \& Shaarawy refer to studies that do not describe the development of their questionnaires and used only a few questions about knowledge. Compared to alternative methods for patient selection, our selection of patients was the best method to minimize selection bias and improve participation levels of ophthalmologists and patients. Both ophthalmologists and patients received an incentive if they participated. Moreover, we have presented results adjusted for confounding factors.

In our article we do not state that the effect found in our study is proven, but rather that it is unlikely that further improving knowledge in Dutch glaucoma patients will greatly improve compliance. It is possible that the general level of knowledge in Dutch glaucoma patients is higher than that found in other countries (for example Oman) because of higher literacy levels.

There are no easy solutions to improve compliance. Compliance with glaucoma medication is based not only on knowledge, but also on behavioural aspects. Several reviews have demonstrated that most successful compliance interventions are complex and include combinations of educational, behavioural and affective components. ${ }^{19-21}$ Sixteen out of 37 trials reported a consistent improvement in adherence, but few interventions affected clinical outcomes significantly. A lot of successful interventions contained multiple elements delivered over time. ${ }^{19}$ In their review of reviews, van Dulmen et al. ${ }^{22}$ showed a positive effect of patient 
education on knowledge and adherence, but the effects of knowledge appeared to diminish over time. They also showed that technical interventions (such as a less frequent dosage) resulted in better adherence and that behavioural interventions were relevant for improving adherence. Roter et al. ${ }^{21}$ found that interventions combining cognitive, behavioural and affective components were more effective than interventions focused on one element alone.

Therefore, we do not to follow the suggestion of Mansouri \& Shaarawy ${ }^{1}$ that improved knowledge will greatly improve compliance or outcome. In our opinion, it is important to achieve a general level of knowledge in glaucoma patients. However, we do not have high expectations that further improvement of knowledge in the Dutch population will enhance compliance greatly. Knowledge on some items was even correlated negatively with compliance: for example, knowing that glaucoma is a condition that progresses slowly without treatment was correlated with worse compliance. More intervention studies are needed to examine other dimensions. We think that compliance-enhancing interventions focused on reducing forgetfulness and increasing usage of dosing aids may be of more benefit than an intervention based on improvement of knowledge.

We thank Mansouri \& Shaarawy for reading our article carefully.

\section{References}

1. Mansouri K, Shaarawy T. Will improvement of knowledge lead to improvement of compliance with glaucoma medication? Acta Ophthalmol 2009;87:468-9.

2. Hoevenaars JG, Schouten JS, van den Borne B, et al. Will improvement of knowledge lead to improvement of compliance with glaucoma medication? Acta Ophthalmol 2008;86:849-55.

3. Khandekar R, Shama ME-S, Mohammed AJ. Noncompliance with medical treatment among glaucoma patients in Oman-a cross-sectional descriptive study. Ophthalmic Epidemiol 2005;12:303-9.

4. MacKean JM, Elkington AR. Compliance with treatment of patients with chronic open-angle glaucoma. Br J Ophthalmol 1983;67:46-9.

5. Zimmerman TJ, Zalta AH. Facilitating patient compliance in glaucoma therapy. Surv Ophthalmol 1983;28:252-7.

6. Amon M, Menapace R, Wedrich A, Radax U. Aspekte der Betreuung von Glaukompatienten und deren Auswirkung auf die Compliance. [Aspects of glaucoma patient care and its impact on compliance]. Spektrum Augenheilkd 1990;4:5-8.

7. Bour T, Blanchard F, Segal A. Therapeutic observance and life of patients with primary open-angle glaucoma. Apropos of 341 cases in the department of Marne. [Observance therapeutique et vecu du glaucome primitif a angle ouvert. A propos de 341 cas dans la Marne]. J Fr Ophtalmol 1993;16:38091.

8. Chang J, Lee D, Petursson G, et al. The effect of a glaucoma medication reminder cap on patient compliance and intraocular pressure. J Ocular Pharmacol 1991;7:117-24.

9. Laster S, Martin J, Fleming J. The effect of a medication alarm device on patient compliance with topical pilocarpine. J Am Optom Assoc 1996;67:654-8.

10. Patel SC, Spaeth GL. Compliance in patients prescribed eyedrops for glaucoma. Ophthalmic Surg 1995;26:233-6.

11. Tsai JC, McClure CA, Ramos SE, et al. Compliance barriers in glaucoma: a systematic classification. J Glaucoma 2003;12:393-8.

12. Bloch S, Rosenthal AR, Friedman DS, Caldarolla P. Patient compliance in glaucoma. Br J Ophthalmol 1977;61:531-4.

13. Winfield AJ, Jessiman D, Esakowitz L. A study of the causes of non-compliance by patients prescribed eyedrops. Br J Ophthalmol 1990;74:477-80.

14. Gurwitz JH, Glynn RJ, Monane M, et al. Treatment for glaucoma: adherence by the elderly. Am J Public Health 1993;83:711-6.

15. Gurwitz JH, Yeomans SM, Glynn RJ, et al. Patient noncompliance in the managed care setting; the case of medical therapy for glaucoma. Med Care 1998;36:357-69.

16. Kass MA, Gordon M, Meltzer DW. Can ophthalmologists correctly identify patients defaulting from pilocarpine therapy? Am J Ophthalmol 1986;101:524-30

17. Olthoff CM, Hoevenaars JG, van den Borne BW, et al. Prevalence and determinants of non-adherence 
to topical hypotensive treatment in Dutch glaucoma patients. Graefes Arch Clin Exp Ophthalmol 2009;247:235-43.

18. Hoevenaars JG, Schouten JS, van den Borne B, et al. Socioeconomic differences in glaucoma patients' knowledge, need for information and expectations of treatments. Acta Ophthalmol Scand 2006;84:84-91.

19. Kripalani S, Yao X, Haynes B. Interventions to enhance medication adherence in chronic medical conditions; a systematic review. Arch Intern Med 2007;167:540-50.

20. McDonald HP, Garg AX, Haynes RB. Interventions to enhance patient adherence to medication prescriptions; scientific review. JAMA 2002;288:2868-79.

21. Roter DL, Hall JA, Merisca R, et al. Effectiveness of interventions to improve patient compliance; a meta-analysis. Med Care 1998;36:1138-61.

22. Dulmen van S, Sluijs E, Dijk van L, et al. Patient adherence to medical treatment: a review of reviews. BMC Health Serv Res 2007;7:55. 


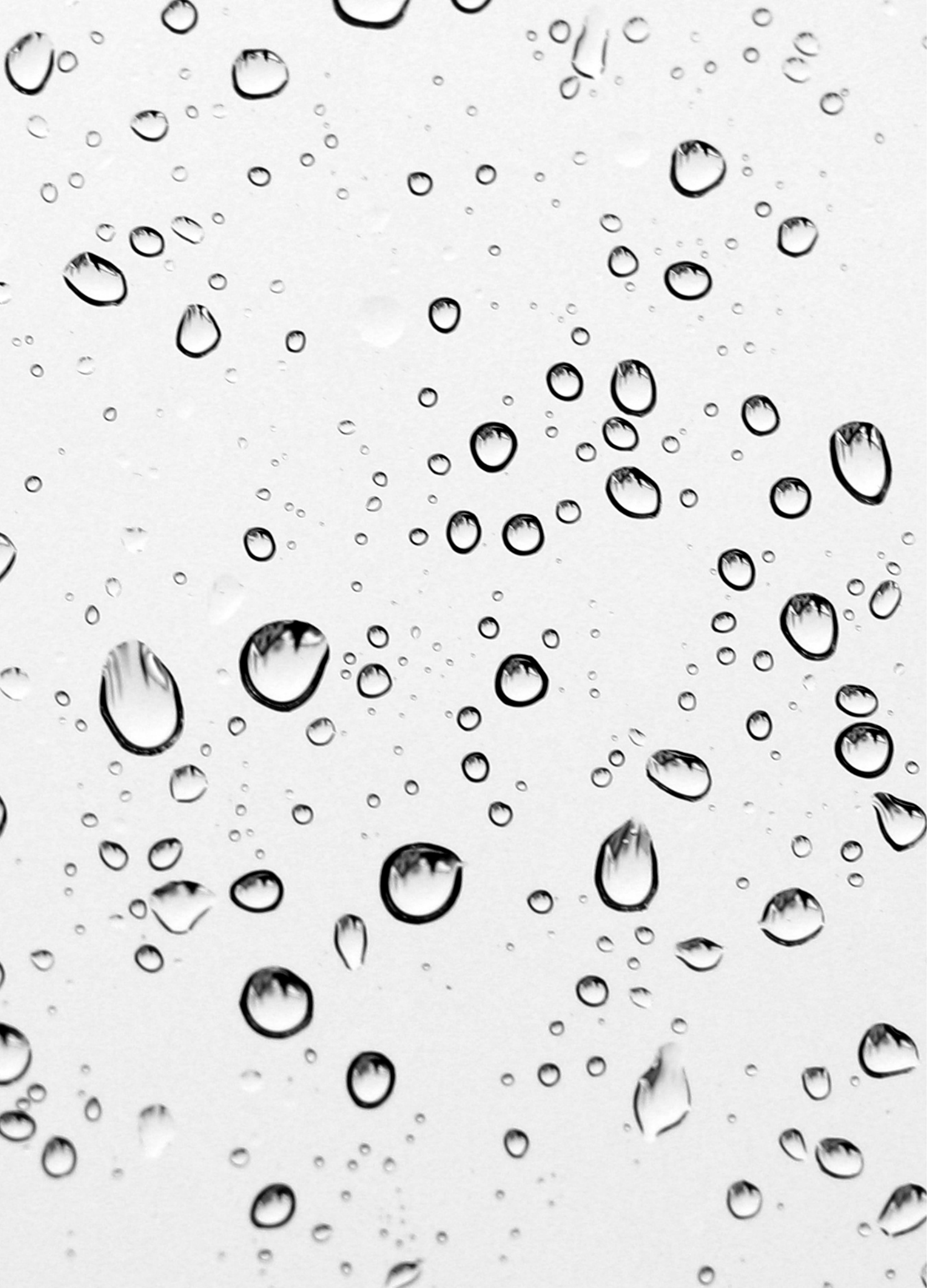

Chapter 5

Prevalence and determinants of non-adherence to topical hypotensive treatment in Dutch glaucoma patients

Christine M.G. Olthoff

Juliette G.M.M. Hoevenaars

Bart W. van den Borne

Carroll A.B. Webers

Jan S.A.G. Schouten

Graefe's Archive for Clinical and Experimental Ophthalmology 2009;247:235-243 


\section{Abstract}

\section{Background}

To assess the prevalence and determinants of non-adherence to topical hypotensive treatment in glaucoma patients in order to support interventions targeting enhancement of patient adherence.

\section{Methods}

One-hundred and sixty-six glaucoma patients, recruited by nationwide multi-stage sampling, filled in an extensive and carefully developed questionnaire covering various theoretically relevant determinants of patient adherence which were categorized as psychosocial aspects, barriers and skills.

\section{Results}

Prevalence of self-reported non-adherence was 27.3\%. Younger patients $(<55$ years of age) had a higher risk of being non-adherent. Forgetfulness, unavailability of eye drops and difficulties with holding the bottle above the eye when applying the eye drops were the most cited reasons for non-adherence. Fifty percent of the patients indicated that they required more information on the correct administration of eye drops. There was no association between non-adherence and sex, level of education, type of insurance, duration of disease or family history of glaucoma.

\section{Conclusions}

Non-adherence to topical glaucoma medication is fairly common. Aids that minimize forgetfulness and delivery systems facilitating the delivery of medications to the eye could be considered to enhance patient adherence before advancing to other therapies with additional risks and costs.

\section{Introduction}

Professionals agree upon the importance of adherence to ocular hypotensive medication in the treatment of glaucoma patients, to reduce the risk of visual impairment. ${ }^{1-5}$ A systematic review of 63 studies assessing the relation between adherence and outcomes of medical treatments showed that non-adherent patients have a greater risk of a poor outcome than adherent patients. ${ }^{6}$ Because poor adherence can result in ineffectiveness of treatments, improvement of adherence could prevent the need to advance to more aggressive therapies. However, despite the introduction of eye drops with fewer side effects and a simpler medication regimen during the last years, still $10 \%$ to $30 \%$ of glaucoma patients regularly omit prescribed doses., 7-11 Few studies have yet been done that systematically assess the causes of deviation from medication regimen in glaucoma patients in order to improve patient care. Taylor et al. used a qualitative methodology to understand the motivation of 28 glaucoma patients not to comply. Forgetfulness was the most reported reason for non-adherence. ${ }^{12}$ Tsai et al. developed a systematic classification of a wide range of potential obstacles to adherence to glaucoma medication. Seventy-one barriers to non-adherence were categorized into four groups: social/environmental factors, patient factors, provider factors and regimen factors. ${ }^{11}$ Sleath et al. listed 13 problem areas, and asked patients if they experienced one or more problems with their glaucoma medications. Most reported problems included practical difficulty with drop administration, paying for medications and remembering to take the medication. ${ }^{13}$ Interventions for enhancing adherence should be based on reasons for non-adherence and should be applicable in regular, daily care..$^{14}$ Our aim was to quantitatively assess various relevant determinants of adherence to topical glaucoma medication that could later be addressed in an adherence enhancing intervention.

\section{Materials and Methods}

\section{Patients}

We conducted a cross-sectional multi-center study in the Netherlands, in which we enrolled 166 adult patients who were treated for primary open-angle glaucoma. Ethics committee approval was obtained and all persons gave their informed consent before being included in the study. No selection was made based on duration of the disease or type of glaucoma medication used. Patients were recruited by multi-stage sampling. We took a random sample of 60 ophthalmologists from the directory of 
the Dutch Ophthalmological Society. They were asked to invite four consecutive glaucoma patients to fill in a self-administered questionnaire during their visit to the outpatient department. In case a patient was not willing or unable to participate in the study, the ophthalmologists were asked to select the next consecutive patient. Selection bias was minimized by asking four consecutive patients as, in this way, ophthalmologists could only select the first patient that they thought to be appropriate for participation. We expected that most ophthalmologists would be able to select a maximum of four patients during one outpatient clinic, and that workload was reduced by the selection of 60 ophthalmologists.

Based on a response rate of $50 \%$ and a target number of 100 patients, we planned to ask 200 patients to participate in the study. The $95 \%$ confidence interval of a frequency of one certain item would be: freq $\pm 1.96 \times(\text { freq } x(1-\text { freq }) / n)^{1 / 2}$. With 100 responding patients and a frequency of $10 \%$, the $95 \%$ confidence interval would have been $4 \%-16 \%$. With 100 responding patients and a frequency of $50 \%$, the $95 \%$ confidence interval would have been $40 \%-60 \%$.

\section{Questionnaire}

Non-adherence was defined as the failure to take topical hypotensive treatment as prescribed, i.e. the omission of prescribed doses. We aimed to include in the questionnaire all potential causes of non-adherence to glaucoma medication that were reported in the literature and that were put forward by patients and experts. To select appropriate items for the questionnaire, a systematic inventory of the relevant literature was conducted and four focus-group interviews with 21 glaucoma patients from four hospitals were held, one of which was a university hospital. In focus group patients, we made allowance for the duration of glaucoma and membership of the Glaucoma Patient Society. The duration of glaucoma in focus group patients ranged from 1 month to 22 years, and nine patients were members of the Glaucoma Patient Society. Members of the Glaucoma Patient Society were placed in one focus group, as well as patients with a short duration of glaucoma. Reasons for not mixing these patients with other patients included prevention of dominance of some patient groups and the different level of knowledge of members of the Glaucoma Patient Society and patients with short duration of glaucoma compared to other patients. In this way, we obtained a variety in patient characteristics in the focus groups.

Experts in ophthalmology, patient education and pharmacology reviewed the concept version of the questionnaire. In addition, we tested the questionnaire in a pilot study with ten patients. Based on key determinants from health education theory, we distinguished three clusters of causes: psychosocial determinants of behavior (including factors as for example attitude and social influence), barriers (e.g. co-morbidity and understanding) and skills. ${ }^{15}$ We listed 34 possible determinants of non-adherence, consisting of 18 psychosocial reasons, six barriers and ten skills. Patients could fill in whether they had never missed an eye drop, whether they had missed an eye drop once or whether they had missed an eyedrop more than once because of the stated reason.

To discover any supplementary topics that could lead to better adherence if addressed in a patient education program, we examined patients' subjective need for information. Therefore, we asked patients to indicate whether they preferred much, some or no information about 22 listed items concerning need for information.

Questions about the various causes of non-adherence were formulated in plain Dutch. Questions covered the past 4 weeks in order to minimize the risk of recall bias.

\section{Statistical analysis}

In order to minimize data-entry errors, experienced data typists entered the data twice and checked for discrepancies. If patients had not answered the question about how often they had missed an eye drop during the past 4 weeks $(n=11)$, we classified them as adherent or non-adherent according to the answers given to the questions concerning causes of non-adherence. Four patients who claimed not to have missed a single dose due to one of the reasons given were classified as adherent. Three patients who had missed an eye drop at least once due to one of the reasons given were classified as non-adherent. Four patients whose status of being adherent or non-adherent could not be determined and eight patients who did not use eye drops for glaucoma treatment at all were excluded from further analysis.

Statistical analyses were performed with 154 patients, using the software package SPSS 10.1. The $\chi^{2}$-test for independence of two nominal variables was employed to examine differences in frequency distributions of categorical variables between adherent and non-adherent patients. A $p$-value of $<0.05$ was used to indicate statistical significance. Univariate logistic models were fitted per item to calculate the odds ratio of being non-adherent. 


\section{Results}

\section{Sociodemographic determinants}

The response among the ophthalmologists was $73 \%$ (44/60). Of the 236 questionnaires we had handed out, 166 (70.3\%) were returned. With respect to the patients, reasons not to participate in the study were cognitive dysfunction, language barriers and lack of time.

Table 1 shows the characteristics of the patients and the prevalence of the omission of doses. Twenty-six percent of the patients reported that they had missed an eye drop once or more than once during the past 4 weeks. After imputation, $27.3 \%$ of the patients were classified as non-adherent.

There was a statistically significant difference $(p=0.01)$ in the proportion of adherent and non-adherent patients between the different age groups (Table 2 ). The odds ratio of being non-adherent was less in the higher age categories compared to the lowest category $(<54$ years).

With respect to type of medication, differences in proportion of adherent and nonadherent patients did not reach statistical significance $(p=0.06)$. The unadjusted odds ratio for non-adherence in the patient group who received a combination therapy ( $\geq 2$ different bottles) was 3.3 (95\% CI [1.2; 9.6], $p=0.02$ ) with patients prescribed a beta-blocker serving as reference group. There was no difference between patients prescribed a beta-blocker and patients prescribed latanoprost.

Patients who had undergone laser treatment seemed to be at greater risk for non-adherence than patients who had no history of surgical or laser treatment. However, this association was not statistically significant.

There were no statistically significant differences in proportion of adherent and non-adherent patients for sex, level of education, type of insurance, duration of disease or family history of glaucoma.
Table 1. Characteristics of the study population and the prevalence of omission of doses during the past four weeks.

\begin{tabular}{lll}
\hline Characteristics of the study population & & \\
\hline Sex $(n=153)$ & Female & $74(48.4 \%)$ \\
Mean age $(n=153)$ & & $64.5( \pm 12.9)$ \\
Educational level $(n=153)$ & Low & $62(40.5 \%)$ \\
& Moderate & $50(32.7 \%)$ \\
Health insurance $(n=153)$ & High & $41(26.8 \%)$ \\
& Private & $56(36.6 \%)$ \\
& Dutch National Health Service $^{\mathrm{b}}$ & $91(59.5 \%)$ \\
Duration of glaucoma $(n=145)$ & Dutch civil servant health insurance & $6(3.9 \%)$ \\
Family members with glaucoma $(n=151)$ & $\leq 2$ years & $35(24.1 \%)$ \\
& Yes & $56(37.1 \%)$ \\
History of surgical or laser therapy $(n=150)$ & Do not know & $38(25.2 \%)$ \\
& None & $97(64.7 \%)$ \\
& Laser therapy & $30(20.0 \%)$ \\
Prescribed medication $(n=154)^{\mathrm{d}}$ & Surgical treatment & $5(3.3 \%)$ \\
& Both & $18(12.0 \%)$ \\
& Latanoprost & $70(45.5 \%)$ \\
& Timolol & $51(33.1 \%)$ \\
& Betaxolol & $22(14.3 \%)$ \\
& Fixed timolol-dorzolamide combination & $9(5.8 \%)$ \\
& Brimonidine & $8(5.2 \%)$ \\
& Levobunolol & $5(3.2 \%)$ \\
& Brinzolamide & $3(1.9 \%)$ \\
Number of times a dose was missed during the past 4 weeks $(n=147$ patients) & $38(24.8 \%)$ \\
& Others & \\
& 1 & $108(73.5 \%)$ \\
& 2 & $14(9.5 \%)$ \\
& 3 & $11(7.5 \%)$ \\
& 4 & $5(3.4 \%)$ \\
& $5(1.4 \%)$ \\
& 5 & -- \\
& 2 & -- \\
& 2 & $7(4.8 \%)$ \\
\hline
\end{tabular}

Data are mean $( \pm$ SD) or number of patients (\%).

${ }^{a}$ Health insurance for patients belonging to higher income categories.

${ }^{b}$ Health insurance for patients belonging to lower and average income categories.

${ }^{c}$ Health insurance for civil servants.

${ }^{\mathrm{d}}$ Multiple prescriptions possible.

e Others: metipranolol, dipivefrine, aceclidine, apraclonidine, pilocarpine, fixed metipranololpilocarpine combination, fixed timolol-pilocarpine combination, fixed epinephrine-guanethidine, carteolol, dorzolamide, befunolol, others.

fi.e. not a single dose was omitted. 
Table 2. Non-adherence by patient characteristics.

\begin{tabular}{|c|c|c|c|}
\hline Patient characteristic & $\begin{array}{l}\text { \% non- } \\
\text { adherent } \\
\text { patients }\end{array}$ & $\begin{array}{l}P \text {-value of the } \\
\chi^{2} \text {-test }\end{array}$ & $\begin{array}{l}\text { Unadjusted odds } \\
\text { ratio }\left(95 \% \mathrm{CI}^{2}\right)\end{array}$ \\
\hline Age & & 0.01 & \\
\hline$<55$ y $(n=38)$ & 44.7 & & 1 \\
\hline $55-64$ y $(n=28)$ & 35.7 & & $0.7(0.3-1.9)$ \\
\hline $65-74$ y $(n=50)$ & 16.0 & & $0.2(0.1-0.6)$ \\
\hline$>74$ y $(n=37)$ & 18.9 & & $0.3(0.1-0.8)$ \\
\hline Sex & & 0.63 & \\
\hline Male $(n=79)$ & 29.1 & & 1 \\
\hline Female $(n=74)$ & 25.7 & & $0.8(0.4-1.7)$ \\
\hline Educational level & & 0.70 & \\
\hline Low $(n=62)$ & 24.2 & & 1 \\
\hline Moderate $(n=50)$ & 28.0 & & $1.2(0.5-2.8)$ \\
\hline High $(n=41)$ & 31.7 & & $1.5(0.6-3.5)$ \\
\hline Insurance & & 0.61 & \\
\hline Private/Civil servant $(n=62)$ & 29.0 & & 1 \\
\hline $\mathrm{NHI}^{\mathrm{b}}(n=91)$ & 25.3 & & $0.8(0.4-1.7)$ \\
\hline Duration of disease & & 0.72 & \\
\hline$<1$ year $(n=15)$ & 26.7 & & 1 \\
\hline $1-2$ years $(n=20)$ & 35.0 & & $1.5(0.3-6.4)$ \\
\hline$>2-5$ years $(n=41)$ & 22.0 & & $0.8(0.2-3.0)$ \\
\hline$>5-10$ years $(n=37)$ & 35.1 & & $1.5(0.4-5.6)$ \\
\hline$>10$ years $(n=32)$ & 28.1 & & $1.1(0.3-4.3)$ \\
\hline Family members with glaucoma & & 0.96 & \\
\hline Yes $(n=56)$ & 28.6 & & 1 \\
\hline No $(n=57)$ & 26.3 & & $0.9(0.4-2.0)$ \\
\hline Don't know $(n=38)$ & 26.3 & & $0.9(0.4-2.3)$ \\
\hline Medication & & 0.06 & \\
\hline Beta blocker $(n=48)$ & 22.9 & & 1 \\
\hline Xalatan $(n=47)$ & 21.3 & & $0.9(0.3-2.4)$ \\
\hline Combination $^{c}(n=24)$ & 50.0 & & $3.4(1.2-9.6)$ \\
\hline Other $(n=35)$ & 25.7 & & $1.2(0.4-3.2)$ \\
\hline Surgery/laser treatment & & 0.08 & \\
\hline None $(n=97)$ & 25.8 & & 1 \\
\hline Laser only $(n=30)$ & 43.3 & & $2.2(0.9-5.2)$ \\
\hline Surgery only/surgery + laser $(n=23)$ & 17.4 & & $0.6(0.2-2.0)$ \\
\hline
\end{tabular}

${ }^{a} \mathrm{CI}=$ confidence interva

${ }^{\mathrm{b}} \mathrm{NHI}=$ National Health Insurance

${ }^{c}$ i.e. $\geq 2$ different bottles

\section{Psychosocial determinants, barriers and skills}

The proportion of patients who admitted to having forgotten to administer their eye drops once or more, was $26.7 \%$ (39/146). Other psychosocial reasons were reported by $0.7 \%$ to $4.2 \%$ of the patients (Table 3 ).

Twenty-three patients out of 145 (15.9\%) reported that they had omitted their medication once or more than once because they did not have eye drops or gel with them (Table 4). All other barriers were reported as a reason for omission of eye drops by less than $5 \%$ of the patients.

Generally, difficulties with the correct administration of eye drops were reported by a greater proportion of patients as a reason for omission of doses than were psychosocial causes or barriers (Table 4). Difficulties with holding the bottle properly above their eye were most often reported ( $16 \%$ of the patients).

Finally, $50 \%$ of the patients indicated that they would like to receive more information on how to administer eye drops correctly (data not shown).

Table 3. Psychosocial determinants of non-adherence in glaucoma patients.

\begin{tabular}{|c|c|c|c|c|c|c|}
\hline \multirow[t]{2}{*}{ Reason } & \multicolumn{2}{|c|}{$\begin{array}{l}\text { Never } \\
\text { missed }\end{array}$} & \multicolumn{2}{|c|}{$\begin{array}{l}\text { Missed } \\
\text { once }\end{array}$} & \multicolumn{2}{|c|}{$\begin{array}{l}\text { Missed } \\
\text { more than } \\
\text { once }\end{array}$} \\
\hline & $\mathrm{n}$ & $\%$ & $\mathrm{n}$ & $\%$ & $\mathrm{n}$ & $\%$ \\
\hline \multicolumn{7}{|l|}{ Psychosocial determinants } \\
\hline I forgot to take the eye drops $(n=146)$ & 107 & 73.3 & 23 & 15.7 & 16 & 11.0 \\
\hline I found putting eye drops in my eye to be such a nuisance ( $n=143$ ) & 137 & 95.8 & 2 & 1.4 & 4 & 2.8 \\
\hline I suffered from side-effects $(n=144)$ & 139 & 96.5 & 2 & 1.4 & 3 & 2.1 \\
\hline I did not consider my glaucoma serious enough $(n=143)$ & 138 & 96.5 & 4 & 2.8 & 1 & 0.7 \\
\hline I did not use the eye drops at certain points in time ( $n=147)$ & 142 & 96.6 & 2 & 1.4 & 3 & 2.0 \\
\hline I thought they would do more harm than good $(n=144)$ & 140 & 97.2 & 1 & 0.7 & 3 & 2.1 \\
\hline I found using eye drops uncomfortable $(n=143)$ & 139 & 97.2 & 2 & 1.4 & 2 & 1.4 \\
\hline I thought that it would not help anyway $(n=144)$ & 141 & 97.9 & 1 & 0.7 & 2 & 1.4 \\
\hline I already had to take the eye drops so often $(n=143)$ & 140 & 97.9 & 2 & 1.4 & 1 & 0.7 \\
\hline I thought I would be able to do without eye drops or gel $(n=142)$ & 140 & 98.6 & 0 & 0.0 & 2 & 1.4 \\
\hline I used the eye drops when it suited me ( $n=143)$ & 141 & 98.6 & 1 & 0.7 & 1 & 0.7 \\
\hline My glaucoma did not deteriorate $(n=143)$ & 141 & 98.6 & 0 & 0.0 & 2 & 1.3 \\
\hline I can still see well $(n=143)$ & 141 & 98.6 & 0 & 0.0 & 2 & 1.4 \\
\hline I did not consider it important to use the eye drops ( $n=143$ ) & 141 & 98.6 & 0 & 0.0 & 2 & 1.4 \\
\hline $\begin{array}{l}\text { I thought that I did not have to use the eye drops because my eyes } \\
\text { were giving me trouble }(n=143)\end{array}$ & 141 & 98.6 & 0 & 0.0 & 2 & 1.4 \\
\hline I thought that I would not become blind anyway $(n=141)$ & 140 & 99.3 & 0 & 0.0 & 1 & 0.7 \\
\hline Because others did not consider it important $(n=143)$ & 142 & 99.3 & 0 & 0.0 & 1 & 0.7 \\
\hline Because my partner thought it to be unnecessary $(n=143)$ & 143 & 100.0 & & & & \\
\hline
\end{tabular}


Table 4. Barriers and skills as reasons for non-adherence in glaucoma patients.

\begin{tabular}{|c|c|c|c|c|c|c|}
\hline \multirow[t]{2}{*}{ Reason } & \multicolumn{2}{|c|}{$\begin{array}{l}\text { Never } \\
\text { missed }\end{array}$} & \multicolumn{2}{|c|}{$\begin{array}{l}\text { Missed } \\
\text { once }\end{array}$} & \multicolumn{2}{|c|}{$\begin{array}{l}\text { Missed } \\
\text { more } \\
\text { than once }\end{array}$} \\
\hline & $\mathrm{n}$ & $\%$ & $\mathrm{n}$ & $\%$ & $\mathrm{n}$ & $\%$ \\
\hline \multicolumn{7}{|l|}{ Barriers } \\
\hline I did not have eye drops, gel or salve with me ( $n=145)$ & 122 & 84.1 & 17 & 11.7 & 6 & 4.2 \\
\hline The eye drops, gel or salve had run out $(n=147)$ & 141 & 95.9 & 6 & 4.1 & 0 & 0.0 \\
\hline $\begin{array}{l}\text { I suffered from another illness that prevented me from } \\
\text { administering the eye drops properly }(n=145)\end{array}$ & 142 & 97.9 & 3 & 2.1 & 0 & 0.0 \\
\hline $\begin{array}{l}\text { I did not have anyone to assist me with administering the eye } \\
\text { drops }(n=145)\end{array}$ & 144 & 99.3 & 1 & 0.6 & 0 & 0.0 \\
\hline $\begin{array}{l}\text { I did not know how often or at what time I had to use the eye } \\
\text { drops }(n=145)\end{array}$ & 144 & 99.3 & 1 & 0.7 & 0 & 0.0 \\
\hline I did not quite understand the prescription $(n=144)$ & 144 & 100.0 & & & & \\
\hline \multicolumn{7}{|l|}{ Skills } \\
\hline I was not able to hold the bottle properly above my eye $(n=149)$ & 125 & 83.9 & 12 & 8.1 & 12 & 8.1 \\
\hline I did not feel whether the drop landed in my eye $(n=144)$ & 128 & 88.9 & 8 & 5.6 & 8 & 5.6 \\
\hline I touched my eye with the bottle $(n=145)$ & 129 & 89.0 & 13 & 9.0 & 3 & 2.1 \\
\hline I could not see the bottle above my eye well $(n=147)$ & 132 & 89.8 & 8 & 5.4 & 7 & 4.8 \\
\hline I was not able to squeeze the bottle well $(n=147)$ & 137 & 93.2 & 5 & 3.4 & 5 & 3.4 \\
\hline I was not able to pull my eyelid down sufficiently ( $n=147)$ & 139 & 94.6 & 4 & 2.7 & 4 & 2.7 \\
\hline $\begin{array}{l}\text { I did not know well how to administer the eye drops properly } \\
(n=145)\end{array}$ & 143 & 98.6 & 2 & 1.4 & 0 & 0.0 \\
\hline I found it difficult to remove the cap from the bottle ( $n=145$ ) & 144 & 99.3 & 1 & 0.7 & 0 & 0.0 \\
\hline I could not hold the bottle well $(n=146)$ & 145 & 99.3 & 1 & 0.7 & 0 & 0.0 \\
\hline It was difficult to open the sealed bottles $(n=145)$ & 145 & 100.0 & & & & \\
\hline
\end{tabular}

\section{Discussion}

Non-adherence to topical hypotensive treatment continues to be a considerable obstacle in the treatment of glaucoma patients, despite the recent development of drugs with relatively simpler treatments and fewer side-effects. In order to make a thorough inventory of the theoretically relevant determinants of non-adherence and their frequency distribution in glaucoma patients, we systematically developed an extensive questionnaire, including questions on psychosocial aspects, potential barriers and skills.

The systematically developed questionnaire, based on focus group interviews, opinions of experts and a pilot test, included various causes of non-adherence. As the questions were formulated in plain Dutch and 95\% of non-adherent patients reported one or more causes of non-adherence, socially acceptable responses are not expected. The risk of recall bias was minimized by asking about the previous 4 weeks. Moreover, $29.7 \%$ of the questionnaires were not returned for analysis, and it is not known whether patients who refused to be included were adherent or non-adherent. Possible bias in the interpretation of the data from this ignorance cannot be excluded. Reasons suggested by patients for not participating were cognitive dysfunction, language barriers and lack of time. Incentives were included for both the ophthalmologists and the patients to improve participation, and all ophthalmologists were contacted by telephone after 2 to 3 weeks and by mail after 6 to 8 weeks. Concerning the selection of patients, it is difficult to assess case order. As described earlier, selection bias was minimized by asking ophthalmologists to invite four consecutive patients to participate. It was the best method for reducing selection bias when compared to the situation in which each ophthalmologist selects one patient, or when compared to alternative methods that select patients in non-randomly selected hospitals, during pharmacy visits or from members of the Glaucoma Patient Society.

In this study adherence was defined quite strictly as missing an eye drop once or more. Different studies use varying definitions of adherence and different assessment methods. Several studies define adherence as strictly as we did. ${ }^{11,16-21}$ Our result of $27.3 \%$ non-adherent patients corresponds with those of other reports that used questionnaires ${ }^{22,23}$, pharmacy refill records ${ }^{8,24}$ or electronic medication monitors ${ }^{25}$ to assess adherence. Based on a systematic review of 569 studies from 1948 to 1998 , involving 17 disease conditions, an average non-adherence rate of $24.8 \%$ was found and a non-adherence rate of $27.4 \%$ was found for eye disorders. ${ }^{26}$ Although self-reported adherence is a subjective measure of adherence, it has been shown to be a much better measure of adherence than one believed formerly. Adherence data assessed by electronic monitoring and a medication diary were comparable in cancer patients with pain. ${ }^{27}$ In a comparison of various methods for measuring adherence to HIV protease inhibitors, patients' self-reported adherence showed relatively high and significant correlations with results from medication event monitoring systems. ${ }^{28}$

Our study shows that forgetfulness, unavailability of medication and insufficient skills for the most part contributed to the omission of doses. Side effects, social influence, inconvenience of therapy or a negative attitude towards the treatment only played a minor role. Furthermore, younger patients and those receiving a combination therapy ( $\geq 2$ different bottles) were significantly more likely to be non-adherent. 
Our findings are consistent with that of various studies which report forgetfulness as one of the major causes cited by glaucoma patients for the omission of prescribed doses. ${ }^{3,12,17,21,29}$ An intuitively obvious and often cited reason why glaucoma patients forget to take their eye drops is that there is no immediate disability from the disease and no direct advantage from the eye drops. ${ }^{5}$ Non-acceptance of the disease as well as the necessity of chronic treatment may also be part of the cause. Tsai et al. categorized obstacles to medication adherence. Forty-nine percent of obstacles were categorized as social/environmental, $32 \%$ reflected regimen factors en $16 \%$ involved individual patient factors. Only $3 \%$ of reported causes of non-adherence were of medical provider origin. ${ }^{11}$

Insufficient skills or a lack of manual dexterity in many, especially older glaucoma patients or patients with co-morbidities have been recognized by different researchers. ${ }^{1,3,12,13,23,30,31}$ Winfield et al. showed that about half of patients experienced technical difficulties with eye-drop administration, such as aiming, squeezing and blinking. ${ }^{23}$ They reported that $72 \%$ of patients were never asked if they had any problems, and that $69 \%$ would not report any problems to their doctor even if asked. ${ }^{23}$ Sleath et al. also showed that $44 \%$ of patients experienced difficulty with drop administration, and $14 \%$ of patients had trouble squeezing the bottle. ${ }^{13}$ Our study agrees with these findings, as it shows that many patients are having difficulties in correctly administering eye drops, and that many patients require information on this issue.

Our result (that patients receiving a combination therapy were less adherent) corresponds to findings of Robin et al., who reported a significant increase in refill intervals after the addition of a second drug. ${ }^{32}$ Moreover, Sleath et al. found that patients using more glaucoma medications experienced problems with the application of their therapy more often than patients taking fewer glaucoma medications. ${ }^{13}$ Being treated with various topical medications at the same time might be confusing for some, especially older, patients, and seems an obvious reason for non-adherence. A recently undertaken study has objectively measured adherence by the use of electronic monitoring, and found that poorer adherence was associated with more complex regimens, although once-daily drugs in a complex dosing regimen resulted in good adherence. ${ }^{33}$ They found a higher percentage of adherence than in our findings, which could be explained by the fact that patients in the study of Robin et al. were informed that their dosing behavior was being monitored. ${ }^{33}$ While some studies suggest that reducing dose frequency will enhance adherence ${ }^{9,34-36}$, it has also been reported that many patients say that it would not make it easier to adhere to the regimen, although it would be more convenient, and patients prefer one drop once a day in terms of lifestyle. ${ }^{11,37,38}$ Stewart et al. reported that $74 \%$ of physicians believed their patients would prefer once a day dosing, and $92 \%$ of physicians believed it would improve adherence. However, only $20 \%$ of patients believed they would be more adherent if they had a once a day dosing regimen. ${ }^{37}$

The same association seems to exist for side-effects. Taylor et al. showed that only a few patients report non-adherence because of side-effects, while a lot of patients complain about them. ${ }^{12}$ Jampel et al. show in a willingness-to-pay analysis that patients place differing value on certain eye-drop characteristics. Patients were especially willing to pay more for eye drops that did not produce blurring of vision, drowsiness or inhibition of sexual performance. Patients were least willing to pay more for reduction of dose frequency, and for a combination of two medications in one bottle rather than two bottles. ${ }^{39}$ We think that a drug regimen with lower dosing frequency and fewer side-effects probably will not be the only solution for the adherence problem.

In our study, patients younger than 55 years of age were significantly less adherent than older patients. The working situation of this younger group, which does not allow the regular use of eye drops, or inconvenient effects such as blurred vision that hinder people in doing their work, might provide an explanation for this difference. ${ }^{29}$ However, this study was not designed to discover why younger patients would be less adherent and no cause-effect relationship can be concluded because of the cross-sectional design of the study. An evidence-based review reported nine studies that had investigated the relation between age and non-adherence, and found that none of them reported significant results. ${ }^{9}$

The finding that patients who had undergone laser therapy tended to be at higher risk of being non-adherent has to be interpreted with caution. Since the underlying study was cross-sectional, a cause-effect relationship cannot be concluded. Patients who had undergone laser therapy might be a selected group of non-adherent patients who had undergone laser therapy because topical hypotensive treatment was ineffective.

Several intervention studies have already tested the effect of a memory aid ${ }^{18,19,40}$ or an education and tailoring program ${ }^{41}$ on the prevalence of omission of doses. These studies lacked different aspects of trial quality, yet they all reported a small, but 
significant improvement of patient adherence. However, there are no data available on the effects of the different interventions in the long run, or on the feasibility or cost-effectiveness of their implementation in daily clinical routine. Newer dosing aids combine alarm features with a dosing lever, and register adherence data. ${ }^{42,43}$ Others suggest written instructions as a simple and inexpensive intervention, as written instructions improved the accuracy of self-reporting medication regimen. ${ }^{44}$ Medication reviews are also seen as a tool for improving adherence..$^{45}$ Systematic reviews have shown that several types of interventions, such as technical, educational, behavioral and combined interventions, are effective in improving medication adherence in chronic medical disorders, but the effect on clinical outcomes was small. ${ }^{35,36}$ However, DiMatteo et al. and Hugen et al. have shown that non-adherence increases the risk of poor outcome of medical treatments. ${ }^{6,28}$ In general, the most powerful intervention is believed to consist of a combination of educational, behavioural and affective components. ${ }^{46}$ No single intervention appears to be superior. ${ }^{47}$

Although the present study has not proved it, we expect that adherence-enhancing interventions should pay special attention to the reduction of patient forgetfulness as well as the improvement of medication administration skills. An intervention focusing on other psychosocial determinants or barriers seems unnecessary. In patients in whom the intraocular pressure continues to be high, or progression of visual field loss occurs despite the prescription of a potent anti-glaucoma drug, patients' skills in administering eye drops should be checked, and the use of a dosing aid or memory aid should be considered before turning to laser or surgical therapy.

\section{References}

1. Busche S, Gramer E. Verbesserung der Augentropfenapplikation und Compliance bei Glaukompatienten; eine klinische Studie. [Improvement of compliance and eyedrop administration in glaucoma patients with combined therapy.] Klin Monatsbl Augenheilkd 1997;211:257-62.

2. Forsman E, Kivel T, Vesti E. Lifetime visual disability in open-angle glaucoma and ocular hypertension. J Glaucoma 2007;16:313-9.

3. Konstas AG, Maskaleris G, Gratsonidis S, Sardelli C. Compliance and viewpoint of glaucoma patients in Greece. Eye 2000;14:752-6.

4. Lee DA, Fechtner RD, Fiscella RG, et al. Emerging perspectives on glaucoma: highlights of a roundtable discussion. Am J Ophthalmol 2000;130:S1-S11.

5. Zimmerman TJ, Zalta AH. Facilitating patient compliance in glaucoma therapy. Surv Ophthalmol 1983;28:252-7.

6. DiMatteo MR, Giordani PJ, Lepper HS, Croghan TW. Patient adherence and medical treatment outcomes; a meta-analysis. Med Care 2002;40:794-811

7. Deokule S, Sadiq S, Shah S. Chronic open angle glaucoma: patient awareness of the nature of the disease, topical medication, compliance and the prevalence of systemic symptoms. Ophthal Physiol Opt 2004;24:9-15.

8. Gurwitz JH, Yeomans SM, Glynn RJ, et al. Patient noncompliance in the managed care setting; the case of medical therapy for glaucoma. Med Care 1998;36:357-69.

9. Olthoff CM, Schouten JS, Van de Borne BW, Webers CA. Noncompliance with ocular hypotensive treatment in patients with glaucoma or ocular hypertension. Ophthalmology 2005;112:953-61.

10. Rotchford AP, Murphy KM. Compliance with timolol treatment in glaucoma. Eye 1998;12:234-6.

11. Tsai JC, McClure CA, Ramos SE, et al. Compliance barriers in glaucoma: a systematic classification. J Glaucoma 2003;12:393-8.

12. Taylor S, Galbraith S, Mills R. Causes of non-compliance with drug regimens in glaucoma patients: a qualitative study. J Ocul Pharmacol Ther 2002;18:401-9.

13. Sleath B, Robin AL, Covert D, et al. Patient-reported behavior and problems in using glaucoma medications. Ophthalmology 2006;113:431-6.

14. Elliot R, Barber N, Horne R. Cost-effectiveness of adherence-enhancing interventions: a quality assessment of the evidence. Ann Pharmacother 2005;39:508-15.

15. Meertens R, Schaalma H, Brug J, de Vries N. Determinanten van gedrag. [Determinants of behavior]. In: Brug J, Schaalma H, Kok G, Meertens RM, Van der Molen HT (Eds). Gezondheidsvoorlichting en Gedragsverandering; een Planmatige Aanpak [Health promotion and behavior change: a systematic approach]. Van Gorcum, Assen, Netherlands 2000:pp 55-72.

16. Amon M, Menapace R, Wedrich A, Radax U. Aspekte der Betreuung von Glaukompatienten und deren Auswirkung auf die Compliance. [Aspects of glaucoma patient care and its impact on compliance.] Spektrum Augenheilkd 1990;4:5-8. 
17. Bour T, Blanchard F, Segal A. Therapeutic observance and life of patients with primary open-angle glaucoma. Apropos of 341 cases in the department of Marne [Observance therapeutique et vecu du glaucome primitif a angle ouvert. A propos de 341 cas dans la Marne]. J Fr Ophtalmol 1993;16:38091.

18. Chang J, Lee D, Petursson G, et al. The effect of a glaucoma medication reminder cap on patient compliance and intraocular pressure. J Ocul Pharmacol 1991;7:117-24.

19. Laster S, Martin J, Fleming J. The effect of a medication alarm device on patient compliance with topical pilocarpine. J Am Optom Assoc 1996;67:654-8.

20. MacKean JM, Elkington AR. Compliance with treatment of patients with chronic open-angle glaucoma. Br J Ophthalmol 1983;67:46-9.

21. Patel SC, Spaeth GL. Compliance in patients prescribed eyedrops for glaucoma. Ophthalmic Surg 1995;26:233-6.

22. Bloch S, Rosenthal AR, Friedman DS, Caldarolla P. Patient compliance in glaucoma. Br J Ophthalmol 1977;61:531-4.

23. Winfield AJ, Jessiman D, Esakowitz L. A study of the causes of non-compliance by patients prescribed eyedrops. Br J Ophthalmol 1990;74:477-80.

24. Gurwitz JH, Glynn RJ, Monane M, et al. Treatment for glaucoma: adherence by the elderly. Am J Public Health 1993;83:711-6.

25. Kass MA, Meltzer DW, Gordon M, et al. Compliance with topical pilocarpine treatment. Am J Ophthalmol 1986;101:515-23.

26. DiMatteo MR. Variations in patients' adherence to medical recommendations; a quantitative review of 50 years of research. Med Care 2004;42:200-9.

27. Oldenmenger W, Echteld $M$, Wit de R, et al. Analgesic adherence measurement in cancer patients: comparison between electronic monitoring and diary. J Pain Symptom Manage 2007;34:639-47.

28. Hugen P, Langebeek N, Burger D, et al. Assessment of adherence to HIV protease inhibitors: comparison and combination of various methods, including MEMS (electronic monitoring), patient and nurse report, and therapeutic drug monitoring.J Acquir Immune Defic Syndr 2002;30:324-34.

29. Kosoko O, Quigley HA, Vitale S, et al. Risk factors for noncompliance with glaucoma follow-up visits in a residents's eye clinic. Ophthalmology 1998;105:2105-11.

30. Brown M, Brown G, Spaeth G. Improper topical self-administration of ocular medication among patients with glaucoma. Can J Ophthalmol 1984;19:2-5.

31. Dietlein TS. Glaukom im Alter; Barrieren fur Aufklarung und Compliance. Ophthalmologe 2006;103:755-8.

32. Robin AL, Covert D. Does adjunctive glaucoma therapy affect adherence to the initial primary therapy? Ophthalmology 2005;112:863-8.

33. Robin A, Novack G, Covert D, et al. Adherence in glaucoma: objective measurements of once-daily and adjunctive medication use. Am J Ophthalmol 2007;144:533-40.

34. Mansukani SS. Improving adherence to drug-treatment regimens for glaucoma. Manag Care
2002;11:49-53.

35. Kripalani S, Yao X, Haynes B. Interventions to enhance medication adherence in chronic medical conditions; a systematic review. Arch Intern Med 2007;167:540-50.

36. Dulmen van S, Sluijs E, Dijk van L, et al. Patient adherence to medical treatment: a review of reviews. BMC Health Serv Res 2007;7:55

37. Stewart WC, Konstas AG, Pfeiffer N. Patient and ophthalmologist attitudes concerning compliance and dosing in glaucoma treatment. J Ocular Pharmacol Ther 2004;20(6):461-9.

38. Buller AJ, Morgan LH, Hercules BL. Patients prefer one-daily glaucoma drops. Graefes Arch Clin Exp Ophthalmol 2007;245:293-4.

39. Jampel HD, Schwartz GF, Robin AL, et al. Patient preferences for eye drop characteristics. Arch Ophthalmol 2003;121:540-6.

40. Sclar D, Skaer T, Chin A. Effectiveness of the C Cap in promoting prescription refill compliance among patients with glaucoma. Clin Ther 1991;13:396-400

41. Norell SE. Improving medication compliance: a randomised clinical trial. Br Med J 1979;2:1031-3.

42. Flowers B, Wand M, Piltz-Seymour J, et al. Patients' and physicians' perceptions of the Travoprost dosing aid: an open-label, multicenter study of adherence with prostaglandin analogue therapy for open-angle glaucoma or ocular hypertension. Clin Ther 2006;28:1803-11.

43. Boden C, Sit A, Weinreb RN. Accuracy of an electronic monitoring and reminder device for use with travoprost eye drops. J Glaucoma 2006;15:30-4

44. Kharod BV, Johnson PB, Nesti HA, Rhee DJ. Effect of written instructions on accuracy of selfreporting medication regimen in glaucoma patients. J Glaucoma 2006;15:244-7

45. Lefante JJ, Harmon GN, Roy W, et al. The effect of medication reviews in a rural community pharmacy assistance program: the cenla medication access program. J Pharm Pract 2005;18:486-

46. Roter DL, Hall JA, Merisca R, et al. Effectiveness of interventions to improve patient compliance; a meta-analysis. Med Care 1998;36:1138-61

47. Peterson A, Takiya L, Finley R. Meta-analysis of trials of interventions to improve medication adherence. Am J Health Syst Pharm 2003;60:657-65. 


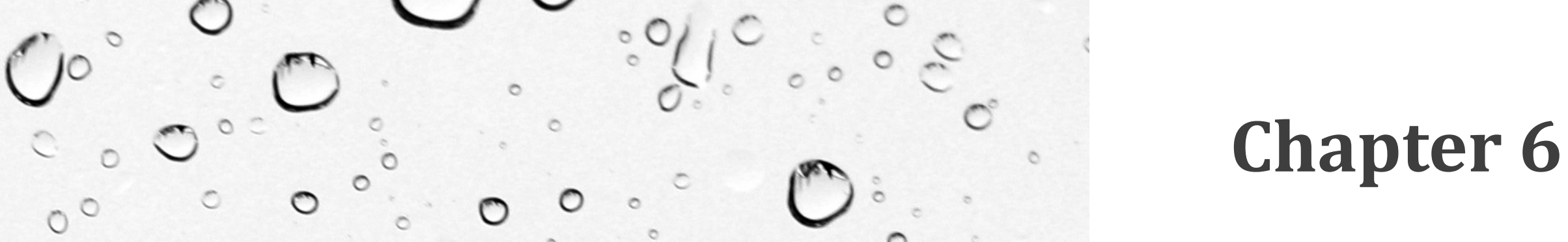

A practical tool to identify and improve non-adherence as a cause of unachieved target pressure in glaucoma patients

Juliette G.M.M. Hoevenaars

Jan S.A.G. Schouten

Kenny J.M. Beckers

Carroll A.B. Webers

Submitted 


\section{Abstract}

\section{Purpose}

To study to what extent clinically identifiable adherence related issues contribute to achieving target pressure and quantify to what extent addressing these issues could improve glaucoma treatment outcome.

\section{Materials and Methods}

Data from 3640 medical records and questionnaires completed by patients were used retrospectively. The relation between number of patients achieving target pressure and patients' type of glaucoma, number of days medication not used, last dosage moment, side effects, discontinuing eye drops because of side effects and satisfaction with eye drops was studied. Relative risks, attributable risks, prevalence and population attributable risks were calculated for last dosage moment and discontinuing eye drops.

\section{Results}

Included patients consisted of 2765 patients (76\%) treated for their right eye and 2770 patients $(76 \%)$ treated for their left eye. Not achieving the target pressure was related to a diagnosis of primary open-angle glaucoma, not using medication in more than $43 \%$ of time, dissatisfaction with eye drops, incorrect last dosage moment and discontinuing eye drops because of side effects. Between $7 \%$ and $9 \%$ improvement in achieved target pressure could be realised when addressing these last two issues.

\section{Conclusions}

Four questions can be asked to discover if non-adherence is a reason for not reaching target pressure: How many days did you not use you eye drops in the last two weeks? Are you satisfied with your eye drops? When did you use your last eye drop? Did you discontinue using eye drops because of side effects? Improvement in achieved target pressure can be realised by addressing the correct dosage moment and discontinuation of eye drops.

\section{Introduction}

Ophthalmologists are regularly confronted with glaucoma patients who do not achieve their target intraocular pressure (IOP) after treatment is started. The response could be to replace the current drug with another drug or add another drug. However, this may not be the most fruitful approach since the cause of not achieving the target pressure could be related to non-adherence issues. In case the target IOP is not achieved because of non-adherence, changing therapy to a new drug may not lead to a lower IOP because of non-adherence to the new drug regimen as well.

Unfortunately, thereareno patientcharacteristics thatidentifynon-adherentpatients easily. ${ }^{1}$ The development of a physician-usable risk-assessment tool to monitor and predict non-adherence has been recommended ${ }^{2}$ since ophthalmologists' skills to detect non-adherence appear to be poor..$^{3-6}$ Ophthalmologists in the Glaucoma Adherence and Persistency Study believed that $23 \%$ of patients were clinically relevant non-adherent and that they could identify $37 \%$ of those patients. ${ }^{7}$

Sleath et al. developed a patient self-efficacy scale that can be used to detect patients with low confidence and non-adherence in using their glaucoma medication. ${ }^{8-10}$

Hahn described several specific communication strategies to detect non-adherence and to identify and address adherence barriers. ${ }^{11}$ Addressing adherence, preferentially based on open-ended questions, is a time consuming activity and requires a tailored, patient-centered approach. ${ }^{11,12}$ Ideally, an ophthalmologist should be able to identify, address and improve adherence by the use of a few questions resulting in a larger proportion of patients achieving their target pressure.

The purpose of this study was to study to what extent adherence related issues contribute to achieving the target pressure and to investigate to what extent addressing these issues would improve treatment outcome.

\section{Materials and Methods}

For this study, we used data from the DURING (DUtch Research project on treatment outcome IN Glaucoma patients) study. In nine randomly selected Dutch hospitals, patients with ocular hypertension or glaucoma were identified between March 2001 and January 2004. All patients were at least medically treated. The hospitals 
included academic, teaching and non-teaching centres. The ethical committees from all participating hospitals approved this study. Patients aged 18 years or older who were able to read and write Dutch were asked to participate. Written informed consent was obtained from all patients. ${ }^{13,14}$

The study was conducted in adherence to the Helsinki declaration. It was an observational study based on medical records and questionnaires. No interventions were conducted. All ophthalmologists recorded the patients' type of glaucoma, a target pressure for both eyes and the moment of use of the last dosage of eye drops (e.g. this afternoon, this morning, yesterday evening, yesterday afternoon, yesterday morning or longer ago). Data concerning the IOP and prescribed medication were collected from medical records. Timing of the last dosage was classified as being correct based on the type of prescribed medication and the moment of last dosage of eye drops. Patients were asked to complete a questionnaire on adherence (see table 1).

To create a new measure for the degree of side effects, the product of the response values for the two questions, "how many days did you suffer from side effects" and "how much did you suffer from side effects" was calculated. The response values per question ranged from 0 to 5 and from 0 to 4 respectively. This gives a new value ranging from 0 to $20(=5 \times 4)$. For example, a patient who suffered almost every day quite some burden, had a product of eight.

Table 1. Questions included in questionnaire and their response categories.

Question: How many days did you not use your eye drops in the last two weeks?

Responses: 0 days, 1 day, 2 days, 3 days, 4 or 5 days, 6 or 7 days, 8 or 9 days, 10 or 11 days, 12 or 13 days, 14 days.

Question: How many days did you suffer from the following side effects from your eye drops in the last two weeks?*

Responses: not a single day, 1 day, few days, half of the days, almost every day, every day (value 0-5).

Question: How much did you suffer from the following side effects from your eye drops in the last two weeks?*

Responses: no burden, a little burden, quite some burden, a lot of burden, very much burden (value 0-4). Question: Did you (temporary) stop using your eye drops because of side effects in the last two weeks? Responses: yes, no.

Question: How satisfied have you been with your eye drops in the last two weeks?

Responses: Very unsatisfied, unsatisfied, a little unsatisfied, neutral, a little satisfied, satisfied and very

*side effects: burning or stinging of the eyes; redness of the eyes; itching eyes; discharge of the eyes; ocular pain; tearing eyes; brow ache; dry eyes; foreign body sensation; eyelid redness; eyelid oedema; blurred vision; visual acuity loss; accommodation difficulties; reading difficulties; night vision problems; bitter taste; strange taste in the mouth; dry mouth; dry nose, running nose, stuffy nose; attacks of shortness of breath; slower heart beat; loss of appetite; headache, tiredness; sleepiness.
We studied the relation between the number of patients achieving the target pressure with patients' type of glaucoma, number of days medication not used, last dosage moment, side effects, discontinuing the use of eye drops because of side effects and satisfaction with eye drops. Statistical analyses were performed using SPSS software for Windows. An analysis of variance was conducted to compare the IOP en target pressure between different categories of a variable. A logistic regression analysis was conducted to examine statistically significant differences in achieving target pressure between different categories of a variable. Dummy variables were used to create the categories and adjustments were made for age and gender. We calculated relative risks, attributable risks, prevalence and population attributable risks for the last dosage moment and discontinuing the use of eye drops.

\section{Results}

The data from 3640 patients were analyzed in this study. Since not all patients were prescribed the same medication regimen for both eyes, we analyzed both eyes separately. After excluding patients with missing IOP, target pressure or medication regimen, 2765 patients (76\%) receiving treatment for their right eye (RE) and 2770 patients $(76 \%)$ receiving treatment for their left eye (LE) were included. The percentage men was $50 \%$ in the group of patients treated for their right eye and $51 \%$ in the group treated for their left eye. The mean age was 70 (range 23-98) in both groups. The percentage of patients achieving their target pressure was $72 \%$ and $75 \%$ in the patients treated for their right and left eye respectively.

Statistical analyses showed that patients diagnosed with primary open-angle glaucoma (POAG) achieved their target pressure less often than patients diagnosed with ocular hypertension $(\mathrm{OH})$, glaucoma suspect (GS), primary angle-closure glaucoma (PACG) and chronic angle-closure glaucoma (CACG) (figure 1). As expected, the mean IOP and mean target pressure were higher in the $\mathrm{OH}$ group and lower in the normal-tension glaucoma (NTG) group as compared to the POAG group (data not shown). 


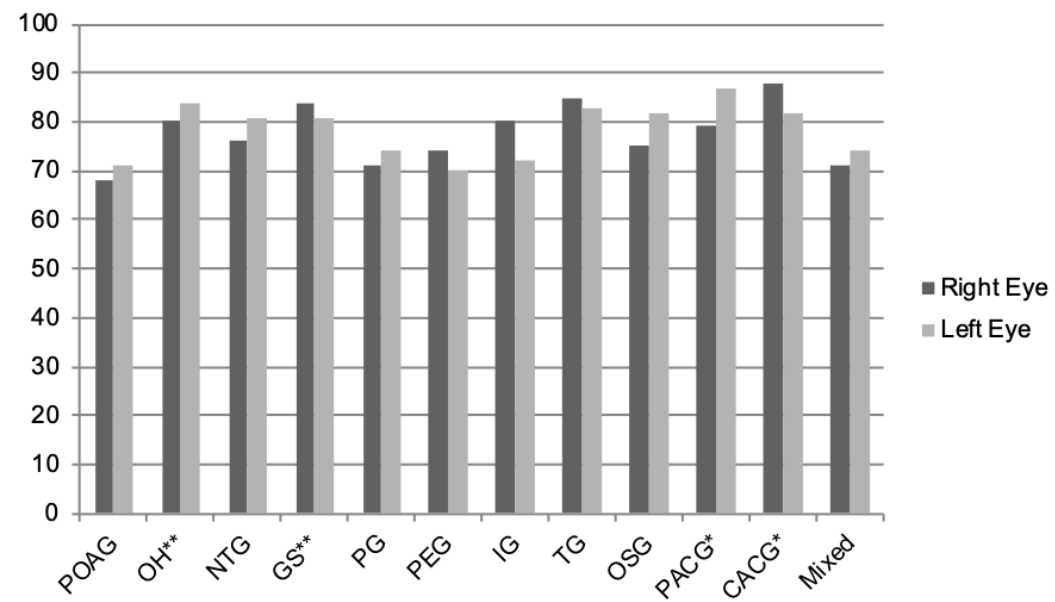

Figure 1. Percentage of patients achieving the target pressure for each type of glaucoma.

POAG=primary open-angle glaucoma; $\mathrm{OH}=$ ocular hypertension; $\mathrm{NTG=normal-tension} \mathrm{glaucoma;}$ GS=glaucoma suspect; $\mathrm{PG}=$ pigmentary glaucoma; $\mathrm{PEG}=$ pseudoexfoliative glaucoma; IG=inflammatory glaucoma: TG=traumatic glaucoma: $\mathrm{OSG}=$ other secondary glaucomas: $\mathrm{PACG}=$ primary angle-closure glaucoma; $\mathrm{CACG=chronic} \mathrm{angle-closure} \mathrm{glaucoma;} \mathrm{mixed=} \mathrm{mixture} \mathrm{of} \mathrm{different} \mathrm{types} \mathrm{of} \mathrm{glaucoma.}$

${ }^{*} \mathrm{p}<0.05$ in regression analyses compared with POAG for 1 eye.

** $\mathrm{p}<0.05$ in regression analyses compared with POAG for both eyes.

Table 2 shows that patients treated for their right and left eye achieved the target pressure significantly less often in at least one eye if they were not using eye drops 6-7 days out of 14 days or more.

Table 2. Percentage of patients achieving their target pressure related to the number of days not using their eye drops in the previous 14 days.

\begin{tabular}{|c|c|c|c|c|c|c|}
\hline \multirow{2}{*}{$\begin{array}{l}\text { Number of days } \\
\text { medication not used } \\
\left(\mathrm{n}=\mathrm{RE} / \mathrm{LE}^{*}\right)\end{array}$} & \multicolumn{3}{|c|}{ Right eye } & \multicolumn{3}{|c|}{ Left eye } \\
\hline & $\begin{array}{c}\text { \% patients } \\
\text { achieving } \\
\text { target } \\
\text { pressure }\end{array}$ & $\begin{array}{r}\text { Mean IOP } \\
(\mathrm{mmHg})\end{array}$ & $\begin{array}{c}\text { Mean } \\
\text { target } \\
\text { pressure } \\
(\mathrm{mmHg}) \\
\end{array}$ & $\begin{array}{c}\text { \% patients } \\
\text { achieving } \\
\text { target } \\
\text { pressure }\end{array}$ & $\begin{array}{l}\text { Mean IOP } \\
(\mathrm{mmHg})\end{array}$ & $\begin{array}{c}\text { Mean } \\
\text { target } \\
\text { pressure } \\
(\mathrm{mmHg}) \\
\end{array}$ \\
\hline $\begin{array}{ll}0 & (\mathrm{n}=1912 / 1914)\end{array}$ & 74 & 17.4 & 18.2 & 76 & 17.3 & 18.2 \\
\hline $1 \quad(n=257 / 260)$ & 73 & 17.5 & 18.3 & 77 & 17.3 & 18.2 \\
\hline $2 \quad(n=110 / 111)$ & 69 & 17.4 & 18.0 & 77 & 17.2 & 18.0 \\
\hline $3 \quad(n=51 / 48)$ & $86^{*}$ & 17.3 & 18.3 & 79 & 17.9 & 18.4 \\
\hline $4-5 \quad(n=29 / 28)$ & 72 & 17.4 & 18.2 & 68 & 17.5 & 17.8 \\
\hline $6-7 \quad(n=12 / 10)$ & $42^{*}$ & 18.6 & 17.8 & 80 & 17.2 & 18.3 \\
\hline $8-9 \quad(n=3 / 3)$ & 33 & 19.3 & 18.3 & 67 & 18.7 & 18.7 \\
\hline $10-11 \quad(n=7 / 7)$ & $14^{*}$ & $21.0^{*}$ & 16.3 & $29^{*}$ & $19.7^{*}$ & 16.1 \\
\hline $12-13 \quad(n=18 / 18)$ & $28^{*}$ & $20.4^{*}$ & 18.0 & $33^{*}$ & 19.2 & 17.6 \\
\hline $14 \quad(n=9 / 9)$ & 67 & 17.8 & 18.6 & $44^{*}$ & 18.9 & 18.3 \\
\hline
\end{tabular}

${ }^{*} \mathrm{p}<0.05$ in regression analyses compared to 0 days medication not used.
No relation was demonstrated between the degree of side effects and achieving the target pressure, even when patients with very high and low degree of side effects were compared. When analyzing the relation between each separate side effect and achieving the target pressure, five side effects showed a statistically significant relation with not achieving the target pressure. These included dry eyes, accommodation difficulties, night vision difficulties, tearing eyes and loss of appetite. No evident trend existed for the degree of side effects and not achieving the target pressure.

On the other hand, patients who discontinued using eye drops because of side effects achieved their target pressure less often (table 3). Nevertheless, only few patients discontinued using eye drops because of side effects.

Table 3. Percentage of patients achieving their target pressure related to the last dosage moment, stopping the use of eye drops because of side effects and satisfaction level.

\begin{tabular}{|c|c|c|c|c|c|c|}
\hline & \multicolumn{3}{|c|}{ Right eye } & \multicolumn{3}{|c|}{ Left eye } \\
\hline & $\begin{array}{c}\text { \% patients } \\
\text { achieving } \\
\text { target } \\
\text { pressure }\end{array}$ & $\begin{array}{l}\text { Mean IOP } \\
(\mathrm{mmHg})\end{array}$ & $\begin{array}{l}\text { Mean } \\
\text { target } \\
\text { pressure } \\
(\mathrm{mmHg}) \\
\end{array}$ & $\begin{array}{c}\text { \% patients } \\
\text { achieving } \\
\text { target } \\
\text { pressure }\end{array}$ & $\begin{array}{l}\text { Mean IOP } \\
(\mathrm{mmHg})\end{array}$ & $\begin{array}{c}\text { Mean } \\
\text { target } \\
\text { pressure } \\
(\mathrm{mmHg})\end{array}$ \\
\hline \multicolumn{7}{|c|}{ Last dosage moment; $\mathrm{n}=\mathrm{RE} / \mathrm{LE}^{\#}$} \\
\hline $\begin{array}{l}\text { Right } \\
n=2002 / 2007\end{array}$ & 74 & 17.2 & 18.1 & 77 & 17.2 & 18.1 \\
\hline $\begin{array}{l}\text { Wrong } \\
\mathrm{n}=690 / 688\end{array}$ & $66^{*}$ & $18.0^{*}$ & 18.2 & $69^{*}$ & $17.6^{*}$ & 18.0 \\
\hline \multicolumn{7}{|c|}{ (Not) stopped because of side effects; $n=R E / L E^{\#}$} \\
\hline $\begin{array}{l}\text { Not stopped } \\
n=2387 / 2384\end{array}$ & 74 & 17.4 & 18.2 & 76 & 17.3 & 18.1 \\
\hline $\begin{array}{l}\text { Stopped } \\
n=46 / 48\end{array}$ & $43^{*}$ & $20.4^{*}$ & 18.0 & $50^{*}$ & $19.2^{*}$ & 18.0 \\
\hline \multicolumn{7}{|c|}{ Satisfaction level of eye drops; $n=R E / L^{\#}$} \\
\hline $\begin{array}{l}\text { Satisfied } \\
\mathrm{n}=2242 / 2247\end{array}$ & 74 & 17.3 & 18.2 & 77 & 17.2 & 18.1 \\
\hline $\begin{array}{l}\text { Neutral } \\
n=105 / 107\end{array}$ & $66^{*}$ & 17.9 & 18.0 & $65^{*}$ & 17.8 & 18.1 \\
\hline $\begin{array}{l}\text { Dissatisfied } \\
n=89 / 82\end{array}$ & $55^{*}$ & $18.8^{*}$ & 18.3 & $51^{*}$ & $19.4^{*}$ & 18.4 \\
\hline
\end{tabular}

$* \mathrm{p}<0.05$ in regression analysis compared to the first group

\# number of patients in group of patients treated for their right/left eye.

The percentage of patients achieving their target pressure was significantly higher in the group of patients that used their last medication at the correct moment 
according to the instruction for the use of that drug, e.g. one drop in the evening for latanoprost (table 3). The eye drops were used at the wrong moment by 690 out of 2692 (26\%) patients. Of these patients 235 out of 690 did not achieve their target pressure. Not achieving the target pressure can be attributed to an incorrect last dosage moment in $24 \%$ of 235 patients. This is the attributable risk. This figure is not $100 \%$ since even in the 690 patients it is expected that some do not achieve their target pressure because of reasons encountered in every patient. This baseline risk is also present in patients who have an incorrect last dosage moment. The attributable part is the part of the risk really due to an incorrect dosage moment. The attributable risk shows the percentage of not achieving the target pressure that would not have occurred if the patient had used the correct dosage moment.

The population attributable risk can be calculated from the prevalence of the presence of the risk factor and the relative risk or attributable risk and in this case is $7 \%$. This implies that $7 \%$ improvement in achieving the target pressure can be achieved for the whole population of patients if the correct last dosage moment is achieved in these patients. This can be achieved by addressing these issues in the 756 patients who did not reach their target pressure. These numbers are also shown for the left eye and for discontinuing the use of eye drops because of side effects (table 4). The population attributable risk for discontinuing the use of eye drops because of side effects is $2 \%$.

Table 4. Analysis of relative risk, attributable risk, prevalence and population attributable risk for two non-adherence issues in patients with glaucoma.

\begin{tabular}{|c|c|c|c|c|}
\hline & Relative risk & Attributable risk & Prevalence* & Population attributable risk \\
\hline \multicolumn{5}{|c|}{ Wrong last dosage moment } \\
\hline $\begin{array}{l}\text { Right eye } \\
n=690\end{array}$ & 1.31 & 0.24 & 0.26 & 0.07 \\
\hline $\begin{array}{l}\text { Left eye } \\
\mathrm{n}=688\end{array}$ & 1.34 & 0.26 & 0.26 & 0.08 \\
\hline \multicolumn{5}{|c|}{ Stopped because of side effects } \\
\hline $\begin{array}{l}\text { Right eye } \\
n=46\end{array}$ & 2.17 & 0.54 & 0.02 & 0.02 \\
\hline $\begin{array}{l}\text { Left eye } \\
n=48\end{array}$ & 2.08 & 0.52 & 0.02 & 0.02 \\
\hline
\end{tabular}

Among the patients who did not achieve target pressure and did not use eye drops at the right moment, $26-32 \%$ can achieve their target pressure if they start using eye drops at the right moment. Among the patients who discontinued eye drops because of side effects, 8-9\% can achieve their target pressure if they do not stop anymore or start using another eye drop without side effects.

This implies that between 7\% and 9\% improvement in achieved target pressure could be realised when addressing these two issues. These issues need to be discussed in a total of 690 to $736(=690+46)$ patients by the ophthalmologist since these were the numbers that did not achieve the target pressure and also did not have a correct dosing moment or stopped because of side effects.

Dissatisfaction with eye drops was negatively associated with achieving the target pressure (table 3).

\section{Discussion}

In the current study we found that patients diagnosed with POAG achieved their target pressure significantly less often compared to patients with OH, GS, PNAG and CNAG. Furthermore, not achieving the target pressure was related to being non-adherent in more than $43 \%$ of the time, an incorrect last dosage moment, discontinuing the use of eye drops because of side effects and dissatisfaction with eye drops.

By addressing the correct dosage moment and discontinuation of eye drops because of side effects in patients that did not achieve their target pressure, a clinical relevant number of these patients can additionally achieve their target pressure. When addressing both issues between $7 \%$ and $9 \%$ of all glaucoma patients can realise an improvement in achieved target pressure.

A strength of this study is the large group of patients included. We acknowledge a possible overlap between the groups treated for the right and left eye, as most patients are treated for both eyes. However, this was the best way of dealing with different medication schedules for either eye. As expected, the results are fairly similar for both groups.

The advantage of a self-administered questionnaire is that it is relatively simple 
and inexpensive. We minimized the risk of recall bias by asking for non-adherence, side effects and satisfaction with eye drops in the previous two weeks. The risk of socially acceptable answers cannot be excluded completely.

Concerning side effects, there was no overall relation between the degree of side effects and achieving the target pressure. The interpretation of the five single side effects that appeared to have a statistically significant relation with achieving target pressure was difficult. There was no evident trend. For example, patients with some amount of dry eyes appeared to achieve their target pressure more often than patients with no signs of dry eyes. This can be explained by the possibility that people who do not use eye drops will have no side effects and patients who are very adherent will suffer from more side effects.

As the question concerning satisfaction with eye drops has been asked after the consultation, bias of these results cannot be excluded. Patient knowing they did not achieve their target pressure could be less satisfied.

The percentage of patients who achieved their target pressure appeared to be significantly higher in patients with a correct last dosage moment and in patients who did not discontinue using eye drops because of side effects. The efficiency of these questions could be considered high since an improvement in $7 \%$ to $9 \%$ in the number of patients achieving their target pressure could be achieved. These questions can be asked in a short time. They could serve as a useful starting point in discovering non-adherence and achieving better treatment results in the busy clinical practice.

Four major types of adherence barriers were identified by Tsai et al.: medication regimen, patient factors, provider factors, and situational or environmental factors. ${ }^{15}$ In a previous study we found that forgetfulness, unavailability of eye drops and difficulties with holding the bottle above the eye were the most cited reasons for non-adherence. ${ }^{16}$

Hahn has described a 4-step adherence assessment interview to detect nonadherence, an ask-tell-ask dialog with open-ended questions to identify patient motivating factors and a readiness-to-change staging model for tailoring interventions. ${ }^{11}$ Ideally one should apply these strategies to every glaucoma patient. However, the clinical reality with short consultation times does not allow the physician to apply these strategies to all patients. An alternative approach is to train support staff to address adherence issues, which gets around the patients' fear of disappointing the physician. ${ }^{11}$ Sleath et al. described a glaucoma medication self-efficacy and outcome expectations scale that can be used to detect patients that need more guidance with their therapy. ${ }^{8-10}$ Patients who were more confident in using their glaucoma medications were more adherent. Since the self-efficacy scale was significantly associated with adherence, the scale may help providers detect non-adherent patients. Providers could address specific challenges based on patients responses. ${ }^{8-10}$

The ultimate goal of addressing adherence is achieving better treatment results. Although adherence with topical hypotensive therapy is thought to be essential in the treatment of glaucoma, it is unknown what degree of adherence is necessary to lower IOP or prevent progression of visual field loss. ${ }^{1}$ There is still no consistent evidence of the impact of non-adherence on the outcome of treatment. ${ }^{1}$ In a review of the effects of interventions for improving adherence, Gray et al. concluded that there is no evidence of reduced IOP or less visual field progression in better adherent patients. ${ }^{17}$ Other authors also did not find a correlation between adherence and IOP. ${ }^{18,19}$ A possible explanation is that poorly adherent patients increase their adherence during the two weeks before the office visit. ${ }^{18}$ Schwartz describes cyclic behaviour with white coat syndrome as patients being best adherent for 5 days before an office visit. ${ }^{20}$ However, non-adherence still appears to be an issue in the last two weeks before an office visit in our study.

On the other hand, Konstas et al. found that non-adherent patients showed higher IOP, more disc cupping and worse visual field loss than adherent patients. ${ }^{21}$ Chen showed a significant association between non-adherence and development of blindness from glaucoma. ${ }^{22}$ Vorwerk et al. described that non-adherence was a cause of unsatisfactory IOP-lowering in $26.8 \%$ of patients. ${ }^{23}$

This study supplies some issues that can be used in clinical practice to improve treatment results by ways of addressing adherence. Four questions can be asked in daily practice to discover if non-adherence is a reason for not reaching target pressure:

- how many days did you not use your eye drops in the last two weeks?

- $\quad$ are you satisfied with your eye drops?

- when did you use your last eye drop?

- did you discontinue using eye drops because of side effects? 
A clinically relevant improvement in achieved target pressure can be realised by addressing the correct dosage moment and discontinuation of eye drops in patients that did not achieve their target pressure. When addressing both issues, between $7 \%$ and $9 \%$ improvement in achieved target pressure could be realised in all patients.

\section{References}

1. Olthoff CM, Schouten JS, Van de Borne BW, Webers CA. Noncompliance with ocular hypotensive treatment in patients with glaucoma or ocular hypertension. Ophthalmology 2005;112:953-61.

2. Reardon G, Kotak S, Schwartz GF. Objective assessment of compliance and persistence among patients treated for glaucoma and ocular hypertension: a systematic review. Patient Prefer Adherence 2011;5:441-63.

3. Djafari F, Lesk MR, Harasymowycz PJ, et al. Determinants of adherence to glaucoma medical therapy in a long-term patient population. J Glaucoma 2009;18:238-43.

4. Friedman DS, Hahn SR, Quigley HA, et al. Doctor-patient communication in glaucoma care: analysis of videotaped encounters in community-based office practice. Ophthalmology 2009;116:2277-85 e1-3.

5. Kass MA, Gordon M, Meltzer DW. Can ophthalmologists correctly identify patients defaulting from pilocarpine therapy? Am J Ophthalmol 1986;101:524-30.

6. Okeke CO, Quigley HA, Jampel HD, et al. Adherence with topical glaucoma medication monitored electronically; the Travatan Dosing Aid Study. Ophthalmology 2009;116:191-9.

7. Gelb L, Friedman DS, Quigley HA, et al. Physician beliefs and behaviors related to glaucoma treatment adherence: the Glaucoma Adherence and Persistency Study. J Glaucoma 2008;17:690-8.

8. Sleath B, Blalock SJ, Carpenter DM, et al. Ophthalmologist-patient communication, self-efficacy, and glaucoma medication adherence. Ophthalmology 2015;122:748-54.

9. Sleath B, Blalock SJ, Robin A, et al. Development of an instrument to measure glaucoma medication self-efficacy and outcome expectations. Eye 2010;24:624-31.

10. Sleath B, Blalock SJ, Stone JL, et al. Validation of a short version of the glaucoma medication selfefficacy questionnaire. Br J Ophthalmol 2012;96:258-62.

11. Hahn SR. Patient-centered communication to assess and enhance patient adherence to glaucoma medication. Ophthalmology 2009;116:S37-42.

12. Tsai JC. A comprehensive perspective on patient adherence to topical glaucoma therapy. Ophthalmology 2009;116:S30-S6.

13. van der Valk $R$, Schouten JS, Webers CA, et al. Changes in glaucoma treatment and achieved IOP after introduction of new glaucoma medication. Graefes Arch Clin Exp Ophthalmol 2006;244:1267-72.

14. van der Valk R, Webers CA, Hendrikse F, et al. Predicting intraocular pressure change before initiating therapy: timolol versus latanoprost. Acta Ophthalmol 2008;86:415-8.

15. Tsai JC, McClure CA, Ramos SE, et al. Compliance barriers in glaucoma: a systematic classification. J Glaucoma 2003;12:393-8.

16. Olthoff CM, Hoevenaars JG, Borne van den BW, et al. Prevalence and determinants of non-adherence to topical hypotensive treatment in Dutch glaucoma patients. Graefes Arch Clin Exp Ophthalmol 2009;247:235-43.

17. Gray TA, Orton LC, Henson D, et al. Interventions for improving adherence to ocular hypotensive 
therapy. Cochrane Database Syst Rev 2009;2:CD006132.

18. Okeke CO, Quigley HA, Jampel HD, et al. Interventions improve poor adherence with once daily glaucoma medications in electronically monitored patients. Ophthalmology 2009;116:2286-93.

19. Gurwitz JH, Yeomans SM, Glynn RJ, et al. Patient noncompliance in the managed care setting; the case of medical therapy for glaucoma. Med Care 1998;36:357-69.

20. Schwartz GF, Quigley HA. Adherence and persistence with glaucoma therapy. Surv Ophthalmol 2008;53:S57-68.

21. Konstas AG, Maskaleris G, Gratsonidis S, Sardelli C. Compliance and viewpoint of glaucoma patients in Greece. Eye 2000;14:752-6.

22. Chen PP. Blindness in patients with treated open-angle glaucoma. Ophthalmology 2003;110:726-

23. Vorwerk C, Thelen U, Buchholz P, Kimmich F. Treatment of glaucoma patients with insufficient intraocular pressure control: a survey of German ophthalmologists in private practice. Curr Med Res Opin 2008;24:1295-301. 


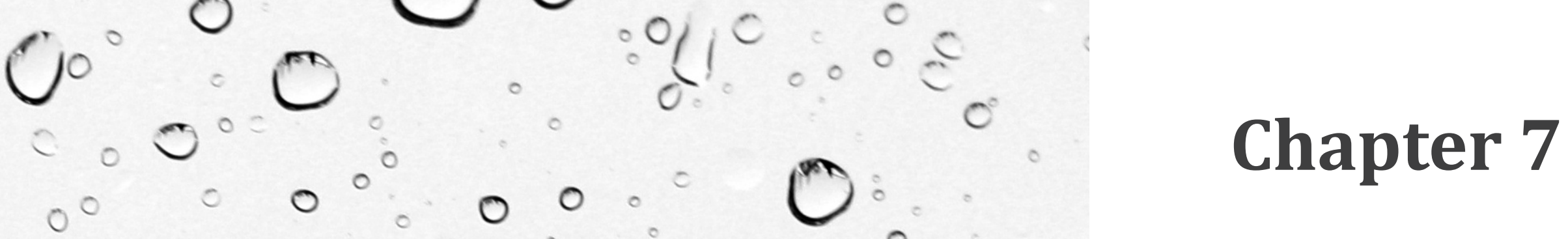

Non-adherence and glaucoma progression

Juliette G.M.M. Hoevenaars

Jan S.A.G. Schouten

Henny J.M. Beckers

Carroll A.B. Webers

Submitted 


\section{Abstract}

\section{Purpose}

Given the proven efficacy of IOP-lowering on the progression of glaucoma, there is no doubt that non-adherence leads to progression of visual field loss. However, it is not known how much non-adherence needs to be present for progression to occur. The purpose of this study was to estimate the strength of the relation between patient adherence with eye drops and progression of glaucoma.

\section{Methods}

For this case-control study, 56 glaucoma patients who showed progression and a random sample of 342 glaucoma patients without progression were identified from a hospital-based cohort of 3883 patients. Pharmacy refill records were used to assess non-adherence. Non-adherence was defined as the medication possession ratio (MPR). The MPR is a ratio of total days' supply (excluding last refill) to number of days of study participation. The ophthalmologist who took into account all available clinical data assessed whether progression was present.

\section{Results}

The progressive patients had a longer period that was not covered by a sufficient amount of eye drops. Depending on the cut-off point of the level of MPR and the assumption of the number of eye drops in a bottle, the number of non-adherent patients was at most $13 \%$ higher in the progressive group.

\section{Conclusions}

This study shows that progression of glaucoma is more common in non-adherent patients who have an insufficient number of eye drops to cover a treatment period. If this non-adherence is the causal factor and can be improved, it could reduce progression in at most $13 \%$ of the progressive glaucoma patients.

\section{Introduction}

Ocular hypotensive therapy is known to be effective in preventing the onset of primary open-angle glaucoma in patients with ocular hypertension and delaying visual field loss in patients with primary open-angle glaucoma. ${ }^{1-4}$ It is therefore inevitable to conclude that non-adherence in glaucoma leads to progression of visual field loss. Several studies found a relation between lower adherence rate and worse outcome of glaucoma. ${ }^{5-7}$ As it is generally accepted that adherence with ocular hypotensive therapy is essential to achieve the desired outcome in glaucoma treatment, and based on the estimated prevalence of non-adherence, ranging from $4.6 \%$ to $80 \%$, the impact of non-adherence could be substantial. ${ }^{8-15}$

Despite the notion that patient non-adherence is common and is likely to influence progression, it is uncertain how much non-adherence is acceptable and how strong the effect of non-adherence on progression of visual field loss is. We used medication refill data from pharmacies to examine the relation between nonadherence and glaucoma progression in a case-control design.

\section{Materials and Methods}

We used data from the DURING (DUtch Research project on treatment outcome IN Glaucoma patients) study. In nine randomly selected Dutch hospitals, medically treated patients diagnosed with glaucoma, glaucoma suspect or ocular hypertension were approached between March 2001 and January 2004 to participate in the DURING study. The randomly selected hospitals included academic, teaching and non-teaching centres. The ethical committee approved the study. Written informed consent was asked from patients aged 18 years or older who were able to read and write Dutch. Patients were asked to give detailed and extended information concerning many topics, including demographic variables and the name and address of their pharmacy. A total of 583 pharmacies were asked to provide all prescription information concerning the patients, containing refill date, medication name, Anatomical Therapeutic Chemical (ATC) Classification System code, number of units, dose per unit and instructions for use. Pharmacy refill records could be supplied digitally or in writing. Pharmacies received eight Euros per patient record as a compensation for their efforts. A reminder letter was sent after two weeks and pharmacies were contacted by telephone after four weeks to improve participation. All ophthalmologists that participated in the DURING study were asked to fill in 
a form concerning ophthalmologic patient data at the first or second visit. One of the questions was "Are you changing therapy". If the answer was "yes", the ophthalmologist was asked why they were changing therapy. Possible answers were "the current therapy has no/little effect on the intraocular pressure", "the target pressure has not been reached", "because of adverse effects", "because of glaucoma progression" or "other reasons".

In the current study, we selected those patients whose therapy was changed because of glaucoma progression ( $\mathrm{n}=81$ ). They are named "progressive glaucoma patients" in this study. We also randomly selected 600 patients from the remaining group of patients (excluding the 81 progressive patients). They are named "non-progressive glaucoma patients" in this article. They were randomly selected from all patients that were seen by the same ophthalmologists as the progressive glaucoma patients. Refill adherence was calculated for both groups until the date at which the ophthalmologist reviewed if the therapy was changed because of progressive glaucoma or judged a patient as not progressive. In case a patient was using two or more different glaucoma medications, one of the medications was selected for calculating refill adherence. We adjusted for switching of medication. For example, in case a patient refilled drug A for 3 months, but switched to drug B after 1 month, the number of bottles was adjusted to supply 1 month for drug $A$ and the other two months for drug B. The number of bottles was used to calculate refill adherence. To calculate refill adherence, we used the medication possession ratio (MPR). The MPR is a ratio of total days' supply (excluding last refill) to number of days of study participation. ${ }^{16,17}$ We decided to calculate MPR for a variety of days of supply per bottle ranging from 30-45 days since the number of eye drops per bottle is not easy to estimate but may be more than needed for 30 days (one month). Therefore, in our study the MPR is defined as:

Number of bottles refilled in observational period X number of days of supply per bottle ○

Number of days in observational period (between first and last dispense date)

An MPR equal to 1.00 means a patient was supplied with sufficient medication to use the eye drops according to prescription. An MPR lower than 1.00 means a patient was not supplied with enough medication to be able to use the eye drops according to prescription. Because there is no consensus on the cut-off point of the MPR for non-adherence, we decided to calculate refill adherence for a variety of definitions of cut-off values above which a patient is considered adherent. We defined three levels of adherence: an MPR $\geq 1.00$, an MPR $\geq 0.95$ and an MPR $\geq 0.85$. We assumed use of bilateral eye drops for all patients.

\section{Results}

A total of 3883 patients participated in the DURING study. Pharmacy information was obtained from 3368 (87\%) patients. For the remainder, no pharmacy refill records were obtained because patients did not fill in the name of their pharmacy, patients could not be identified by the pharmacy or because the pharmacy refused to participate. Glaucoma therapy was changed specifically because of glaucoma progression in 81 patients.

In the progressive glaucoma patients group, 56 of the 81 patients were included (69\%), while 342 of 600 non-progressive glaucoma patients were included (57\%). Reasons for exclusion were no availability of prescription information at all, visiting the pharmacy to fill a prescription only once, no availability of prescription information prior to the data at which progression was reviewed, or unclear information concerning progression. One progressive patient and three nonprogressive patients were excluded because they had never retrieved glaucoma medication according to the information retrieved from their pharmacists.

Table 1 shows demographic data for both groups.

Figure 1 shows the number of days one bottle of eye drops is used in progressive and non-progressive glaucoma patients. Thirty-six percent of the progressive glaucoma patients and $29 \%$ of the non-progressive glaucoma patients used one bottle of eye drops to supply 25-29 days of therapy. More progressive than nonprogressive glaucoma patients supplied more than 35 days of therapy with only one bottle of eye drops. 
Table 1. Demographics and data on MPR and observational period for progressive and non-progressive glaucoma patients.

\begin{tabular}{llcc}
\hline & & $\begin{array}{c}\text { Progressive glaucoma } \\
\text { patients } \\
\mathrm{N}=56\end{array}$ & $\begin{array}{c}\text { Non-progressive glaucoma } \\
\text { patients } \\
\mathrm{N}=342\end{array}$ \\
\hline Gender & \% Male & 46 & 52 \\
Age & Average & 70 & 69 \\
& Median & 70 & 70 \\
& Minimum & 46 & 36 \\
& Maximum & 91 & 98 \\
MPR (30 days of supply & Minimum & 0,14 & 0,22 \\
per bottle) & Maximum & 1,95 & 2,14 \\
Observational period & Average & 3,3 & 3,0 \\
(years) & SD & 2,5 & 2,2 \\
& Minimum-maximum & 56 days-11,6 years & 10 days-9,3 years \\
\hline
\end{tabular}

$\overline{\mathrm{N}=\text { number; } \mathrm{MPR}=\text { medication possession ratio; } \mathrm{SD}=\text { standard deviation; Observational period=period }}$ between first and last dispense date.

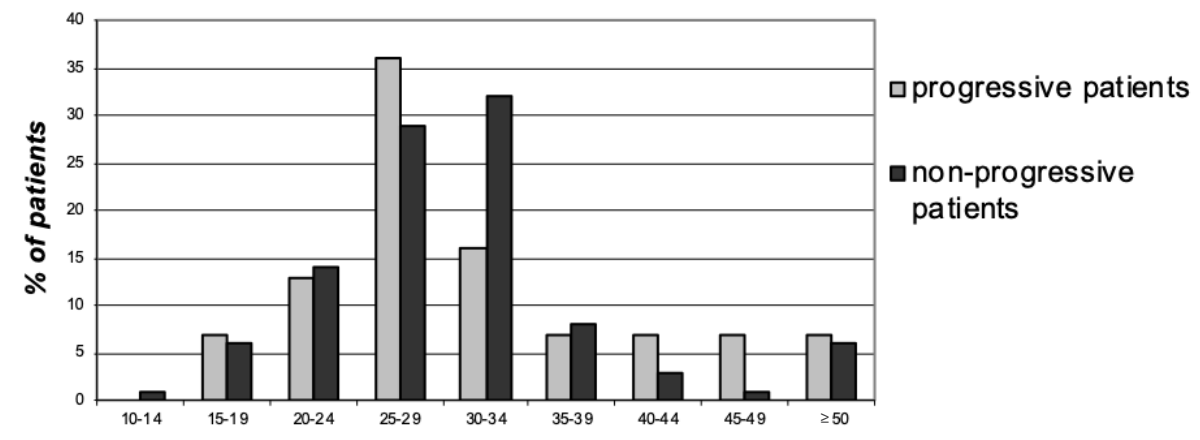

Number of days one bottle is used

Figure 1. Percentage of patients using one bottle of eye drops for a variety of days.

Figure 2 shows the percentage adherent patients in the progressive and nonprogressive group according to a definition of adherence as an MPR $\geq 1.00$. The horizontal axis shows the range of assumed days of supply per bottle. For example, based on the assumption of a 35 days of supply per bottle, $71 \%$ of the progressive glaucoma patients and $82 \%$ of the non-progressive glaucoma patients was adherent. A difference in percentage adherent patients of $10 \%$ or more between both groups was found between 35 and 43 days of supply per bottle. The maximum difference in percentage adherent patients between both groups is $13 \%$ based on 43 days of supply per bottle.

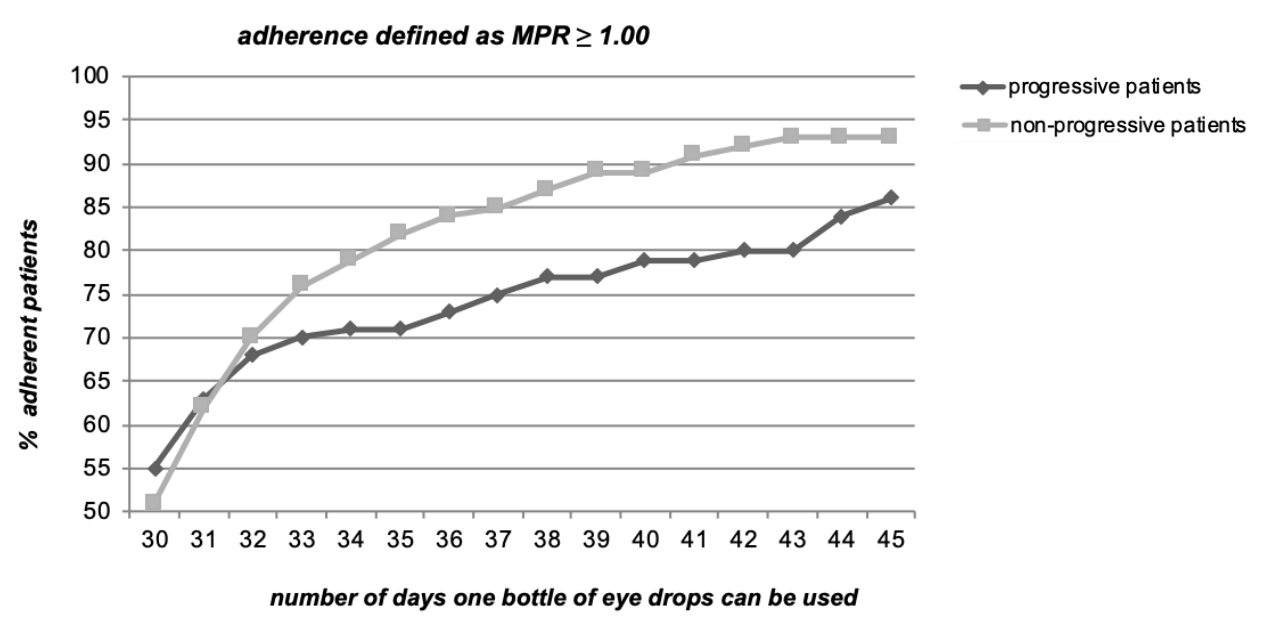

Figure 2. Percentage of adherent patients in the progressive and non-progressive group according to a definition of adherence as an MPR $\geq 1.00$ and specified for a variety of number of days of supply per bottle.

Figure 3 shows the percentage of adherent patients in progressive and nonprogressive glaucoma patients if adherence is defined as an MPR $\geq 0.95$. This means a patient was classified as adherent when he had enough eye drops to supply $95 \%$ of the observational period. The difference between the progressive and nonprogressive group remains present, with a maximum difference of $12 \%$.

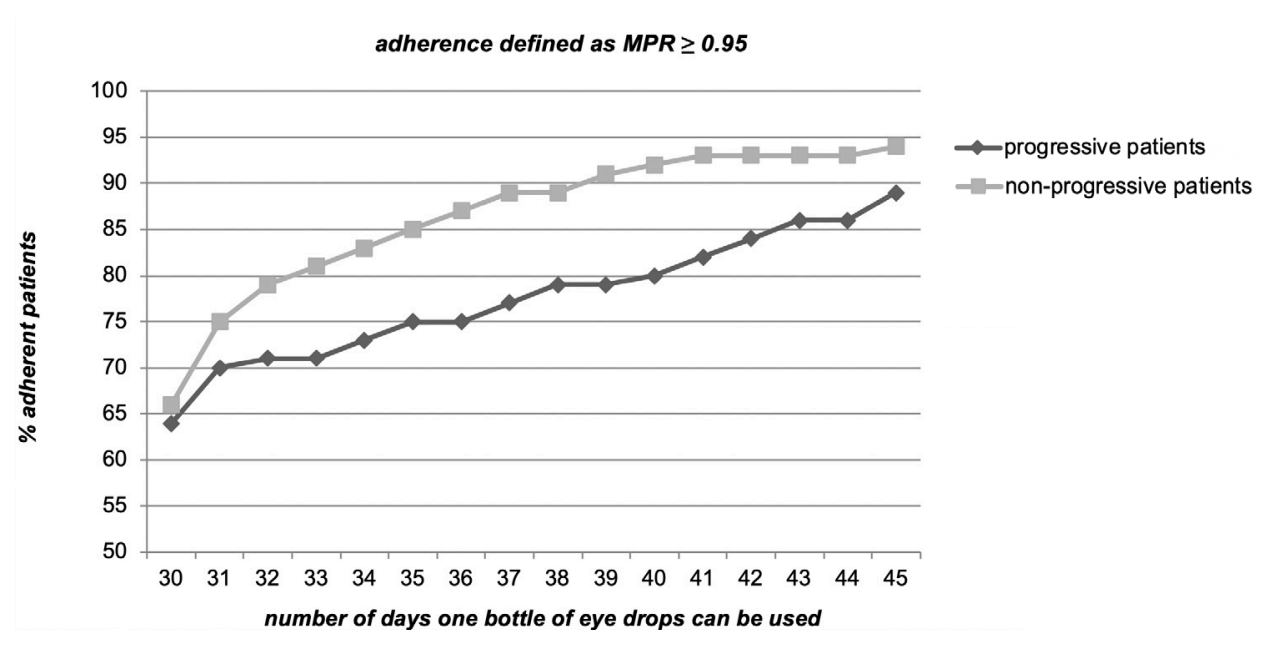

Figure 3. Percentage of adherent patients in the progressive and non-progressive group according to a definition of adherence as an MPR $\geq 0.95$ and specified for a variety of number of days of supply per bottle. 
In figure 4 patients were regarded adherent if they had an MPR $\geq 0.85$. The difference between both groups remains present, with a maximum difference of $12 \%$.

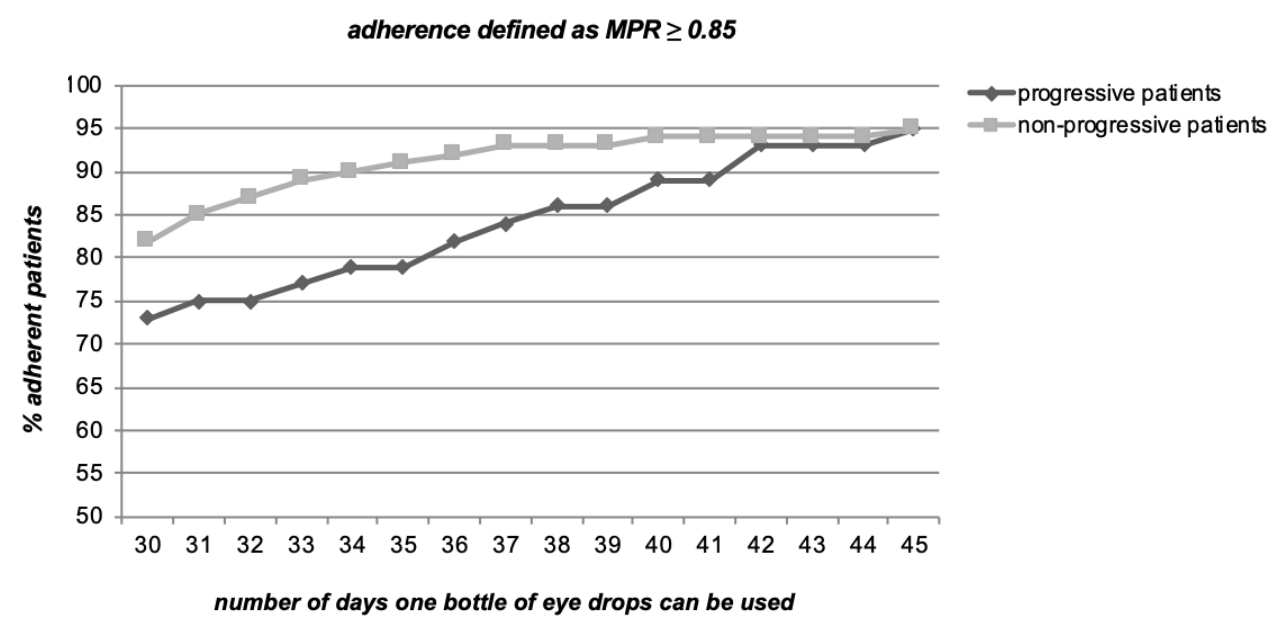

Figure 4. Percentage of adherent patients in the progressive and non-progressive group according to a definition of adherence as an MPR $\geq 0.85$ and specified for a variety of number of days of supply per bottle.

\section{Discussion}

In this study refill adherence of progressive glaucoma patients was compared with refill adherence of non-progressive glaucoma patients. Refill adherence was calculated by means of the MPR. Adherence was calculated for a variety of definitions of adherence and for a variety of number of days of supply per bottle. This study shows that the majority of progressive and non-progressive glaucoma patients use one bottle of eye drops to supply 25-34 days of therapy. More progressive than non-progressive glaucoma patients use only one bottle of eye drops for more than 35 days of therapy. The percentage of adherent patients is maximally $13 \%$ higher in non-progressive glaucoma patients than in progressive glaucoma patients, depending on the cut-off value of the MPR for adherence and the assumed number of days one bottle could cover.

We used pharmacy refill records to assess adherence. Advantages of the use of pharmacy records are that they are easily accessible, cover an extended period of time and correlate with other measures of adherence. ${ }^{18}$ Moreover, in other studies refill adherence correlated with important outcome measures. For example, in patients with diabetes it was shown that the MPR and the proportion of days covered (PDC) for oral anti-diabetic medications had the highest predictive value for hospitalization episodes compared to other measures of non-adherence. ${ }^{19}$ In another study, refill rate was the measure compared to electronic monitoring or self-reporting that correlated best with HIV viral load and CD4 count. ${ }^{20}$ Interestingly, in this study the cut-off point for non-adherence below which the risk of HIV recurrence was increased could be assessed; at least $90 \%$ refill adherence was related to a greater change in CD4 count and a lower viral load. ${ }^{20}$

In long-term pharmacological treatments, like glaucoma treatment, pharmacy records can provide reliable information regarding a patient's adherence to therapy. ${ }^{18}$ One limitation of this measure of adherence is the inability to assess the timing of doses, which is one of the aspects of adherence. ${ }^{18}$ Second, since refill adherence identifies the maximum amount of drug a patient can be consuming, it is a highly specific but possibly insensitive measure of partial adherence. ${ }^{18}$ Nevertheless, refill adherence is a necessary condition for adherence to drug use; without possession of drugs, they cannot be used.

Several other measures for assessing adherence have been developed. Patient selfreports are simple and inexpensive, but may lead to overestimation of adherence. Pill counts, serum drug levels or weighing bottles are impracticable and not or less useful in assessing adherence with eye drops. Electronic adherence monitors, the gold standard for assessing adherence, are expensive, cumbersome for daily practice and do not ensure that a patient actually used the drug possibly causing overestimation of adherence as patients are aware of the fact that the monitor registers them opening the bottle. ${ }^{18,21,22}$ A study using electronic monitoring in hypertension observed a significant decrease in blood pressures although medication was not changed, suggestion electronic monitoring to be useful as a tool to improve adherence. . $^{23,24}$

It is possible for patients to fill their prescription at a different pharmacy than where they are registered. However, at the time of this study, the majority of patients in the Netherlands was a member of the National Health Care Insurance Board that obligated patients to obtain drugs at one pharmacy. In addition, several regions in the Netherlands have a general registration system for pharmacies in one region to register medicines. Therefore, this limitation is not expected to have caused any bias in this study. 
Several earlier studies used pharmacy refill data to describe adherence with ocular hypotensive medication. Reardon et al. report in a systematic literature review, as they cite, an MPR or PDC of only 56\% (range 37-92\%) in the first year of therapy in six studies. The rate of total non-adherence, defined as no refills following the start of treatment in the first year, was $24 \%{ }^{25}$ Friedman et al. found a mean MPR of $64 \%$ with a mean follow-up period of 22 months. ${ }^{26}$ In a study reported by Wilensky et al. $76.5 \%$ of the days in a 12 month period could be dosed with the available medication. ${ }^{27}$

In the Maccabi Glaucoma Study glaucoma patients had eye drops for only 58\% of the period during an average follow-up of six years (PDC). Using a cut-off point of $80 \%$ for high adherence, $25 \%$ of the study population in the Maccabi Glaucoma Study exhibited high adherence and 13\% exhibited low adherence. ${ }^{28}$ Hwang et al. reported that $43.3 \%$ of glaucoma patients had an MPR $<1$ within two years of followup. ${ }^{29}$ Methodological differences between studies can explain differences between reported adherence rates, e.g. differences in medication groups, assumption of unilateral or bilateral use of eye drops, analysis of single or multiple agents and different assumptions on duration of supply per bottle. Moreover, there could be differences in characteristics that are related to adherence e.g. drug reimbursement, prices or socioeconomic differences.

Other studies investigated the relation between adherence and progression or outcome of glaucoma. Granström found no significant association between adherence with pilocarpine drops and visual field defect progression. ${ }^{30}$ However, adherence was studied during a few weeks only and patients were told the purpose of the medication monitor. ${ }^{30}$ This may have led to a bias since non-adherent patients could have changed their use of eye drops thereby equalizing the amount of nonadherence between progressive and non-progressive patients. Chen showed that non-adherence with glaucoma treatment regimen was significantly associated with development of blindness. ${ }^{5}$ In Chen's study non-adherence was noted by the treating physician and defined as incorrect use of eye drops, missing multiple office visits, having more than eight months elapse between visits or refusal of recommended surgical treatment. ${ }^{5}$ They did not report the relation between each separate adherence parameter and the development of blindness. Most of their encountered non-adherence concerned missed follow-up appointments. Chen et al. report that becoming blind in at least one eye was sometimes related to a high level of non-adherence. ${ }^{5}$
Rossi et al. showed a significant relation between lower adherence rates recorded by the Travatan Dosing Aid and progression of visual field. ${ }^{6}$ No progression was found in patients who were at least $90 \%$ adherent, while $43.5 \%$ of patients with lower adherence showed progression. ${ }^{6}$ This finding of no progression in patients with at least $90 \%$ adherence is interesting as progression also occurs, due to other reasons, in adherent patients. Moreover, visual field progression was reported not to be associated with baseline IOP or IOP over time. The small number of included patients $(n=35)$ could be an explanation for these findings. ${ }^{6}$

Sleath et al. reported significantly worse visual field defect severity in patients who were less than $80 \%$ adherent according to the electronic monitoring devices and patients with lower scores on a glaucoma medication adherence self-efficacy scale. ${ }^{7}$ These studies did not analyse the relation between refill adherence and progression of glaucoma.

Joseph and Pasquale state in their review that no studies have definitely proven an association between poor adherence and visual field loss. ${ }^{31}$ They mention lack of data and the difficulty in proving how adherence impacts a slowly progressive disease like glaucoma as possible explanations for this interesting finding. ${ }^{31}$

In our study progression was based on the ophthalmologist's judgement. The advantage is that it reflects clinical practice. A fair level of agreement between subjective expert determination of visual field progression and the Glaucoma Progression Analysis software was reported by Tanna et al. ${ }^{32}$ Ernest et al. reported a relatively high ability to discriminate progressive and non-progressive patients by expert assessment of visual field progression. ${ }^{33}$

The current study measured the relation of refill adherence with progression of glaucoma for a variety of days of supply per bottle and for a variety of definitions of non-adherence. It shows that progression of glaucoma is more common in non-adherent patients. If adherence by having sufficient number of bottles of eye drops can be improved, it could reduce progression in a maximum of $13 \%$ of the progressive patients. 


\section{References}

1. Maier PC, Funk J, Schwarzer G, et al. Treatment of ocular hypertension and open angle glaucoma: meta-analysis of randomised controlled trials. BMJ 2005;331:134.

2. Kass MA, Heuer DK, Higginbotham EJ, et al. The Ocular Hypertension Treatment Study. A randomized trial determines that topical ocular hypotensive medication delays or prevents the onset of primary open-angle glaucoma. Arch Ophthalmol 2002;120:701-13.

3. Heijl A, Leske C, Bengtsson B, et al. Reduction of intraocular pressure and glaucoma progression. Results from the early manifest glaucoma trial. Arch Ophthalmol 2002;120:1268-79.

4. Inatani M, Iwao K, Inoue $\mathrm{T}$, et al. Long-term relationship between intraocular pressure and visual field loss in primary open-angle glaucoma. J Glaucoma 2008;17:275-9.

5. Chen PP. Blindness in patients with treated open-angle glaucoma. Ophthalmology 2003;110:726-33.

6. Rossi GC, Pasinetti GM, Scudeller L, et al. Do adherence rates and glaucomatous visual field progression correlate? Eur J Ophthalmol 2011;21:410-4.

7. Sleath B, Blalock S, Covert D, et al. The relationship between glaucoma medication adherence, eye drop technique, and visual field defect severity. Ophthalmology 2011;118:2398-402.

8. Olthoff CM, Schouten JS, Van de Borne BW, Webers CA. Noncompliance with ocular hypotensive treatment in patients with glaucoma or ocular hypertension. Ophthalmology 2005;112:953-61.

9. Lee DA, Fechtner RD, Fiscella RG, et al. Emerging perspectives on glaucoma: highlights of a roundtable discussion. Am J Ophthalmol 2000;130:S1-S11.

10. Konstas AG, Maskaleris G, Gratsonidis S, Sardelli C. Compliance and viewpoint of glaucoma patients in Greece. Eye 2000;14:752-6.

11. Busche S, Gramer E. Verbesserung der augentropfenapplikation und compliance bei glaukompatienten; eine klinische studie. [Improvement of eye drop application and compliance of glaucoma patients]. Klin Monbl Augenheilkd 1997;211:257-62.

12. Zimmerman TJ, Zalta AH. Facilitating patient compliance in glaucoma therapy. Surv Ophthalmol 1983;28:252-7.

13. Patel SC, Spaeth GL. Compliance in patients prescribed eyedrops for glaucoma. Ophthalmic Surg 1995;26:233-6.

14. Vincent PA. Patients' viewpoint of glaucoma therapy. Sight Sav Rev 1972;42:213-21.

15. Deokule S, Sadiq S, Shah S. Chronic open angle glaucoma: patient awareness of the nature of the disease, topical medication, compliance and the prevalence of systemic symptoms. Ophthalmic Physiol Opt 2004;24:9-15.

16. Andrade SE, Kahler KH, Frech F, Chan KA. Methods for evaluation of medication adherence and persistence using automated databases. Pharmacoepidemiol Drug Saf 2006;15:565-74.

17. Hess LM, Raebel MA, Conner DA, Malone DC. Measurement of adherence in pharmacy administrative databases: a proposal for standard definitions and preferred measures. Ann Pharmacother 2006; 40:1280-8.
18. Steiner JF, Prochazka AV. The assessment of refill compliance using pharmacy records: methods, validity and applications. J Clin Epidemiol 1997;50:105-16.

19. Karve S, Cleves MA, Helm M, et al. An empirical basis for standardizing adherence measures derived from administrative claims data among diabetic patients. Med Care 2008;46:1125-33.

20. Konkle-Parker DJ, Erlen JA, Dubbert PM. Lessons learned from an HIV Adherence Pilot Study in the Deep South. Patient Educ Couns 2010;78:91-6.

21. Wetzels GE, Nelemans P, Schouten JS, Prins MH. Facts and fiction of poor compliance as a cause of inadequate blood pressure control: a systematic review. J Hypertens 2004;22:1849-55.

22. Krousel-Wood M, Thomas S, Muntner P, Morisky D. Medication adherence: a key factor in achieving blood pressure control and good clinical outcomes in hypertensive patients. Curr Opin Cardiol 2004;19:357-62.

23. Burnier M, Schneider MP, Chiolero A, et al. Electronic compliance monitoring in resistant hypertension: the basis for rational therapeutic decisions. J Hypertens 2001;19:335-41.

24. Wetzels GE, Nelemans PJ, Schouten JS, et al. Electronic monitoring of adherence as a tool to improve blood pressure control. A randomized controlled trial. Am J Hypertens 2007;20:119-25.

25. Reardon G, Kotak S, Schwartz GF. Objective assessment of compliance and persistence among patients treated for glaucoma and ocular hypertension: a systematic review. Patient Prefer Adherence 2011;5:441-63.

26. Friedman DS, Quigley HA, Gelb L, et al. Using pharmacy claims data to study adherence to glaucoma medications: methodology and findings of the Glaucoma Adherence and Persistency Study (GAPS). Invest Ophthalmol Vis Sci 2007;48:5052-7.

27. Wilensky J, Fiscella RG, Carlson AM, et al. Measurement of persistence and adherence to regimens of IOP-lowering glaucoma medications using pharmacy claims data. Am J Ophthalmol 2006;141:S28-33.

28. Goldshtein I, Shalev V, Zigman N, et al. The Maccabi Glaucoma Study: treatment patterns and persistence with glaucoma therapy in a large Israeli health maintenance organization. J Glaucoma 2016;25:e386-91.

29. Hwang DK, Liu CJ, Pu CY, et al. Persistence of topical glaucoma medication: a nationwide populationbased cohort study in Taiwan. JAMA Ophthalmol 2014;132:1446-52.

30. Granström PA. Progression of visual field defects in glaucoma. Relation to compliance with pilocarpine therapy. Arch Ophthalmol 1985;103:529-31.

31. Joseph A, Pasquale LR. Attributes associated with adherence to glaucoma medical therapy and its effects on glaucoma outcomes: an evidence-based review and potential strategies to improve adherence. Semin Ophthalmol 2017;32:86-90.

32. Tanna AP, Budenz DL, Bandi J, et al. Glaucoma Progression Analysis software compared with expert consensus opinion in the detection of visual field progression in glaucoma. Ophthalmology 2012;119:468-73.

33. Ernest PJ. Visual field progression in patients with open-angle glaucoma. Universitaire Pers Maastricht, 2014 
$00^{\circ}: 0: \because 0 / 0^{0}: \varepsilon_{0}^{0}$

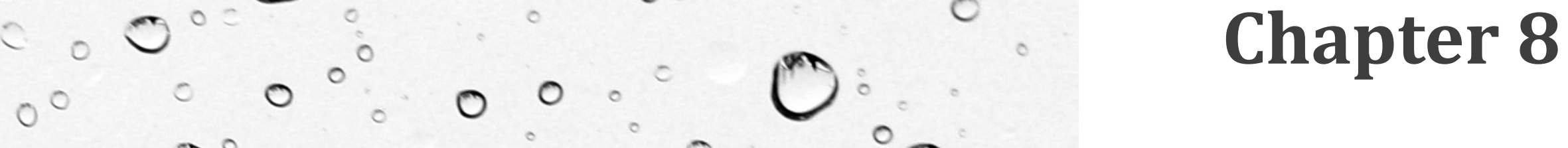

General discussion 


\section{General discussion}

\section{Glaucoma as a chronic disease}

Glaucoma is a chronic progressive optic neuropathy resulting in visual field loss and blindness in about half of the cases when left untreated. ${ }^{1}$ Most often, the patient has no subjective complaints at the time of diagnosis as the disease is detected often accidently at (screening) visits at the optician, optometrist or ophthalmologist. The patient is confronted with a diagnosis of a potentially blinding disease that cannot be cured, a need for lifelong follow-up and often a lifelong therapy with eye drops. A lack of knowledge about glaucoma has been reported in glaucoma patients. ${ }^{2-9}$ It is thought that more knowledgeable glaucoma patients are better adherent with their medication. ${ }^{8,10-16}$ To provide proper patient education with the aim to improve adherence, it is important 1) to investigate for which items a knowledge gap exists, 2) to assess if it is useful to differentiate patient education for different socioeconomic groups, 3) to identify the knowledge items that are related to adherence that could potentially be influenced to change the level of adherence, 4) how non-adherent patients could be identified and 5) to study the barriers to adherence that exist in glaucoma patients. Moreover, a quantification of the contribution of non-adherence to the occurrence of an unachieved target pressure or progression of glaucoma is desirable to further underline the importance of non-adherence.

\section{Lack of knowledge}

This thesis describes a cross-sectional multicentre study in which a systematically developed questionnaire including 37 items concerning knowledge and 22 items concerning need for information was conducted.

It shows that many glaucoma patients lack knowledge about essential elements of the disease or its treatment. Half of the patients had $49 \%$ or fewer correct answers to questions about glaucoma or its treatment. For example, only $27 \%$ of patients knew that untreated glaucoma is a slowly progressing condition and $43 \%$ of patients knew that early detection and subsequent treatment can slow down the course of glaucoma. Moreover, fifty percent of patients knew that an impaired visual field cannot be repaired and $68 \%$ of patients knew that eye drops cannot repair the damage caused by glaucoma. Only $18 \%$ of patients knew that the intraocular pressure is not always increased in glaucoma, an important item as many people still think that measurement of the intraocular pressure is enough to exclude a diagnosis of glaucoma. A systematic review of knowledge assessment also revealed significant knowledge gaps in glaucoma patients. ${ }^{8}$
We also found that, besides the objective assessment of the lack of knowledge, patients themselves have a high need for information, especially concerning new developments in glaucoma and its treatment and concerning their own state of glaucoma. Patients preferred the ophthalmologist as the most important source from whom they wish to receive information. A nurse or representative of the Glaucoma Patient Society could play a role as well. Other research also showed a major reliance on the ophthalmologist for their information. ${ }^{17}$

In our study lack of knowledge was associated with low level of education, short duration of glaucoma, and high age. This raised a question whether patient education should be different between socioeconomic groups. Later on, Peralta et al. also reported that higher age and low level of education correlated with greater lack of disease knowledge. ${ }^{8}$ We questioned if there are any specific items for which socioeconomic differences in glaucoma patients' knowledge, need for information and expectations of treatments exist?

We have shown important socioeconomic differences in knowledge, need for information and expectations of glaucoma patients. Patients from the low socioeconomic group showed poorer results when compared with the middle and high socioeconomic groups. Items on knowledge with socioeconomic differences concerned risk factors, pathophysiology and consequences of glaucoma, as well as effects and adverse effects of treatments. The lowest socioeconomic group also demonstrated more need for information on the use of eye drops, public assistance and practical aspects of glaucoma and more often expected that glaucoma damage could be repaired. The overlap in level of knowledge between socioeconomic groups is considerable and the level of knowledge is low in every socioeconomic group.

To our opinion, patient education should focus on every glaucoma patient to establish a basic knowledge level. In addition, better provision of information to patients in lower socioeconomic groups about specific items is necessary to reduce the socioeconomic differences in knowledge and need for information. It is possible that this will have an impact on eye care utilization and visual impairment in this group of glaucoma patients. Addressing the awareness of family predisposition could encourage glaucoma patients to alert family members to screen for glaucoma and thereby reduce the socioeconomic difference in visual field defect severity at time of diagnosis. 
This thesis identified knowledge gaps in glaucoma patients and provides specific items that can be helpful in the development of a glaucoma patient education program.

\section{Association between knowledge and adherence}

The goal of glaucoma treatment is to slow down worsening of the visual field. The intraocular pressure is the only known modifiable factor to achieve this. The ophthalmologist will decide which target pressure is aimed at beyond which the risk of progressive disease is minimalized. In dialogue with the patient, the ophthalmologist will decide which treatment will be initiated; chronic use of eye drops, oral medication, laser therapy or surgery. The patient needs to adhere with the prescribed treatment since ocular hypotensive treatment is known to be effective in delaying visual field loss in glaucoma patients. As a consequence, non-adherence with the prescribed treatment is expected to lead to progression of visual field loss. Glaucoma patients are at risk of non-adherence with their treatment given the asymptomatic nature of glaucoma and the lifelong therapeutic regimen without apparent subjective improvement. The reported rate of nonadherence varies between $4.6 \%$ and $80 \%{ }^{14}$

Since we know that significant knowledge gaps exist in glaucoma patients and an association between progression and adherence should be present, we wondered if lack of knowledge and certain knowledge items is related to adherence. Olthoff et al. stated that adherent and non-adherent patients differed with regard to their knowledge of specific items rather than their overall level of knowledge. ${ }^{14}$ A need to identify these specific items was mentioned. ${ }^{14,16}$

In this thesis the association between knowledge and self-reported adherence, and the association between need for information and self-reported adherence is reported. In concordance with Olthoff et al. this thesis found no significant correlation between total level of knowledge and adherence or total level of need for information and adherence. Studying each separate item in the questionnaire showed an important finding. Patients who knew that eye drops cannot repair glaucomatous damage were more adherent. The adjusted odds ratio was 3.3. This implies that patients should be well informed about this issue. Another relevant issue on the need for information concerned the need to be informed about the heredity of glaucoma. Patients not needing this information were more adherent. This could be due to the fact that they already knew from their relatives what the impact of glaucoma could be.
The finding that some specific items, rather than an overall level of knowledge, were correlated with adherence is in concordance with other studies. ${ }^{11,13,14,16} \mathrm{Ung}$ et al. found no correlation between glaucoma knowledge and adherence in their study with only a limited assessment of knowledge. ${ }^{18}$

In our view, although patient education is an important aspect in the improvement of adherence, it will not be the only solution in the adherence dilemma. Combinations of educational, behavioural and affective interventions are mentioned to be successful in improving adherence. ${ }^{14,19,20}$

\section{Barriers and risk factors of adherence}

The issue of adherence was further addressed in this thesis by a study on the determinants of non-adherence in the Netherlands. In our population, $27.3 \%$ of patients were classified as non-adherent. It is useful to divide risk factors in modifiable and non-modifiable risk factors as intervention programs should focus on modifiable risk factors. Age appeared to be a non-modifiable risk factor: patients younger than 55 years of age had a higher risk of being non-adherent. In this thesis the most cited reasons for non-adherence included forgetfulness, unavailability of eye drops and difficulties with holding the bottle above the eye when applying eye drops. Various other studies report forgetfulness as one of the major reasons for non-adherence. ${ }^{21-24}$ The absence of immediate advantage of eye drops and no direct disability from the disease could be contributing factors to forget to use eye drops. More information about the correct administration of eye drops was required by $50 \%$ of patients in the study included in this thesis. The involuntary non-adherence found in this thesis is in agreement with other studies which also recognize insufficient skills or manual dexterity in especially older patients as reasons for non-adherence. ${ }^{22,24-30}$ The term dyscompliance is used when a patient's physical problems, like arthritis, lead to difficulties in applying eye drops. ${ }^{31}$

In 2003 Tsai et al. systematically identified common barriers to adherence in glaucoma therapy by means of a prospective case series of structured interviews. Almost all items covered in the interview are covered in our questionnaire described in chapter 5. They describe 71 unique patient-reported obstacles to adherence, which they divide into four main categories: social/environmental factors ( $49 \%$ of the studied obstacles), regimen factors (23\% of the studied obstacles), individual patient factors $(16 \%$ of the studied obstacles) and medical provider factors $(3 \%$ of the studied obstacles). By dividing these categories into subcategories, they developed a more detailed taxonomy of barriers to adherence. ${ }^{32}$ 
A systematic review by Olthoff et al. in 2005 showed that there were no specific patient characteristics that identify non-adherent patients sufficiently despite a lot of reported associations between adherence and patient-related determinants. They found only a definite association with non-adherence for male gender, lower level of knowledge and dosing frequency of eye drops higher than two. ${ }^{14}$

In 2009 Tsai et al. performed a literature search and presented a focused summary of the literature on risk factors for non-adherence to topical glaucoma medication regimens. They state that there are many adherence obstacles inherent to the glaucoma patient population. According to their report, older age was not a consistent factor for non-adherence. Based on various studies, varied effects on adherence were found for medication costs, disease severity, role of complicated dosing regimens and limited health insurance. Non-adherence to follow-up visits was associated with non-adherence to medication regimens. ${ }^{33}$

The Glaucoma Adherence and Persistency Study (GAPS) showed eight variables to be independently associated with lower adherence measured by medication possession ratio (MPR). Modifiable risk factors were difficulty taking medication while being away from home, lack of concern about possible vision loss of not taking medication as recommended, passive dependence of the doctor for obtaining information about glaucoma and not receiving a phone call visit reminder. Not acknowledging stinging and burning were also associated with lower MPR. Stinging and burning seemed a marker for adherence. ${ }^{34}$

Non-modifiable (according to the authors) risk factors in the GAPS study were problems paying for medication and being non-white. ${ }^{34}$

An update on the observed risk factors and barriers for non-adherence shows several non-consistent risk factors like

younger age ${ }^{35-42}$ or older age ${ }^{43,44}$,

advanced ${ }^{44}$ or less advanced ${ }^{18}$ stage of disease,

worse general health status ${ }^{35}$ or less other health conditions or non-ocular medication $^{41}$.

Consistent risk factors and barriers for non-adherence that are reported are: gender: male $^{38,39,42,45}$,

ethnic background: African americans ${ }^{35,37,39,40,46,47}$, minorities ${ }^{48}$

socioecononomic status: lower income $e^{36-38,47}$ or lower level of education ${ }^{37,38,47}$,
- knowledge of glaucoma: lower level of knowledge about glaucoma and its treatment ${ }^{46,49-52}$,

- drug administration: self-administration of eye drops/no help ${ }^{43,50,52}$, temporary medication ${ }^{43}$, regimen complexity ${ }^{36,42,46,48,53}$, difficulty instilling eye drops ${ }^{53-55}$, relying on someone else for drop installation ${ }^{36}$, side effects ${ }^{53}$, shorter duration of therapy ${ }^{35}$, fear of using eye drops ${ }^{54}$,

- follow-up visits: fewer consultations ${ }^{38,42,47}$

- disease: fewer symptoms of glaucoma ${ }^{45}$,

- financial issues: financial problems/affordability/costs $44,47,53,56$

- provider: no support from physician or nurse ${ }^{49,54}$, not believing their eye doctor spent sufficient time with patient ${ }^{52}$, not discussing importance of adherence ${ }^{36,}$ ${ }^{47}$, prescription discrepancies ${ }^{54}$,

- patient: forgetfulness ${ }^{50-54,56,57}$, decreased self-efficacy ${ }^{48,55}$, lower quality of life ${ }^{45}$, more effect on their lives from glaucoma ${ }^{45}$, less motivation and fewer cues to action $^{48}$, no acquaintances with glaucoma ${ }^{36}$, greater number of eye diseases ${ }^{37}$, more concerns about /less beliefs in therapy ${ }^{36,40,41,45,47,56}$.

Sleath et al. found that positive reinforcement and encouraging patients to take their glaucoma medication improved adherence. ${ }^{46}$

Studies on risk factors cannot only be used to identify modifiable risk factors to improve adherence but also be used to identify groups with a high risk of being non-adherent. The conclusion of Olthoff et al. holds that, although there are risk factors for non-adherence, they discriminate only to a limited extent between patients who are adherent and non-adherent. ${ }^{14}$

It could therefore be more efficient to focus on groups in whom non-adherence can be shown or could be a problem because it already had consequences for the outcome of treatment. The former approach starts with measuring non-adherence and the second approach starts with identifying the presence of an unwanted outcome e.g. the target pressure is not reached or there is progression of visual field loss.

\section{Assessment of non-adherence}

The assessment of non-adherence can start in daily practice by asking questions. In the literature, the development of a physician-usable risk-assessment tool to monitor and predict non-adherence has been recommended since ophthalmologists' skills to detect non-adherence appear to be poor. ${ }^{30,58-61}$ Addressing adherence, 
preferentially based on open-ended questions, is a time-consuming activity and requires a tailored, patient-centered approach. ${ }^{62-64} \mathrm{Hahn}$ et al. described several specific communication strategies to detect non-adherence and to identify and address adherence barriers. ${ }^{62}$ Hahn et al. developed a stepwise approach that has been evaluated. The ophthalmologist could use this stepwise approach to assess and enhance patient adherence, individualised to the specific patient. The steps to be taken are (1) a 4-step adherence assessment interview designed to detect nonadherence that decreases patient resistance to revealing non-adherence by applying a shared decision-making process and mitigating social undesirability; (2) asking open-ended questions in ask-tell-ask sequences; and (3) tailoring interventions to the patient's stage of readiness for change. This is an individualised patientcentered approach that has been advocated by others and seems to be effective. ${ }^{65}$ However, addressing adherence in this way is a time-consuming activity in daily practice and requires a tailored, patient-centered approach. ${ }^{33,62}$

Sleath et al. described a self-efficacy scale that could be used to assess when patients do not feel comfortable using their glaucoma medication under certain circumstances. $^{66-68}$ Patients with more confidence in using their glaucoma medication were more adherent. Since the self-efficacy scale was significantly associated with adherence, the scale could help providers detect non-adherent patients. Based on patients' responses, providers can attempt to improve selfefficacy and address specific challenges with the aim to improve adherence. ${ }^{66-68}$

Another approach in daily practice could be to use pharmacy data to calculate the medication possession ratio (MPR). Pharmacy refill records are easily accessible, cover an extended period of time and correlate with other measures of adherence. ${ }^{69}$ In long-term pharmacological treatments, like glaucoma treatment, pharmacy records can provide reliable information regarding a patient's adherence to therapy ${ }^{69} \mathrm{An}$ important element of this measure is that it gives the upper limit of being able to be adherent. That is, if you do not have the medication, you cannot use it. In patients with diabetes it was shown that the MPR and the proportion of days covered (PDC) for oral anti-diabetic medications had the highest predictive validity for hospitalization episodes. ${ }^{70}$ In another study refill rate was the measure compared to electronic monitoring or self-reporting that correlated best with HIV viral load and CD4 count. ${ }^{71}$ Moreover, at least $90 \%$ adherence based on refill data was related to a greater change in CD4 counts and lower viral load. ${ }^{71}$

In our study described in chapter 7, we used the MPR for measuring refill adherence.
Several mathematical formulas can be used for various adherence measures. In a systematic literature review Hess et al. report that there is no need for a variety of measurements because of the high level of comparability between the formulas. ${ }^{72}$ One should always recognize the context and limitations of used measures and data. Hess recommends the medication refill adherence (MRA) as measure for refill adherence because of its simplicity, necessity of few data and requirement of equivalent results compared with those achieved with other refill measures. MRA and MPR are judged as identical, equivalent values in terms of measuring adherence in refill records. ${ }^{72}$ In a comparison of the predictive validity of eight different adherence measures in diabetes patients, Karve et al. concluded that MPR and PDC are first-choice measures for measuring refill adherence. ${ }^{70}$

Limitations of this refill measure of adherence are the inability to assess the timing of doses, ${ }^{69,73}$, the patient's ability to waste, bias by drug samples, whether unilateral or bilateral therapy is prescribed, misclassification of added or switched medication and possible inaccuracies in data due to differences in prescribing and dispensing eye drops. ${ }^{30,73,74}$ Cate et al. who found that refill adherence as measured by the MPR was an unreliable measure of persistence with eye drops describe an example of possible inaccuracy in data. Patients included in that study were not consistently given one bottle of drops per month. Participants reported that they received two bottles per month, one bottle for each eye. ${ }^{73}$

\section{Non-adherence in groups with an unwanted outcome}

In the overall discussion on knowledge and adherence we should keep in mind that the ultimate goal of this discussion is to avoid preventable progression of glaucoma. Given the proven efficacy of ocular hypotensive therapy in delaying visual field loss in glaucoma patients, it is clear that adherence is essential to achieve the desired outcome of glaucoma therapy and that non-adherence leads to glaucoma progression. It is not known how much adherence is necessary to prevent progression or how much non-adherence is acceptable. There is no consistent evidence of the impact of non-adherence on the outcome of therapy. ${ }^{14,75}$ Some authors did not find a correlation between adherence and intraocular pressure ${ }^{76}$, ${ }^{77}$ or visual field progression. ${ }^{76,78,79}$ On the other hand, other authors did find a correlation between non-adherence and higher intraocular pressure ${ }^{22,80}$, visual field progression ${ }^{22,81,82}$ or blindness. ${ }^{83}$

It could therefore be more efficient in daily practice if the ophthalmologist addresses non-adherence in patients in whom non-adherence affects the outcome 
of glaucoma; patients in whom the target pressure is not reached or in whom progression of visual field loss has been observed. It is especially in these groups that reducing non-adherence is important as it is needed to improve the outcome of glaucoma.

Chapter 6 describes how data from 3640 medical records and questionnaires completed by ophthalmologists and patients were used to study the relation between the number of patients achieving the target pressure and the patients' type of glaucoma, number of days medication not used, last dosage moment, side effects, discontinuing the use of eye drops because of side effects and satisfaction with eye drops. Not achieving target pressure was related to being non-adherent in more than $43 \%$ of the time, an incorrect last dosage moment, discontinuing the use of eye drops because of side effects and dissatisfaction with eye drops. Based on this thesis four questions can be asked to discover if non-adherence is a reason for not reaching target pressure:

1) how many days did you not use your eye drops in the last two weeks?

2) are you satisfied with your eye drops?

3 ) when did you use your last eye drop?

4) did you discontinue using eye drops because of side effects?

A clinically relevant improvement in achieved target pressure could be realised by addressing the correct dosage moment and by addressing discontinuation of eye drops because of side effects in patients that did not achieve their target pressure. When addressing both issues, between $7 \%$ and $9 \%$ improvement in achieved target pressure could be realised in all patients.

In this thesis we used medication refill data from pharmacies to examine the relation between non-adherence and glaucoma progression in a case-control design. Non-adherence was defined as the MPR. The ophthalmologist assessed the presence of progression taking into account all available clinical data. More progressive than non-progressive glaucoma patients supplied more than 35 days of therapy with only one bottle of eye drops. Depending of the cut-off point of the MPR and the assumption of the number of eye drops in a bottle, the number of nonadherent patients was $12-13 \%$ higher in the progressive group compared with the non-progressive group. If adherence by having sufficient number of bottles of eye drops can be improved, it could reduce progression in a maximum of $13 \%$ of the progressive patients.
One could have noticed a difference is patient number participating in the DURING (DUtch Research project on treatment outcome IN Glaucoma patients) study in chapter 6 and chapter 7 of this thesis. Chapter 6 describes 3640 patients participating in the DURING study while chapter 7 describes 3883 patients participating in the DURING study. This difference in patient number has been discovered late in the process of this thesis. It could not clearly be explained by exploring the logbook and original data sets. Most likely, the difference in patient number is explained by a delay in receiving data. Exploring the logbooks and original data sets shows that the data set used in chapter 7 does not contain duplicate data. As it would not be right to adjust the data afterwards without full and detailed underpinning, the difference in patient number has remained present in these two chapters and is addressed in this general discussion, based on good clinical practice and needed scientific transparency.

\section{Non-adherence: an issue to be solved?}

Adherence is an important aspect of glaucoma treatment. However, there is limited evidence to recommend a particular intervention to improve adherence. ${ }^{14,47,75,84}$ Moreover, we need to realize that some non-adherent patients will not be able to improve their adherence sufficiently in order to stabilize their glaucoma. It therefore can be considered to perform a laser treatment or (minimally invasive) glaucoma surgery in patients who do not reach their target pressure or who show glaucoma progression. The LiGHT study has shown that patients initially treated with selective laser trabeculoplasty achieved better stability of intraocular pressure over 36 months, with more hospital visits at target pressure, compared with patients who started on eye drops. ${ }^{85}$ The future may also hold other strategies to solve the problem of non-adherence by means of slow release drug depots. This can counter the issue of non-adherence in a more definite way for those in whom non-adherence is really an issue. 


\section{References}

1. van Gestel A, Webers CA, Severens JL, et al. The long-term outcomes of four alternative treatment strategies for primary open-angle glaucoma. Acta Ophthalmol 2012;90:20-31.

2. Attebo K, Mitchell P, Cumming R, Smith W. Knowledge and beliefs about common eye diseases. Aust N Z J Ophthalmol 1997;25:283-7.

3. Huusko H, Viinamäki M, Krause K. Developing standards for instructions to patients with glaucoma. Nurs Pract 1990;3:23-6.

4. Kim S, Stewart JF, Emond MJ, et al. The effect of a brief education program on glaucoma patients. J Glaucoma 1997;6:146-51.

5. Livingston PM, Lee SE, de Paola C, et al. Knowledge of glaucoma, and its relationship to self-care practices, in a population sample. Aust N Z J Ophthalmol 1995;23:37-41.

6. MacKean JM, Elkington AR. Alerting close relatives of patients with glaucoma. Br Med J (Clin Res Ed) 1984;289:800-1.

7. Odberg T, Jakobsen JE, Hultgren SJ, Halseide R. The impact of glaucoma on the quality of life of patients in Norway. II. Patient response correlated to objective data. Acta Ophthalmol Scand 2001;79:121-4.

8. Peralta E, Muir KW, Rosdahl JA. Systematic Review of Knowledge Assessments for Glaucoma Patients. Semin Ophthalmol 2018;33:377-388.

9. Rosenthal AR, Zimmerman JF, Tanner J. Educating the glaucoma patient. Br J Ophthalmol 1983;67:814-7.

10. Amon M, Menapace R, Wedrich A, Radax U. Aspekte der Betreuung von Glaukompatienten und deren Auswirkung auf die Compliance. [Aspects of glaucoma patient care and its impact on compliance]. Spektum Augenheilkd 1990;4:5-8.

11. Bloch S, Rosenthal AR, Friedman DS, Caldarolla P. Patient compliance in glaucoma. Br J Ophthalmol 1977;61:531-4.

12. Chawla A, McGalliard J, Batterbury M. Use of eyedrops in glaucoma: how can we help to reduce non-compliance? Acta Ophthalmol Scand 2007;85:464.

13. MacKean JM, Elkington AR. Compliance with treatment of patients with chronic open-angle glaucoma. Br J Ophthalmol 1983;67:46-9.

14. Olthoff CM, Schouten JS, van de Borne BW, Webers CA. Noncompliance with ocular hypotensive treatment in patients with glaucoma or ocular hypertension an evidence-based review. Ophthalmology 2005;112:953-61.

15. Spaeth GL. Visual loss in a glaucoma clinic. I. Sociological considerations. Invest Ophthalmol 1970;9:73-82.

16. Vincent PA. Patients' viewpoint of glaucoma therapy. Sight Sav Rev 1972;42:213-21.

17. Herndon LW, Brunner TM, Rollins JN. The glaucoma research foundation patient survey: patient understanding of glaucoma and its treatment. Am J Ophthalmol 2006;141:S22-S7.
18. Ung C, Zhang E, Alfaro T, et al. Glaucoma severity and medication adherence in a county hospital population. Ophthalmology 2013;120:1150-7.

19. McDonald HP, Garg AX, Haynes RB. Interventions to enhance patient adherence to medication prescriptions; scientific review. JAMA 2002;288:2868-79.

20. Roter DL, Hall JA, Merisca R, et al. Effectiveness of interventions to improve patient compliance; meta-analysis. Med Care 1998;36:1138-61.

21. Bour T, Blanchard F, Segal A. Observance therapeutique et vecu du glaucome primitif a angle ouvert. A propos de 341 cas dans la Marne. [Therapeutic observance and life of patients with primary open-angle glaucoma. Apropos of 341 cases in the department of Marne]. J Fr Ophtalmol 1993;16:380-91.

22. Konstas AG, Maskaleris G, Gratsonidis S, Sardelli C. Compliance and viewpoint of glaucoma patients in Greece. Eye 2000;14:752-6.

23. Patel SC, Spaeth GL. Compliance in patients prescribed eyedrops for glaucoma. Ophthalmic Surg 1995;26:233-6.

24. Taylor S, Galbraith S, Mills R. Causes of non-compliance with drug regimens in glaucoma patients: a qualitative study. J Ocul Pharmacol Ther 2002;18:401-9.

25. Brown M, Brown G, Spaeth G. Improper topical self-administration of ocular medication among patients with glaucoma. Can J Ophthalmol 1984;19:2-5.

26. Busche S, Gramer E. Verbesserung der augentropfenapplikation und compliance bei glaukompatienten; eine klinische studie. [Improvement of eye drop application and compliance of glaucoma patients]. Klin Monbl Augenheilkd 1997;211:257-62

27. Dietlein TS. Glaukom im Alter; Barrieren fur Aufklarung und Compliance. [Glaucoma in the aged-barriers to understanding and compliance]. Ophthalmologe 2006;103:755-8

28. Sleath B, Robin AL, Covert D, et al. Patient-reported behavior and problems in using glaucoma medications. Ophthalmology 2006;113:431-6.

29. Winfield AJ, Jessiman D, Esakowitz L. A study of the causes of non-compliance by patients prescribed eyedrops. Br J Ophthalmol 1990;74:477-80.

30. Reardon G, Kotak S, Schwartz GF. Objective assessment of compliance and persistence among patients treated for glaucoma and ocular hypertension: a systematic review. Patient Prefer Adherence 2011;5:441-63.

31. European Glaucoma Society. Terminology and guidelines for glaucoma (4th ed.). Savona, Italy: PubliComm, 2014.

32. Tsai JC, McClure CA, Ramos SE, et al. Compliance barriers in glaucoma: a systematic classification. J Glaucoma 2003;12:393-8.

33. Tsai JC. A comprehensive perspective on patient adherence to topical glaucoma therapy. Ophthalmology 2009;116:S30-6.

34. Friedman DS, Hahn SR, Gelb L, et al. Doctor-patient communication, health-related beliefs, and adherence in glaucoma results from the Glaucoma Adherence and Persistency Study. Ophthalmology 
2008;115:1320-7.

35. Chang DS, Friedman DS, Frazier T, et al. Development and validation of a predictive model for nonadherence with once-daily glaucoma medications. Ophthalmology 2013;120:1396-402.

36. Cohen Castel O, Keinan-Boker L, Geyer O, et al. Factors associated with adherence to glaucoma pharmacotherapy in the primary care setting. Fam Pract 2014;31:453-61.

37. Dreer LE, Girkin C, Mansberger SL. Determinants of medication adherence to topical glaucoma therapy. J Glaucoma 2012;21:234-40.

38. Goldshtein I, Shalev V, Zigman N, et al. The Maccabi Glaucoma Study: treatment patterns and persistence with glaucoma therapy in a large Israeli health maintenance organization. J Glaucoma 2016;25:e386-91.

39. Jones JP, Fong DS, Fang EN, et al. Characterization of glaucoma medication adherence in kaiser permanente Southern California. J Glaucoma 2016;25:22-6.

40. Rees G, Chong XL, Cheung CY, et al. Beliefs and adherence to glaucoma treatment: a comparison of patients from diverse cultures. J Glaucoma 2014;23:293-8.

41. Rees G, Leong 0, Crowston JG, Lamoureux EL. Intentional and unintentional nonadherence to ocular hypotensive treatment in patients with glaucoma. Ophthalmology 2010;117:903-8.

42. Vandenbroeck S, Geest de S, Dobbels F, et al. Prevalence and correlates of self-reported nondadherence with eye drop treatment: the belgian compliance study in ophthalmology (BSCO). J Glaucoma 2011;20:414-21.

43. Osman EA, Alqarni BA, AlHasani SS, et al. Compliance of glaucoma patients to ocular hypotensive medications among the Saudi population. J Ocul Pharmacol Ther 2016;32:50-4.

44. Tamrat L, Gessesse GW, Gelaw Y. Adherence to topical glaucoma medications in Ethiopian patients. Middle East Afr J Ophthalmol 2015;22:59-63.

45. Loon SC, Jin J, Jin Goh M. The relationship between quality of life and adherence to medication in glaucoma patients in Singapore. J Glaucoma 2015;24:e36-42.

46. Sleath B, Carpenter DM, Blalock SJ, et al. Applying the resources and supports in self-management framework to examine ophthalmologist-patient communication and glaucoma medication adherence. Health Educ Res 2015;30:693-705.

47. Vélez-Gómez M, Vásquez-Trespalacios. Adherencia al tratamiento tópico del glaucoma, factores protectores y de riesgo;una revisión del tema. [Adherence to topical treatment of glaucoma, risk and protective factors: a review]. Arch Soc Esp Oftalmol 2018;93:87-92.

48. Cook PF, Schmiege SJ, Mansberger SL, et al. Predictors of adherence to glaucoma treatment in a multisite study. Ann Behav Med 2015;49:29-39.

49. Lunnela J, Kaariainen M, Kyngas H. Adherence of Finnish people with glaucoma to treatment plans and connected factors. Int J Circumpolar Health 2011;70:79-89.

50. Mansouri K, Iliev ME, Rohrer K, Shaarawy T. Compliance and knowledge about glaucoma in patients at tertiary glaucoma units. Int Ophthalmol 2011;31:369-76

51. Park MH, Kang KD, Moon J, Korean Glaucoma Compliance Study Group. Noncompliance with glaucoma medication in Korean patients: a multicenter qualitative study. Jpn J Ophthalmol 2013;57:47-56.

52. Stryker JE, Beck AD, Primo SA, et al. An exploratory study of factors influencing glaucoma treatment adherence. J Glaucoma 2010;19:66-72.

53. Dreer LE, Girkin CA, Campbell L, et al. Glaucoma medication adherence among African Americans: program development. Optom Vis Sci 2013;90:883-97.

54. Gray TA, Fenerty C, Harper R, et al. Preliminary survey of educational support for patients prescribed ocular hypotensive therapy. Eye 2010;24:1777-86.

55. Newman-Casey PA, Robin AL, Blachley T, et al. The most common barriers to glaucoma medication adherence: a cross-sectional survey. Ophthalmology 2015;122:1308-16.

56. Mowatt L, Nelson-Imoru J, Gordon-Strachan G. Glaucoma medication compliance issues in a Jamaican hospital eye clinic. West Indian Med J 2011;60:541-7.

57. Newman-Casey PA, Blachley T, Lee PP, et al. Patterns of glaucoma medication adherence over four years of follow-up. Ophthalmology 2015;122:2010-21.

58. Djafari F, Lesk MR, Harasymowycz PJ, et al. Determinants of adherence to glaucoma medical therapy in a long-term patient population. J Glaucoma 2009;18:238-43.

59. Friedman DS, Hahn SR, Quigley HA, et al. Doctor-patient communication in glaucoma care: analysis of videotaped encounters in community-based office practice. Ophthalmology 2009;116:2277-85.

60. Kass MA, Gordon M, Meltzer DW. Can ophthalmologists correctly identify patients defaulting from pilocarpine therapy? Am J Ophthalmol 1986;101:524-30

61. Okeke CO, Quigley HA, Jampel HD, et al. Adherence with topical glaucoma medication monitored electronically; the Travatan Dosing Aid Study. Ophthalmology 2009;116:191-9.

62. Hahn SR. Patient-centered communication to assess and enhance patient adherence to glaucoma medication. Ophthalmology 2009;116:S37-42.

63. Tsai JC. A comprehensive perspective on patient adherence to topical glaucoma therapy. Ophthalmology 2009;116:S30-S6.

64. Hahn SR, Friedman DS, Quigley HA, et al. Effect of patient-centered communication training on discussion and detection of nonadherence in glaucoma. Ophthalmology 2010;117:1339-47.

65. Gray TA, Fenerty C, Harper R, et al. Individualised patient care as an adjunct to standard care for promoting adherence to ocular hypotensive therapy: an exploratory randomised controlled trial. Eye 2012;26:407-17.

66. Sleath B, Blalock SJ, Carpenter DM, et al. Ophthalmologist-patient communication, self-efficacy, and glaucoma medication adherence. Ophthalmology 2015;122:748-54.

67. Sleath B, Blalock SJ, Robin A, et al. Development of an instrument to measure glaucoma medication self-efficacy and outcome expectations. Eye 2010;24:624-31.

68. Sleath B, Blalock SJ, Stone JL, et al. Validation of a short version of the glaucoma medication selfefficacy questionnaire. Br J Ophthalmol 2012;96:258-62

69. Steiner JF, Prochazka AV. The assessment of refill compliance using pharmacy records: methods, 
validity and applications. J Clin Epidemiol 1997;50:105-16.

70. Karve S, Cleves MA, Helm M, et al. An empirical basis for standardizing adherence measures derived from administrative claims data among diabetic patients. Med Care 2008;46:1125-33.

71. Konkle-Parker DJ, Erlen JA, Dubbert PM. Lessons learned from an HIV adherence pilot study in the Deep South. Patient Educ Couns 2010;78:91-6.

72. Hess LM, Raebel MA, Conner DA, Malone DC. Measurement of adherence in pharmacy administrative databases: a proposal for standard definitions and preferred measures. Ann Pharmacother 2006; 40:1280-8.

73. Cate H, Bhattacharya D, Clark A, et al. A comparison of measures used to describe adherence to glaucoma medication in a randomised controlled trial. Clin Trials 2015;12:608-17.

74. Friedman DS, Quigley HA, Gelb L, et al. Using pharmacy claims data to study adherence to glaucoma medications: methodology and findings of the Glaucoma Adherence and Persistency Study (GAPS). Invest Ophthalmol Vis Sci 2007;48:5052-7.

75. Joseph A, Pasquale LR. Attributes associated with adherence to glaucoma medical therapy and its effects on glaucoma outcomes: an evidence-based review and potential strategies to improve adherence. Semin Ophthalmol 2017;32:86-90.

76. Gray TA, Orton LC, Henson D, et al. Interventions for improving adherence to ocular hypotensive therapy. Cochrane Database Syst Rev 2009;2:CD006132.

77. Okeke CO, Quigley HA, Jampel HD, et al. Interventions improve poor adherence with once daily glaucoma medications in electronically monitored patients. Ophthalmology 2009;116:2286-93.

78. Granström PA. Progression of visual field defects in glaucoma. Relation to compliance with pilocarpine therapy. Arch Ophthalmol 1985;103:529-31.

79. Gurwitz JH, Yeomans SM, Glynn RJ, et al. Patient noncompliance in the managed care setting; the case of medical therapy for glaucoma. Med Care 1998;36:357-69.

80. Vorwerk C, Thelen U, Buchholz P, Kimmich F. Treatment of glaucoma patients with insufficient intraocular pressure control: a survey of German ophthalmologists in private practice. Curr Med Res Opin 2008;24:1295-301.

81. Rossi GC, Pasinetti GM, Scudeller L, et al. Do adherence rates and glaucomatous visual field progression correlate? Eur J Ophthalmol 2011;21:410-4.

82. Sleath B, Blalock S, Covert D, et al. The relationship between glaucoma medication adherence, eye drop technique, and visual field defect severity. Ophthalmology 2011;118:2398-402.

83. Chen PP. Blindness in patients with treated open-angle glaucoma. Ophthalmology 2003;110:72633.

84. Waterman H, Evans JR, Gray TA, et al. Interventions for improving adherence to ocular hypotensive therapy. Cochrane Database Syst Rev 2013;4:CD006132.

85. Gazzard G, Konstantakopoulou E, Garway-Heath D, et al. Selective laser trabeculoplasty versus eye drops for first-line treatment of ocular hypertension and glaucoma (LiGHT): a multicentre randomised controlled trial. Lancet 2019;393:1505-16. 
Chapter 9

Samenvatting

(Summary in Dutch) 


\section{Samenvatting}

Dit proefschrift gaat over onderzoek naar de kennis van glaucoompatiënten over hun aandoening, de relatie tussen deze kennis en therapietrouw met glaucoommedicatie en de relatie tussen therapietrouw en uitkomsten van behandeling.

Glaucoom is een langzaam progressieve chronische oogaandoening waarbij de oogzenuw wordt aangetast. Hierbij treedt een typische uitval van het gezichtsveld op. Onbehandeld leidt glaucoom in ongeveer $50 \%$ van de patiënten tot blindheid. Wereldwijd is het een veel voorkomende oorzaak van blindheid. De oogdruk is de belangrijkste risicofactor voor glaucoom en het verlagen van de oogdruk is de belangrijkste behandeling van glaucoom. Patiënten met oculaire hypertensie hebben wel een verhoogde oogdruk, maar geen beschadigde oogzenuw. Patiënten met normale druk glaucoom hebben wel een beschadigde oogzenuw, maar geen verhoogde oogdruk.

De meeste patiënten hebben geen klachten op het moment dat de diagnose glaucoom gesteld wordt. Ze horen dat ze een chronische aandoening hebben waarvoor regelmatig de oogarts bezocht moet worden en waarvoor, meestal, dagelijks en levenslang oogdruppels gebruikt moeten worden. Kennis over hun ziekte en behandeling is voor patiënten met een chronische ziekte van groot belang om een eigen regie in te kunnen vullen en om te kunnen gaan met deze chronische aandoening. De asymptomatische aard van (beginnend) glaucoom, de mogelijke bijwerkingen van oogdruppels en het uitblijven van een subjectief positief effect van de behandeling zorgen ervoor dat het voor veel patiënten lastig is om volledig therapietrouw te zijn. Therapietrouw is de mate waarin een patiënt de therapie zoals afgesproken met de behandelaar uitvoert. Gebrekkige therapietrouw kan de uitkomst van de behandeling beïnvloeden. Kennis en therapietrouw zijn de thema's waarop dit proefschrift is gebaseerd.

Hoofdstuk 2 beschrijft het kennisniveau en de informatiebehoefte van glaucoompatiënten. Er is gebruikt gemaakt van een schriftelijke vragenlijst om het niveau en de inhoud van de kennis over glaucoom en de behandeling te onderzoeken. De vragenlijst is ontwikkeld op basis van focusgroep interviews onder glaucoompatiënten en adviezen van experts op het gebied van glaucoom. De vragenlijst is uitgedeeld door 60 willekeurig geselecteerde oogartsen. Per oogarts werden vier opeenvolgende glaucoompatiënten gevraagd deel te nemen. In totaal hebben 166 patiënten deelgenomen. Uit dit onderzoek blijkt dat de kennis over glaucoom en de behandeling laag is. Vijftig procent van de deelnemers had bij minder dan $50 \%$ van de vragen een goed antwoord. Patiënten met een lager opleidingsniveau, een korte duur van hun glaucoom, een hogere leeftijd of zonder internetvoorziening hadden een lagere score. Er was een grote behoefte aan informatie, met name over de eigen glaucoom situatie. De oogarts en eventueel een verpleegkundige of een vertegenwoordiger van de glaucoomvereniging waren bij voorkeur de aanbieders van informatie. Een schriftelijke methode had de voorkeur.

Hoofdstuk 3 beschrijft de sociaaleconomische gezondheidsverschillen in kennis en informatiebehoefte in dezelfde groep patiënten. Patiënten met een lagere sociaaleconomische status gebaseerd op opleidingsniveau weten minder over glaucoom en de behandeling. Zij weten met name minder over risicofactoren, pathofysiologie en gevolgen van glaucoom, evenals over de werking en bijwerkingen van glaucoommedicatie. Zij verwachten vaker dat de schade door glaucoom hersteld kan worden. Verder hebben zij meer behoefte aan informatie, met name over ondersteuning en praktische aspecten van glaucoom.

Hoofdstuk 4 beschrijft vervolgens de studie naar de relatie tussen kennisniveau en therapietrouw met glaucoommedicatie. In dit onderzoek is de therapietrouw vastgesteld met behulp van een vragenlijst. Er was geen verband tussen de totale kennisscore en therapietrouw. Enkele specifieke items lieten een statistisch significant verband zien. Patiënten die wisten dat glaucoomdruppels de glaucomateuze schade niet kunnen herstellen, waren meer therapietrouw. Patiënten die geen informatiebehoefte over de erfelijkheid van glaucoom hadden, waren ook vaker therapietrouw. Het is mogelijk dat deze patiënten reeds via hun familieleden op de hoogte waren van de mogelijke gevolgen (slechtziendheid) van glaucoom. Gezien het aantal gerelateerde items, de richting van het verband en de moeilijkheid om een causaal verband te hypothetiseren, is het over het algemeen onwaarschijnlijk dat verbetering van het kennisniveau zal leiden tot een veel betere therapietrouw.

Hoofdstuk 5 beschrijft of er andere risicofactoren zijn die gerelateerd zijn aan therapietrouw. Het identificeren van risicofactoren voor therapieontrouw is relevant om patiënten met gebrekkige therapietrouw op te sporen en de beïnvloedbare risicofactoren te verhelpen. Deze risicofactoren voor therapieontrouw zijn onderzocht in 166 patiënten middels een vragenlijst. Er werd gevraagd naar relevante factoren zoals psychosociale aspecten, barrières voor het gebruik van oogdruppels en vaardigheden in het gebruik van oogdruppels. 
De mate van therapietrouw werd vastgesteld met behulp van een vragenlijst. Het percentage zelf-gerapporteerde therapieontrouw was $27,3 \%$. Onder jongere patiënten ( $<55$ jaar) was het percentage therapieontrouw hoger dan onder oudere patiënten. De meest voorkomende redenen voor gebrekkige therapietrouw waren het vergeten om de druppels te gebruiken, het niet meer in het bezit hebben van oogdruppels en moeite hebben om het oogdruppelflesje boven het oog te houden. Vijftig procent van de respondenten gaf aan meer informatie te willen over het correct toedienen van oogdruppels. Geslacht, opleidingsniveau, type verzekering, duur van het glaucoom en de aanwezigheid van glaucoom in de familie waren niet geassocieerd met therapieontrouw. Een gebrekkige therapietrouw komt dus geregeld voor. Strategieën en hulpmiddelen die ervoor zorgen dat druppels tijdig worden aangevuld, die patiënten eraan herinneren te druppelen en die een goede toediening van oogdruppels bevorderen zouden de therapietrouw kunnen verbeteren.

In de discussie over therapietrouw is het belangrijk om te realiseren dat de glaucoombehandeling als doel heeft om progressie van het ziektebeeld te voorkomen. Aangezien oogdrukverlaging een bewezen effectieve behandeling is voor glaucoom, is het logisch dat therapietrouw noodzakelijk is om de behandeling te laten slagen. Het is echter lastig om patiënten die niet therapietrouw zijn te identificeren en het is onbekend welke mate van therapietrouw nodig is om de behandeling te laten slagen. Het zou het meest efficiënt in de dagelijkse praktijk zijn als een oogarts díe patiënt kan identificeren bij wie de therapieontrouw de uitkomst van de behandeling negatief beïnvloedt.

Hoofdstuk 6 beschrijft de bestudering van de relatie tussen therapieontrouw en het niet behalen van de streefdruk. De streefdruk is de bij de behandeling na te streven oogdruk die is vastgesteld door de oogarts. Het onderzoek is uitgevoerd onder 3640 patiënten die glaucoommedicatie gebruikten. Deze patiënten waren onder behandeling in negen willekeurig geselecteerde ziekenhuizen. Dataverzameling geschiedde door middel van een vragenlijst aan de oogarts, een vragenlijst aan de patiënt en het medisch dossier. Het aantal geïncludeerde patiënten was 2765 (76\%) voor het rechter oog en 2770 (76\%) voor het linker oog. Het niet bereiken van de streefdruk kwam vaker voor bij patiënten met primair open kamerhoek glaucoom dan bij andere typen glaucoom, bij patiënten die in meer dan $43 \%$ van de tijd geen druppels gebruikten, bij patiënten die ontevreden waren over de oogdruppels, bij patiënten met een incorrect laatste toedieningsmoment en bij patiënten die gestopt waren met de medicatie als gevolg van bijwerkingen. Bij respectievelijk 7\% en 9\% kan een verbetering in het behalen van de streefdruk bereikt worden als de laatste twee situaties niet meer voorkomen. De oogarts kan vier specifieke vragen stellen om te ontdekken of therapieontrouw een reden kan zijn voor het niet bereiken van de streefdruk: Hoe veel dagen heeft u uw glaucoommedicatie niet gebruikt in de laatste twee weken? Bent u tevreden over uw oogdruppels? Wanneer heeft u uw laatste oogdruppel gebruikt? Bent u gestopt met uw oogdruppels wegens bijwerkingen?

Hoofdstuk 7 beschrijft de case-control studie die is uitgevoerd om de relatie tussen therapietrouw met glaucoommedicatie en progressie van glaucoom te onderzoeken. In deze studie werden 56 progressieve glaucoompatiënten en 342 willekeurig geselecteerde niet-progressieve glaucoompatiënten geïncludeerd. Aan de hand van apotheekgegevens werd bepaald of iemand therapietrouw was door te berekenen of er voldoende medicatie in het bezit was om te druppelen volgens voorschrift. De progressieve groep deed vaker, onterecht, langer dan 35 dagen met een flesje oogdruppels dan de niet-progressieve groep. Het percentage therapietrouwe patiënten was maximaal 13\% hoger in de niet-progressieve groep dan in de progressieve groep. Als deze therapietrouw verbeterd zou worden, dan zou bij maximaal $13 \%$ van de progressieve patiënten de progressie verminderd kunnen worden.

Hoofdstuk 8 bevat de algemene discussie waarin de betekenis en de beperkingen van de bevindingen worden besproken. Daarnaast worden de bevindingen in de context van de literatuur geplaatst.

Therapietrouw is een belangrijk onderdeel van de medicamenteuze behandeling van glaucoom. Er is echter weinig onderbouwing om een bepaalde interventie om therapietrouw te verbeteren aan te bevelen. Bovendien zal het voor sommige glaucoompatiënten onmogelijk zijn om een mate van therapietrouw te bereiken die voldoende is om hun glaucoom te stabiliseren. Voor patiënten die hun streefdruk niet halen of die progressie vertonen als gevolg van gebrekkige therapietrouw, kan het zinvol zijn om alternatieve behandelingen te overwegen zoals lasertherapie of (minimaal invasieve) chirurgie. Wellicht gaan toekomstige implantaten die gereguleerd medicatie afgeven tot de mogelijkheden behoren. Deze behandelingen kunnen een, niet gegarandeerde, oplossing zijn voor de patiënt waarbij gebrekkige therapietrouw een serieus obstakel vormt. 



\section{Valorisation}

In this valorisation paragraph the practical implications of this thesis and its impact at social and economic level are highlighted. Valorisation is defined as 'the process of creating value from knowledge by making knowledge suitable and/or available for economic and/or societal use and translating that knowledge into competitive products, services, processes and entrepreneurial activity'. ${ }^{1}$ Valorisation is about the impact that can be created through the transfer of scientific knowledge.

The European Glaucoma Society (EGS) has published the $4^{\text {th }}$ edition of the Terminology and Guidelines for Glaucoma in 2014. These guidelines are intended to share the view of the EGS on the diagnosis and management of glaucoma. ${ }^{2}$ They are widely used in Europe and the guidelines are also adopted by the Dutch Glaucoma Workgroup of the Dutch Ophthalmological Society.

In the light of the valorisation process of this thesis, a letter to the editor of the EGS Guidelines is presented to add value to the use of the next EGS Guidelines.

Dear editor of the EGS Guidelines,

In the thesis "Knowledge, adherence and outcome in glaucoma" interesting findings are published that can be useful in the writing process of a new chapter concerning adherence in glaucoma treatment in the next edition of the EGS Guidelines.

The $4^{\text {th }}$ edition of the EGS Guidelines states that "the patient's cooperation described as adherence and persistence, with the prescribed glaucoma management is mandatory to obtain effective IOP lowering and to prevent glaucoma progression. No drug can work unless it is taken." It has now empirically been shown that progression of glaucoma is more common in nonadherent patients than in adherent patients. ${ }^{3}$ If adherence by having sufficient number of bottles of eye drops can be improved, it could reduce progression in a maximum of $13 \%$ of the progressive patients. ${ }^{3}$

Therefore, addressing adherence is an important aspect of glaucoma treatment. Discovering non-adherence is a challenge for most ophthalmologists. Besides, as the current EGS guidelines state, "patients themselves overestimate their adherence and persistence rate." 
Knowing the risk factors and barriers of non-adherence can help identifying groups with a high risk of being non-adherent and identifying modifiable risk factors to improve adherence.

The $4^{\text {th }}$ edition of the EGS guidelines describes four groups offactors encountered as common obstacles to glaucoma medication adherence ${ }^{2,4}$ :

- $\quad$ situational/environmental (for example: major life events, unsteady lifestyle with many travels)

- $\quad$ medication (for example: costs, side effects, complicated dosing regimen)

- $\quad$ patients (for example: comorbidity, poor understanding of the disease)

- $\quad$ provider (for example: lacking communication with the doctor)

According to the $4^{\text {th }}$ edition of the EGS Guidelines, gender and stage of the disease were other influencing factors; men and patients with less advanced disease tend to be less adherent. ${ }^{2}$

These issues can be fine-tuned in order to give the EGS guidelines more value for the practicing ophthalmologist. The most patient-reported reasons for non-adherence are forgetfulness, unavailability of eye drops and difficulties with holding the bottle above the eye when applying eye drops. ${ }^{5}$ However, risk factors discriminate only to a limited extent between patients who are adherent and non-adherent.

One could therefore use several methods to measure non-adherence in order to identify non-adherent patients. Although electronic monitoring is seen as a gold standard to assess adherence, questionnaires and pharmacy data can be more practical.

A systematically developed questionnaire based on focus groups and experts opinions that addresses non-adherence and relevant factors could be used. ${ }^{5}$ Questionnaires are relatively simple and inexpensive, but contain a risk of recall bias, socially acceptable behaviour and overestimation of adherence.

Pharmacy records were used to assess refill adherence in glaucoma patients. ${ }^{3}$ They showed that patients who have insufficient eye drops to cover a treatment period more often show progression of their glaucoma. ${ }^{3}$ Using pharmacy data and calculating the medication possession ratio helps to assess non-adherence and to identify those patients that are really at risk of progression because of non-adherence. It also gives an easy tool to improve non-adherence by organising regular dispensing of glaucoma eye drops by the pharmacy to a patient. Pharmacy data can provide reliable information regarding a patient's adherence to therapy and cover an extended period of time. ${ }^{6}$ Timing of doses cannot be assessed with these data. It gives the upper limit of being able to be adherent.

However, going one step further in addressing groups with non-adherence, we should ask ourselves if it is really necessary to discover every non-adherent patient. As the aim of glaucoma treatment is to reduce glaucoma progression, it will be more efficient in daily practice if the ophthalmologist addresses non-adherence in patients in whom non-adherence affects the outcome of glaucoma; patients in whom the target pressure is not reached or in whom progression of visual field loss has been observed. It is especially in these groups that reducing non-adherence is important as it is needed to improve the outcome of glaucoma treatment.

For patients not achieving their target pressure four questions can be recommended to discover relevant non-adherence in a clinical setting:

1) how many days did you not use your eye drops in the last two weeks?

2) are you satisfied with your eye drops?

3) when did you use your last eye drop?

4) did you discontinue using eye drops because of side effects?

Not achieving the target pressure was related to being non-adherent in more than $43 \%$ of the time, dissatisfaction with eye drops, an incorrect last dosage moment and discontinuing the use of eye drops because of side effects. A clinically relevant improvement in the achieved target pressure could be realised by addressing the correct dosage moment and by addressing discontinuation of eye drops in patients that did not achieve their target pressure.

Another challenge is how to improve adherence in such a way that the outcome of glaucoma treatment is improved. There is limited evidence to recommend a particular intervention to improve adherence. Patient education has regularly been identified as an intervention to improve adherence. ${ }^{7-10}$

Many glaucoma patients lack knowledge about essential elements of the disease or its treatment, specifically about certain risk factors, rate of progression without treatment and side effects of glaucoma therapy. ${ }^{11}$ Patients 
had a high need for information, especially concerning new developments in glaucoma and its treatment and concerning their own state of glaucoma. ${ }^{11}$ The ophthalmologist is the preferred provider of information, particularly about the state of the glaucoma of the individual patient. ${ }^{11}$

In addition, better provision of information to patients in lower socioeconomic groups about specific items is necessary to reduce the socioeconomic differences in knowledge and need for information about risk factors, pathophysiology and consequences of glaucoma, effects and adverse effects of treatment, public assistance and practical aspects of glaucoma. ${ }^{12}$ Moreover, addressing the awareness of family predisposition needs to be done more often to reduce the socioeconomic difference in visual field defect severity at time of diagnosis. ${ }^{12}$

It is important to achieve a general level of knowledge in glaucoma patients, but it is unlikely that improving knowledge beyond the current level of knowledge will greatly improve adherence with glaucoma medication. ${ }^{13}$ Moreover, care should be taken in patients who are well informed since non-adherence is higher in patients who know that glaucoma is a slowly progressive disease. ${ }^{13}$ After the diagnosis of glaucoma is made, a patient should be counselled concerning the disease, its treatment and its functional consequences. The questionnaire developed by us can be used to address the questions patients commonly have. ${ }^{11}$ The relevance of adherence to the prescribed medication should be stressed. $A$ point can be made that non-adherence leads to progression of the disease.

Adherence-enhancing interventions that focus on reducing forgetfulness and increasing usage of dosing aids may be of more benefit than an intervention based on improvement of knowledge above the current level. Dosing regimens are preferred to be kept simple.

In addition, as also stated in the current EGS Guidelines, the patient should be instructed how to apply the drops correctly. ${ }^{2}$ Patients need these instructions, even time after their diagnosis. The partner or home nurse can be asked to apply the drops if a patient can not apply the drops oneself. Moreover, hints reminders can be helpful to connect the application of eye drops to daily routine activities since forgetfulness is a common cause of non-adherence.

To improve adherence with glaucoma treatment, a combination of educational, behavioural and affective interventions is recommended.
As mentioned earlier, adherence is an important aspect of glaucoma treatment. However, one should realize that some non-adherent patients will not be able to achieve a sufficient level of adherence in order to stabilize their glaucoma. In these patients, a laser treatment or (minimally invasive) glaucoma surgery can be considered. A laser treatment could even be considered as an initial treatment, thereby possibly eliminating the issue of non-adherence.

The future may also hold other strategies to solve the problem of nonadherence by means of slow release drug depots. This can counter the issue of non-adherence in a more definite way for those in whom non-adherence is really an issue

I hope these findings and recommendations are helpful in writing a next edition of the EGS Guidelines with updated guidelines on how to identify non-adherent patients, address patient education and improve adherence.

Yours sincerely

Juliette Hoevenaars 


\section{References}

1. Drooge van L, VandeBerg R, Zuijdam F, et al. Valuable: Indicators for Valorisation. The Hague Rathenau Institute 2013.

2. European Glaucoma Society. Terminology and guidelines for glaucoma (4th ed.). Savona, Italy: PubliComm, 2014.

3. Hoevenaars JG, Schouten JS, Beckers HJ, Webers CA. Non-adherence and glaucoma progression. Article in submission 2020

4. Tsai JC, McClure CA, Ramos SE, et al. Compliance barriers in glaucoma: a systematic classification. J Glaucoma 2003;12:393-8.

5. Olthoff CM, Hoevenaars JG, van den Borne BW, et al. Prevalence and determinants of non-adherence to topical hypotensive treatment in Dutch glaucoma patients. Graefes Arch Clin Exp Ophthalmol 2009;247(2):235-43.

6. Steiner JF, Prochazka AV. The assessment of refill compliance using pharmacy records: methods, vaidity and applications. J Clin Epidemiol 1997;50:105-16.

7. Lee DA, Fechtner RD, Fiscella RG, et al. Emerging perspectives on glaucoma: highlights of a roundtable discussion. Am J Ophthalmol 2000;130:S1-S11.

8. Olthoff CM, Schouten JS, van de Borne BW, Webers CA. Noncompliance with ocular hypotensive treatment in patients with glaucoma or ocular hypertension an evidence-based review. Ophthalmology 2005;112:953-61.

9. Tsai JC. Medication adherence in glaucoma: approaches for optimizing patient compliance. Curr Opin Ophthalmol 2006;17:190-5.

10. Zimmerman TJ, Zalta AH. Facilitating patient compliance in glaucoma therapy. Surv Ophthalmol 1983;28:252-7.

11. Hoevenaars JG, Schouten JS, van den Borne B, et al. Knowledge base and preferred methods of obtaining knowledge of glaucoma patients. Eur J Ophthalmol 2005;15:32-40.

12. Hoevenaars JG, Schouten JS, van den Borne B, et al. Socioeconomic differences in glaucoma patients' knowledge, need for information and expectations of treatments. Acta Ophthalmol Scand 2006;84:84-91.

13. Hoevenaars JG, Schouten JS, van den Borne B, et al. Will improvement of knowledge lead to improvement of compliance with glaucoma medication? Acta Ophthalmol 2008;86:849-55 


\section{Dankwoord}

Graag wil ik iedereen bedanken die heeft bijgedragen aan het tot stand komen van dit proefschrift. Het schrijven en afronden van een proefschrift is allerminst vanzelfsprekend en ik ben dan ook oprecht dankbaar voor alle hulp en steun die ik van iedereen heb mogen ontvangen. Een aantal mensen wil ik graag persoonlijk bedanken.

Allereerst het primaire onderzoeksteam, promotor prof. dr. Carroll Webers en copromotor dr. Jan Schouten. Beste Carroll en Jan, wij kennen elkaar al sinds het onderzoekstraject dat ik tijdens mijn studie geneeskunde bij jullie heb gevolgd. Het bleek de start te zijn van mijn carrière in de oogheelkunde.

Beste Jan, jij maakte me enthousiast voor het wetenschappelijk onderzoek en stimuleerde me om hierin verder te gaan. Tijdens mijn hele onderzoekstraject ben jij een cruciale drijvende kracht geweest. Jouw wetenschappelijke ideeën hebben dit proefschrift verrijkt. Jouw werkethos, onuitputtelijke energie en enthousiasme zijn bijzonder inspirerend. Ik wil je ontzettend bedanken voor alle energie en tijd die je in de begeleiding van dit proefschrift hebt gestoken, je motiverende woorden, je geduld en vertrouwen.

Beste Carroll, jij hebt mij het mooie van "de oogheelkunde" laten zien. Jij hebt me al tijdens mijn studie geneeskunde de kans gegeven om mee te kijken op de poli, naar refereeravonden te gaan, onderzoek te doen en naar congressen te gaan. Mijn enthousiasme voor de oogheelkunde en voor glaucoom is destijds begonnen. Jij bent een belangrijke spil geweest in dit proefschrift; jouw betrokkenheid en kritische blik was onmisbaar. Bedankt voor alle faciliteiten en mogelijkheden die je me hebt geboden, voor je geduld en vertrouwen.

Prof. dr. F. Hendrikse, voormalig hoofd van de Universiteitskliniek voor Oogheelkunde Maastricht. Ik wil u bedanken dat u mij de mogelijkheid heeft gegeven om oogarts te worden en dit onderzoek uit te voeren. Ook ing. Astrid Hacking wil ik bedanken voor de ondersteuning tijdens mijn specialisatie en het uitvoeren van het onderzoek.

Prof. dr. Henny Beckers, beste Henny, wij kennen elkaar ook als sinds mijn studie geneeskunde. Jij nam me onder je hoede tijdens mijn eerste buitenlandse presentatie op de EGS in Florence. Tijdens mijn specialisatie hebben we veel samengewerkt in het onderzoek en in de patiëntenzorg. Heel erg bedankt voor alles wat je me geleerd hebt, voor het meedenken met het onderzoek en de prettige samenwerking. 
De beoordelingscommissie wil ik bedanken voor het bestuderen van dit proefschrift: prof. dr. P.M. Steijlen, dr. med. F. Meier-Gibbons, prof. dr. J.W.M. Muris, dr. W.D. Ramdas en prof. dr. G.D.E.M. van der Weijden.

Het Zorginstituut Nederland wil ik bedanken voor de subsidie voor het onderzoek. Alle oogartsen, ziekenhuizen en patiënten die hun medewerking hebben verleend aan dit onderzoek. Hartelijk bedankt, zonder jullie inzet was dit onderzoek er niet geweest.

Het secretariaat oogheelkunde van het MUMC+, met name Ellen Vrancken, bedankt voor alle hulp en secretariële ondersteuning.

Mireille van Helden, wat hebben wij veel uren samen doorgebracht met het bespreken en verwerken van alle data. Bedankt voor je aanhoudende energie, positiviteit en natuurlijk de gezelligheid.

Alle aiossen, aniossen en onderzoekers met wie ik jarenlang veel lief en leed heb gedeeld, bedankt!

Al mijn collega's in het VieCuri Medisch Centrum met wie ik mag of heb mogen samenwerken; collega's in de breedste zin van het woord. Bedankt voor jullie prettige samenwerking, de gezellige momenten en de fijne werksfeer. Mede dankzij jullie kom ik met plezier naar mijn werk.

Al mijn lieve vrienden en vriendinnen, bedankt voor jullie waardevolle vriendschap! We hebben samen al veel mooie, maar ook verdrietige momenten gedeeld. Fijn dat we altijd bij elkaar terecht kunnen.

Mijn schoonouders, bedankt voor al jullie steun, hulp en vertrouwen. Ondanks jullie eigen beperkingen staan jullie voor ons klaar waar mogelijk. Bedankt voor alles.

Mijn lieve ouders, bedankt voor jullie onuitputtelijke vertrouwen, voor de steun en motivatie die jullie altijd hebben gegeven en nog steeds geven. Voor alle hulp op zoveel vlakken; het was nooit teveel en altijd vanzelfsprekend. Bedankt dat jullie altijd in mij geloofd hebben.

Lieve mam, helaas moesten wij in 2017 afscheid van jou nemen; het gemis blijft. Ik weet dat je heel trots, en natuurlijk met een glimlach, meekijkt. Bedankt voor alles.
Roy, als grote broer ben je altijd mijn voorbeeld geweest. Jouw mental support, nuchtere inzichten en relativeringsvermogen zijn heel waardevol.

Joyce, onze vakgebieden raken elkaar. We zitten in hetzelfde "onderzoeksschuitje". Leuk om samen te overleggen, elkaar moed in te praten en te sparren. Bedankt voor de gezellige familie aangelegenheden.

Lieve Paul, bedankt voor al je geduld, vertrouwen, begrip, steun en liefde. Het is niet altijd eenvoudig geweest voor jou, en voor je bedrijf, om mij te volgen tijdens mijn carrière. Jouw steun is een cruciale spil geweest in mijn specialisatie tot oogarts en promotie. We vormen een heerlijk gezin in ons eigen paradijsje. Bedankt voor alles!

Lieve Bas en Jurre, jullie zijn het allerbelangrijkste in mijn leven. Bedankt voor al jullie knuffels en voor jullie onvoorwaardelijke liefde. Jullie mooie glimlach en omhelzing maakt elke dag weer mooi. Het is geweldig om te zien hoe jullie je eigen persoonlijkheid ontplooien. Ik ben heel erg trots op jullie! 


\section{Curriculum Vitae}

Juliette Hoevenaars was born on August $20^{\text {th }} 1981$ in Maastricht, the Netherlands. She attended her pre-university education at the Jeanne d'Arc College in Maastricht from 1993 until 1999. She started her medical study in 1999 at the University of Maastricht. She received her doctorate degree cum laude in 2003 and her medical degree cum laude in 2005. During her medical study, her interest in ophthalmology became evident during research at the department of Opthalmology at the Maastricht University Medical Center and an elective internschip at the same department. In 2005, she started her residency in Ophthalmology in the same hospital. She has continued her research during her residency and thereafter. She has presented parts of this thesis at a congres of the European Glaucoma Society and several (inter)national congresses and meetings. In 2010 she was registered as ophthalmologist. She practiced ophthalmology in Atrium Medical Center in Heerlen and a private Eye Clinic in Maastricht from 2010 until 2012. Since 2012 she is working as an ophthalmologist in VieCuri Medical Center in Venlo and Venray in the Netherlands. 


\section{List of publications}

Hoevenaars JGMM, Schouten JSAG, Van den Borne B, Beckers HJM, Webers CAB. Knowledge base and preferred methods of obtaining knowledge of glaucoma patients. Eur J Ophthalmol 2005;15:32-40.

Hoevenaars JGMM, Schouten JSAG, Van den Borne B, Beckers HJM, Webers CAB. Socioeconomic differences in glaucoma patients' knowledge, need for information and expectations of treatments. Acta Ophthalmol Scand 2006;84:84-91.

Hoevenaars JGMM, Schouten JSAG, Van den Borne B, Beckers HJM, Webers CAB. Will improvement of knowledge lead to improvement of compliance with glaucoma medication? Acta Ophthalmol 2008;86:849-855.

Hoevenaars JGMM, Schouten JSAG, Van den Borne B, Beckers HJM, Webers CAB. Will improvement of knowledge lead to improvement of compliance with glaucoma medication? Authors' reply. Acta Ophthalmol 2009;87:469-471.

Goezinne F, La Heij EC, Berendschot TTJM, Tahzib NG, Koetsier LS, Hoevenaars JGMM, Liem ATA, Kijlstra A, Webers CAB, Hendrikse F. Patient ignorance is the main reason for treatment delay in primary rhegmatogenous retinal detachment in The Netherlands. Eye 2009;23:1393-1399.

Olthoff CMG, Hoevenaars JGMM, Van den Borne B, Webers CAB. Schouten JSAG. Prevalence and determinants of non-adherence to topical hypotensive treatment in Dutch glaucoma patients. Graefes Arch Clin Exp Ophthalmol 2009;247:235-243.

Nederlandse Glaucoomgroep, namens deze: Hoevenaars JGMM, Beckers HJM, Schouten JSAG, Webers CAB. Een advies over therapietrouw in de behandeling van glaucoom -in het kader van vision 2020-. September 2009.

Tan AN, Hoevenaars JGMM, Webers CAB, Damato B, Beckers HJM. Baerveldt implant for secondary glaucoma due to iris melanoma. Case report. Clin Ophthalmol 2010;4:407-409.

Lemij HG, Hoevenaars JGMM, van der Windt C, Baudouin C. Patient satisfaction with glaucoma therapy: reality or myth? Clin Ophthalmol 2015;9:785-793. 
